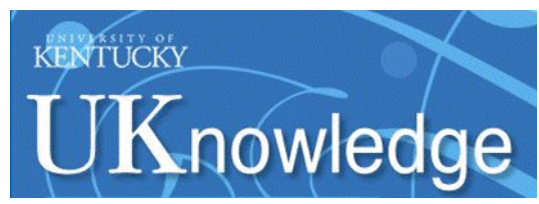

University of Kentucky

UKnowledge

Theses and Dissertations--Educational, School, and Counseling Psychology

\title{
LONG-TERM TRENDS OF PARTICIPATION IN PHYSICAL ACTIVITY DURING ADOLESCENCE WITH EDUCATIONAL AMBITION AND ATTAINMENT
}

Frances Jillian Priesmeyer

University of Kentucky, jpriesmeyer@gmail.com

Right click to open a feedback form in a new tab to let us know how this document benefits you.

\section{Recommended Citation}

Priesmeyer, Frances Jillian, "LONG-TERM TRENDS OF PARTICIPATION IN PHYSICAL ACTIVITY DURING ADOLESCENCE WITH EDUCATIONAL AMBITION AND ATTAINMENT" (2014). Theses and Dissertations-Educational, School, and Counseling Psychology. 18.

https://uknowledge.uky.edu/edp_etds/18

This Doctoral Dissertation is brought to you for free and open access by the Educational, School, and Counseling Psychology at UKnowledge. It has been accepted for inclusion in Theses and Dissertations--Educational, School, and Counseling Psychology by an authorized administrator of UKnowledge. For more information, please contact UKnowledge@lsv.uky.edu. 


\section{STUDENT AGREEMENT:}

I represent that my thesis or dissertation and abstract are my original work. Proper attribution has been given to all outside sources. I understand that I am solely responsible for obtaining any needed copyright permissions. I have obtained needed written permission statement(s) from the owner(s) of each third-party copyrighted matter to be included in my work, allowing electronic distribution (if such use is not permitted by the fair use doctrine) which will be submitted to UKnowledge as Additional File.

I hereby grant to The University of Kentucky and its agents the irrevocable, non-exclusive, and royalty-free license to archive and make accessible my work in whole or in part in all forms of media, now or hereafter known. I agree that the document mentioned above may be made available immediately for worldwide access unless an embargo applies.

I retain all other ownership rights to the copyright of my work. I also retain the right to use in future works (such as articles or books) all or part of my work. I understand that I am free to register the copyright to my work.

\section{REVIEW, APPROVAL AND ACCEPTANCE}

The document mentioned above has been reviewed and accepted by the student's advisor, on behalf of the advisory committee, and by the Director of Graduate Studies (DGS), on behalf of the program; we verify that this is the final, approved version of the student's thesis including all changes required by the advisory committee. The undersigned agree to abide by the statements above.

Frances Jillian Priesmeyer, Student

Dr. Alicia Fedewa, Major Professor Dr. Kenneth Tyler, Director of Graduate Studies 
LONG-TERM TRENDS OF PARTICIPATION IN PHYSICAL ACTIVITY DURING ADOLESCENCE WITH EDUCATIONAL AMBITION AND ATTAINMENT

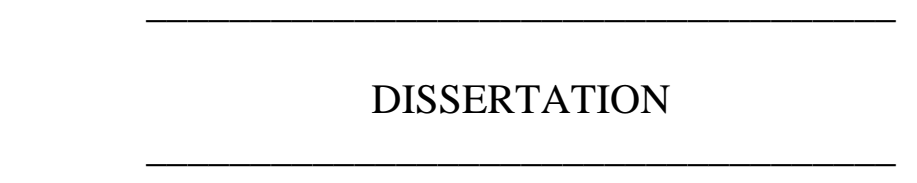

A dissertation submitted in partial fulfillment of the

requirements for the degree of Doctor of Philosophy in the

College of Education at the University of Kentucky

By

Frances Jillian Priesmeyer

Lexington, Kentucky

Co-Directors: Dr. Alicia Fedewa, Professor of School Psychology

and Dr. H. Thompson Prout, Professor of School Psychology

Lexington, Kentucky

Copyright (C) Frances Jillian Priesmeyer 2014 


\section{ABSTRACT OF DISSERTATION}

\section{LONG-TERM TRENDS OF PARTICIPATION IN PHYSICAL ACTIVITY DURING ADOLESCENCE WITH EDUCATIONAL AMBITION AND ATTAINMENT}

Insufficient physical activity is a serious concern for the youth of this nation. In 2008, more than one third of children and adolescents could be classified as either obese or overweight (Centers for Disease Control and Prevention, 2011). Poor nutrition and lack of physical activity are two major factors contributing to this epidemic. A physically active lifestyle during youth not only improves physical health, but has also been shown to improve emotional health, behavior, and academic performance. It is important that this area of research is continued and expanded so appropriate educational policies that support the health and well-being of America's youth can be established. No research to date has explored the long term impact of physical activity levels in adolescence on educational outcomes in adulthood. The purpose of this proposed study is to address this research gap by investigating the longitudinal relationships between physical activity in adolescence and physical activity in adulthood, educational ambition, and educational attainment. In order to achieve these research goals, secondary analysis of data from the National Longitudinal Study of Adolescent Health was analyzed. Results revealed that higher levels of physical activity during adolescence are associated with higher levels of physical activity during young adulthood. Higher levels of physical activity during adolescence were also negligibly and weakly correlated to higher levels of academic

ambition and later academic attainment. A discussion of the results and the limitations of the current study follow.

KEYWORDS: Physical Activity, National Longitudinal Study of Adolescent Health, Educational Ambition, Educational Attainment, Adolescents

Frances Jillian Priesmeyer

Student's Signature

6/20/2014

Date 


\title{
LONG-TERM TRENDS OF PARTICIPATION IN PHYSICAL ACTIVITY DURING ADOLESCENCE WITH EDUCATIONAL AMBITION AND ATTAINMENT
}

\author{
By
}

Frances Jillian Priesmeyer

Dr. Alicia Fedewa

Co-Director of Dissertation

Dr. H. Thompson Prout

Co-Director of Dissertation

Dr. Kenneth Tyler

Director of Graduate Studies 
DEDICATED TO ALL THE MEN AND WOMEN WHO SPEND

THEIR TIME AND ENERGY HELPING ADOLESCENTS CULTIVATE A LOVE FOR PHYSICAL ACTIVITY. YOU DO MAKE A DIFFERENCE. 


\section{ACKNOWLEDGEMENTS}

The following dissertation, while an individual work, would not have been possible without the insights and direction of several people. First, my Dissertation Chair, Dr. Alicia Fedewa, exemplifies the roles of researcher, teacher, and practitioner. Throughout this process, her timely and instructive feedback, as well as her support, enabled me to complete this project. Additionally, this project would not have been possible without consultation from Dr. Michael Toland. He provided his expertise in research methods and statistics, as well as never ending patience, guidance, and support. Next, I would like to thank the remaining members of my Dissertation Committee, Dr. Tom Prout, Dr. Kenneth Tyler, and Dr. Aaron Beighle, as well as my outside reader, Dr. James Holsinger. Each individual provided invaluable insights that guided and challenged my thinking. As a result, the final product is substantially improved and I have made growth as a researcher and writer.

I also received considerable support from friends and family. Brett Winterberg was supportive and understanding even when much of my time was consumed by this process. He provided much needed encouragement and never doubted I could complete this project, even when I doubted myself. Jessica Thomason was also a dependable source of practical and emotional support. She comforted and advised me when I struggled, and celebrated with me when I was successful. Additionally, I would like to thank my parents, Fred and Elaine Priesmeyer, who taught me to value education, intellectual curiosity, and a hard work ethic from a young age. Last but not least, I would like to recognize my cat, Boots, for years of keeping me company late at night by sleeping at my feet or on my papers while I wrote. 


\section{TABLE OF CONTENTS}

Acknowledgments....................................................................................................... iii

List of Tables...................................................................................................... vii

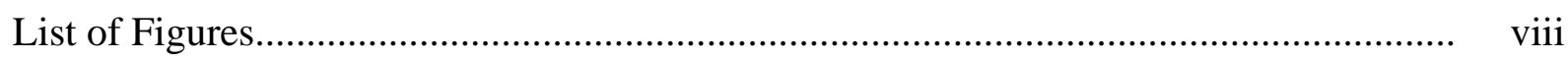

Chapter One: Introduction.............................................................................................

Chapter Two: Literature Review...................................................................................

Theoretical Frameworks of Physical Activity Patterns.................................................. 4

Theory of reasoned action and planned behavior......................................................... 4

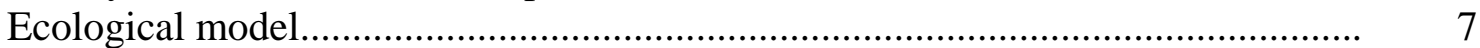

Physical Activity and Health................................................................................. 9

Physical Activity and Mental Health/Emotional Well-Being........................................ 11

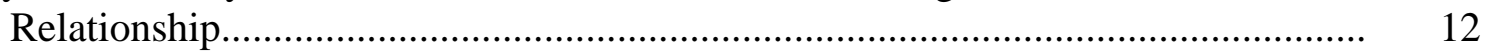

Confounding and moderator variables.................................................................. 16

Gender................................................................. 18

Physical Activity and Behavior.......................................................................... 20

Relationship between classroom behavior and physical activity............................ 20

Physical activity as a protective factor........................................................................ 21

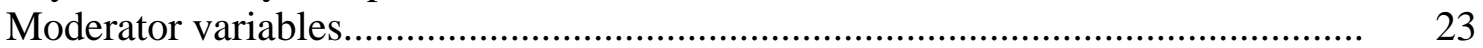

Gender............................................................ 23

Race................................................................... 24

Physical Activity and Educational Achievement....................................................... 25

Relationship between physical activity and cognitive functioning.......................... 25

Relationship between physical activity and academic performance......................... 26

Moderator variables................................................................................................ 31

Gender........................................................... 31

Age ................................................................... 32

Race and culture...................................................... 33

Socioeconomic status................................................. 34

Race and socioeconomic status.................................................................. $\quad 35$

Intensity and amount of activity ........................................... 36

Physical Activity and Educational Attainment......................................................... 37

Relationship............................................................................................. 37

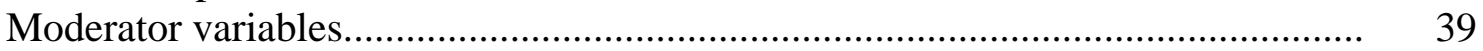

Habitual Physical Activity...................................................................................... 41

Habit formation............................................................................................. 41

Habits established in youth........................................................................................ 43

Previous ADD Health Physical Activity Research........................................................ 43

Summary ...................................................................................................... 48

Research Questions.............................................................................................. 48

Chapter Three: Methodology...................................................................................... 50

Participants........................................................................................................ 50 
Add Health Instruments...................................................................................... 53

Wave I In-School Questionnaire..................................................................... 54

Wave I In-Home Questionnaire......................................................................

Wave II In-Home Questionnaire.......................................................................... 55

Wave III In-Home Questionnaire....................................................................... 56

Wave IV In-Home Questionnaire......................................................................... 56

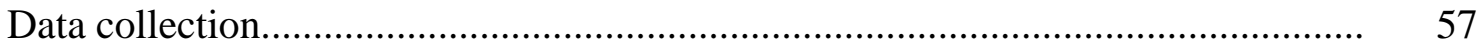

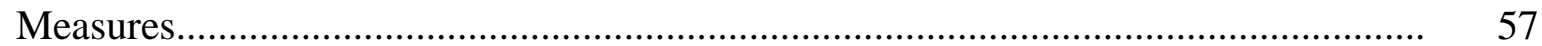

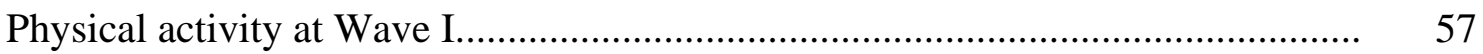

Physical activity at Waves II, III, and IV ........................................................... 57

Educational ambition at Waves I and II.............................................................. 58

Educational attainment at Waves III and IV...................................................... 58

Data Analysis........................................................................................... 58

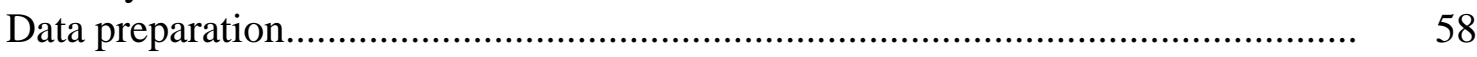

Wave I............................................................... 60

Wave II.............................................................. 61

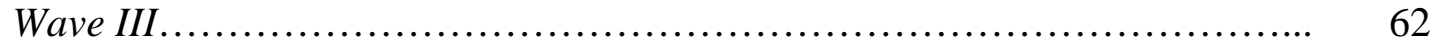

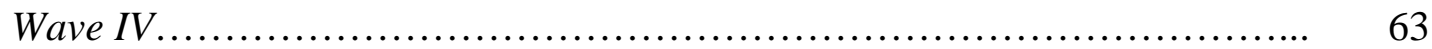

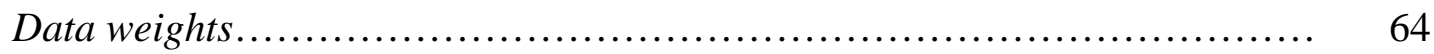

Data analysis of research question one................................................................... 65

Data analysis of research question two.............................................................. 66

Data analysis of research question three.............................................................. 67

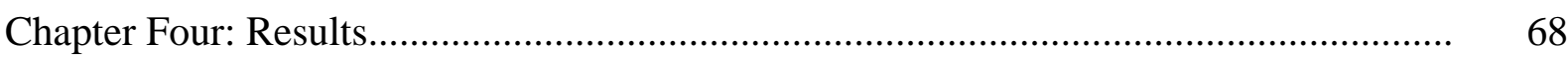

Research Question One: Growth in Physical Activity............................................... 68

Research Question Two: Physical Activity as a Predictor of
Educational Ambition..............................................................................

Physical activity (Wave I) and educational ambition (Wave I).............................. $\quad 74$

Physical activity (Wave I) and educational ambition (Wave II)............................... 82

Research Question Three: Physical Activity as a Predictor of

Educational Acheivement......................................................................................... 90

Physical activity (Wave I) and educational achievement (Wave III)....................... 90

Physical activity (Wave I) and educational achievement (Wave IV)........................ 95

Chapter Five: Discussion........................................................................................... 101

Research Question One....................................................................................... 101

Research Question Two............................................................................................. 103

Research Question Three......................................................................................... 105

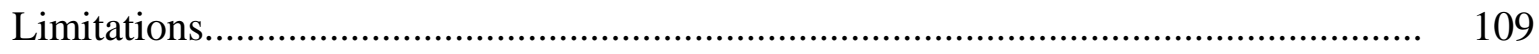

Conclusion.................................................................................................. 113

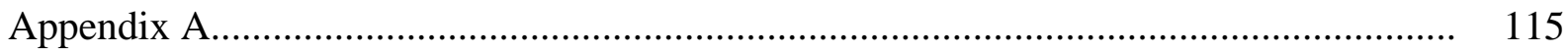

Appendix B ................................................................................................ 116

Appendix C................................................................................................ 117

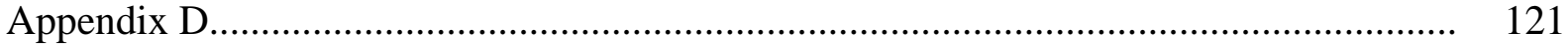

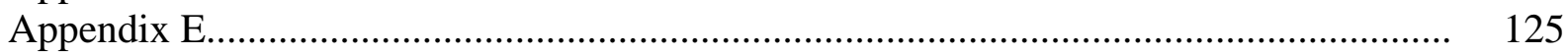




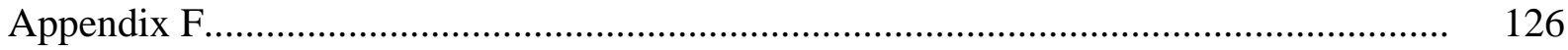

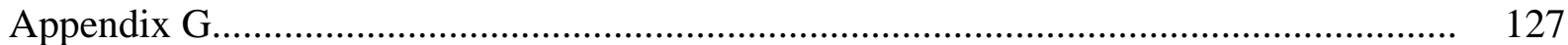

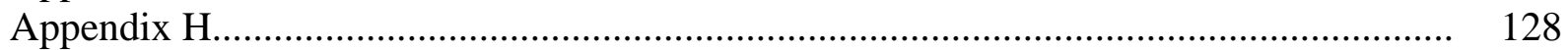

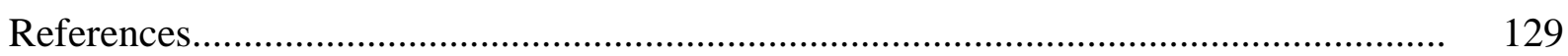

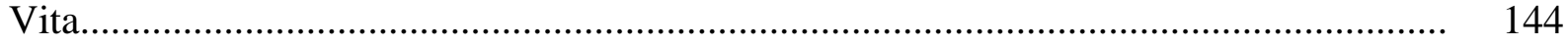




\section{LIST OF TABLES}

Table 3.1, Characteristics of Participating High Schools.

51

Table 3.2, Age and Number of Participants at Each Data Collecting Point.

Table 4.1, Predicted Log Odds of Reporting Physical Activity within Specific Age,

Gender, and Ethnicity Parameters with Data Set Weights.

Table 4.2, Predicted Log Odds of Reporting Physical Activity within Specific Age,

Gender, and Ethnicity Parameters without Data Set Weights....

Table 4.3, Proportional Odds (Ordinal Logistic Regression) Model Predicting Desire to go to College (h1ee1) at Wave I from Physical Activity at Wave 1, Gender, Age, and Ethnicity: Coefficients, Standard Errors for Coefficients (SE), Odds Ratios (ORs), and 95\% Confidence Intervals (CIs) of Odds Ratios.

Table 4.4, Proportional Odds (Ordinal Logistic Regression) Model Predicting Reported Likelihood of Attending College (h1ee1) at Wave I from Physical Activity at Wave 1, Gender, Age, and Ethnicity: Coefficients, Standard Errors for Coefficients (SE), Odds Ratios (ORs), and 95\% Confidence Intervals (CIs) of Odds Ratios.

Table 4.5, Proportional Odds (Ordinal Logistic Regression) Model Predicting Desire to go to College (h2ee1) at Wave II from Physical Activity at Wave 1, Gender, Age, and Ethnicity: Coefficients, Standard Errors for Coefficients (SE), Odds Ratios (ORs), and 95\% Confidence Intervals (CIs) of Odds Ratios.

Table 4.6, Proportional Odds (Ordinal Logistic Regression) Model Predicting Reported Likelihood of Attending College (h2ee2) at Wave II from Physical Activity at Wave 1, Gender, Age, and Ethnicity: Coefficients, Standard Errors for Coefficients (SE), Odds Ratios (ORs), and 95\% Confidence Intervals (CIs) of Odds Ratios.

Table 4.7, Proportional Odds (Ordinal Logistic Regression) Model Predicting Desire to go to College (h3ed1) at Wave I from Physical Activity at Wave I, Gender, Age, and Ethnicity: Coefficients, Standard Errors for Coefficients (SE), Odds Ratios (ORs), and 95\% Confidence Intervals (CIs) of Odds Ratios.

Table 4.8, Proportional Odds (Ordinal Logistic Regression) Model Predicting Desire to go to College (h4ed2) at Wave IV from Physical Activity at Wave I, Gender, Age, and Ethnicity: Coefficients, Standard Errors for Coefficients (SE), Odds Ratios (ORs), and 95\% Confidence Intervals (CIs) of Odds Ratios. 


\section{LIST OF FIGURES}

Figure 3.1, Scree Plot of Items Measuring Physical Activity at Wave I........................... 61

Figure 3.2, Scree Plot of Items Measuring Physical Activity at Wave II......................... 62

Figure 3.3, Scree Plot of Items Measuring Physical Activity at Wave III......................... 63

Figure 3.4, Scree Plot of Items Measuring Physical Activity at Wave IV........................ 64 


\section{Chapter One: Introduction}

Insufficient physical activity is a current concern for children and adolescents. Children and adolescents today are more sedentary than previous generations (Roddy, Fairclough, Atkinson, \& Stratton, 2012; Sifferlin, 2013; Tomkinson, Macfarlane, Noi, Kim, Wang \& Hong, 2012). Current research has demonstrated that physical activity during youth has positive impacts on physical health (Centers for Disease Control, 2011; Dwyer, Coonan, Leitch, Hetzel, \& Baghurst, 1983; Hills, King, \& Armstrong, 2007; Miles, 2007; Shephard \& Trudeau, 2005, 2008; Story, 2009), mental wellbeing (Desha, Ziviani, Nicholson, Martin, \& Darnell, 2007; Lagerberg, 2005; Parfitt \& Eston, 2005; Sagatun, Sogaard, Bjertness, Selmer, \& Heyerdahl, 2007; Valois, Umstattd, Zullig, \& Paxton, 2008; Wiles, Jones, Haase, Lawlor, Macfarlane, \& Lewis, 2008), and educational achievement (Chomitz, Slining, McGowan, Mitchell, Dawson, \& Hacker, 2009; Coe,

Pivarnik, Womack, Reeves, \& Malina, 2006; Fedewa \& Ahn, 2011; Fox, Barr-Anderson, Neumark-Sztainer, \& Wall, 2010; Raspberry, Lee, Robin, Laris, Russell, Coyle, \& Nihiser, 2011; Ratey, 2008; Stevens, To, Stevenson, \& Lochbaum, 2010; Tomporowski, Davis, Miller, \& Naglieri, 2007; VanDusen, Kelder, Kohl, Ranuit, \& Perry, 2011).

Despite research highlighting the benefits of physical activity, many children and adolescents still do not engage in recommended amounts of physical activity (Centers for Disease Control, 2011). One way to address this concern is to develop initiatives that will introduce physical activity to children and adolescents in ways that will encourage them to live active lives. Initiatives that impact children and adolescents on a broad scale typically occur within the school system (Ratey, 2008). It is important that educational policy makers are provided with research that documents all of the benefits of physical 
activity during youth. The positive impact of physical activity on physical and mental health is well documented (Desha et al., 2007; Lagerberg, 2005; Parfitt \& Eston, 2005; Sagatun et al., 2007; Valois et al., 2008; Wiles et al., 2008). The impact of physical activity on educational achievement has become a growing research topic as well (Chomitz et al., 2009; Coe et al., 2006; Fedewa \& Ahn, 2011; Fox et al., 2010; Raspberry et al., 2011; Ratey, 2008; Stevens et al., 2010; Tomporowski et al., 2007; VanDusen et al., 2011). However, up-to-date research exploring the impact of physical activity on long-term educational outcomes is limited. In order to expand the body of research on the lifelong benefits of a physically active lifestyle, the current study provides a review of the current literature on the widespread benefits of physical activity. The study also uses longitudinal data to determine if physical activity during childhood and adolescence impacted long-term educational attainment in adulthood.

In the current study, long-term benefits of physical activity during adolescence were explored and analyzed at length. Chapter two focuses on topics relevant to understanding the role physical activity plays in childhood and adolescence. The theories behind physical activity determinants and patterns are discussed. The increasing obesity rates in the United States and other developed nations and the important role of physical activity in alleviating this crisis is addressed. Additionally, the relationships between physical activity and emotional well-being, mental health, behavior, academic achievement, and educational attainment are outlined. Chapter three describes the methodology used in the study and details the participants, measures, and research variables included for analysis. Chapter four presents the results of the statistical 
analyses. Chapter five summarizes the results, links them to previous literature and presents the limitations of the current study.

Copyright (C) Frances Jillian Priesmeyer 2014 


\section{Chapter Two: Literature Review}

\section{Theoretical Frameworks of Physical Activity Patterns}

Five prominent theoretical frameworks are used for health promotion and studies of physical activity determinants and patterns. These include the health belief model, the theories of reasoned action and planned behavior, the transtheoretical model, the social cognitive theory and the ecological model (Doshi, Patrick, Sallis, \& Calfas, 2003). Each theory is comprised of several behavior change strategies and each strategy may be applicable to more than one theory. The following sections will focus on the theory of reasoned action and planned behavior as well as the ecological model because these two frameworks provide theoretical information on how an individual's physical activity patterns may relate to physical health, mental health, behavioral, and educational outcomes.

Theory of reasoned action and planned behavior. Fishbein (1973) and Fishbein and Ajzen (1975) developed the theory of reasoned action in order to explain voluntary behavior. According to this theory, the most critical determinant of behavior is an individual's behavioral intention to perform a specific act in a situation. Behavioral intention is determined by two factors; attitude toward the act and subjective norm. Attitudes are defined as the product of important behavioral beliefs about the likely outcomes associated with the act and weighted by the amount of importance the individual places on these outcomes. Subjective norm is the actual or perceived social pressure to engage in a behavioral act and is derived from the views of people or groups important to the individual. The theory of reasoned action has been shown to impact voluntary behavior (Hagger, Chtzisan, \& Biddle, 2002; Shephard \& Trudeau, 2008; 
Wankel, Mummery, Stephens, \& Craig, 1994). It has yielded positive results when applied to physical activity and exercise. Several studies have found support for the utility of behavioral intention when predicting exercise behavior. Interestingly, the attitudinal component of this theory has been demonstrated to be more predictive than the subjective norm component (Wankel et al., 1994). This indicates that an individual's personal attitude towards the benefits of physical activity is more important than the attitudes of the individual's social support network. Therefore, an individual's physical activity is more likely to increase if they are aware of all of the benefits of and have a positive attitude towards physical activity.

Despite how frequently the theory of reasoned action is cited and how widely it is accepted, there are a few notable weaknesses. For example, other factors besides attitude and subjective norm--such as exercise behavior history--have been found to be effective predictors of exercise intentions (Wankel et al., 1994). Additionally, the theory is limited to behaviors that are under complete volitional control. This is a significant limitation to the theory because many behaviors that occur in real situations are influenced and restricted by available resources such as time, money, and the cooperation of others (Wankel et al., 1994).

In order to address some of this model's limitations, Ajzen (1991) developed the theory of planned behavior as an extension to the theory of reasoned action. In his theory, Ajzen adds a behavioral control construct to the attitudinal and subjective norm constructs. The behavioral control construct is based on Bandura's ideas of self-efficacy in his social cognitive theory. The more influence an individual perceives he has over his behavior, the more likely he is to engage in that behavior (Ajzen, 1991; Wankel et al., 
1994). Studies have demonstrated that, while the theory of reasoned action is predictive of physical activity behavior, with the integration of Ajzen's behavioral control construct, the theory becomes more effective in predicting an individual's engagement in physical activity (Hagger, Chatzisan, \& Biddle, 2002; Wankel, et al. 1994).

For several reasons, this model fits a conceptualization of how physical activity during youth could be related to long-term health and life outcomes. If an individual is exposed to physical activity during youth, they will become aware of its benefits at a time when habits and attitudes are likely to be formed. As a result, they will believe in the important results and benefits of physical activity, which according to Fishbein's theory, will lead them to be more likely to engage in physical activity on a voluntary basis. Additionally, if youth are engaged in physical activity, it is likely that important people around them such as parents, teachers, and peers believe in the value of physical activity, making participation in these activities the subjunctive norm for the individual. This would be especially true if the individual was in a school environment with a culture that supported physical activity. Finally, if Ajzen's added behavioral control construct is met and the individual feels like she can control how, when, and why she engages in physical activity, she will be intrinsically motivated to seek out and engage in physical activity.

If all three constructs of the theory of reasoned action and planned behavior (attitude, subjunctive norm, and behavioral control) are present during a young individual's physical activity, then he will likely internalize attitudes and views associated with these constructs. Throughout life these individuals will continue to have a positive attitude towards physical activity, they will view their participation in physical activity to be important to those around them, and they will believe that their 
participation in physical activity has a meaningful impact. Particularly, if these individuals continue to be in environments in which it is possible to control when and how they participate in physical activity, it is even more likely the individual will continue to be physically active into adulthood because the third construct of the theory will also be met. Related factors that influence how likely it is for people to become and remain physically active are physical environments and social climates (Dyck, Cardon, Deforche, Giles-Corti, Sallis, Owen, \& Bourdeaudhuij, 2011; Kaczynski \& Henderson, 2007; Ratey, 2008). The ecological model addresses these factors and integrates them into a theory that views the individual as influenced by the system in which she is a part.

Ecological model. Another theoretical framework that is particularly applicable to how physical activity patterns are related to lifelong health and life outcomes is the ecological model. The ecological model acknowledges that individuals do not live in bubbles, but are impacted and influenced by the environment and cultural factors that surround them. Other theoretical frameworks, including the theory of reasoned action and planned behavior, do not acknowledge the important role of physical environment and societal norms on an individual's behavior. In many situations, conscious individual decision making is not the only thing that goes into behavioral choices (Oglivie, Bull, Powell, Cooper, Brand, Preston, \& Rutter, 2011). Individuals are influenced by their environments and government policies on both local and national levels.

Several studies have demonstrated that physical environment and sociodemographic factors have an impact on the physical activity levels of individuals. Dyck et al., (2011) administered the Neighborhood Environmental Walkability Scale and the International Physical Activity Scale to 1,200 Belgian adults. The participants in the 
Belgian study also wore an accelerometer for seven days. Results found that individuals who perceived their neighborhoods to be highly walkable and to have convenient recreation facilities or use of home physical activity equipment were the most likely to be physically active. Kaczynski and Henderson (2007) reviewed fifty studies that reported an empirical relationship between parks or recreation areas and physical activity variables. They found a significant correlation between an individual's proximity to parks or recreation areas and increased physical activity.

The fact that environments have an impact on levels of physical activity is an important consideration when studying the physical activity levels of children and adolescents. Schools that embrace a culture of healthy living and provide access to recreation opportunities and physical health monitoring make it easier for students to make healthy choices and reap benefits of a physically active lifestyle. For example, Naperville Central High School in suburban Chicago implemented a physical education program in which students learned how to develop and maintain a healthy body through exercise. These students used heart rate monitors during class to ensure they were meeting the recommended requirements of moderate to vigorous physical activity and were graded on how much time they spent in their target heart rate zones (Ratey, 2008). At Naperville Central High School, only 3 percent of the sophomore class was overweight compared to the national average at the time of 30 percent (Ratey, 2008). At Woodland Elementary School in Kansas City, the physical education class was expanded from one class a week to a forty-five minute per day class focused primarily on cardiovascular activity. After one school year, the fitness levels of the students showed substantial improvement (Ratey, 2008). 


\section{Physical Activity and Health}

Childhood obesity is a rapidly growing epidemic in the United States. The percentage of children aged 6-11 years old who were obese increased from 7\% in 1980 to almost $20 \%$ in 2008 . At the same time, the percentage of obese adolescents aged 12-19 increased from $5 \%$ to $18 \%$. In 2008 , more than one third of children and adolescents could be classified as either obese or overweight (Centers for Disease Control and Prevention, 2011). Currently, the majority of United States children do not consume diets that meet the Dietary Guidelines for Americans, nor do they achieve the recommended 60 minutes of daily physical activity (Story, Nanney, Schwartz, 2009). It has been shown that the lack of physical activity is one of the most evident causes of obesity, diabetes, and cardiovascular diseases among children (Guedes, 2007; Hobin, Leatherdale, Manske, Burkhalter, \& Woodruff, 2010). It is also estimated that the current generation of American youth could be the first generation in history to have a shorter life expectancy than their parents (Centers for Disease Control, 2011).

Perhaps the most accepted and widely understood benefit of physical activity is its impact on physical health. There is a significant amount of evidence that physical activity can lead to attainment of a healthy weight and improved overall health (Centers for Disease Control, 2011; Shephard \& Trudeau, 2008; Story et al., 2009). Physical activity can change body composition by decreasing fat mass and increasing lean mass, reduce resting blood pressure, regulate blood glucose levels, regulate blood lipid levels and boost the functioning of the immune system (Miles, 2007). There is also substantial evidence that physical activity is a protective factor for many chronic diseases. These effects can be seen either as direct impact or indirectly through the weight loss and 
control benefits of physical activity. Physically active adults have a 33-50\% lower risk of developing Type 2 diabetes than inactive adults (Miles, 2007). Physical activity has been linked to a lower risk of cardiovascular disease and some types of cancers, including colon, breast, and lung cancers (Centers for Disease Control, 2011; Miles, 2007). In childhood and adolescence, physical activity during growth periods, particularly puberty, has a long term effect on improving bone health (Hills, King, \& Armstrong, 2007; Miles, 2007). Regular physical activity during the years of body growth contributes to the healthy development of the musculoskeletal system and helps maintain a healthy body composition (Hills, King, \& Armstrong, 2007).

One of the most comprehensive evaluations of the effects of increased physical activity on children's physical health was conducted at a rural school in Trois-Rivieres in Quebec, Canada. Participants were 546 primary school students. Half of the students were assigned to an experimental program that included five hours of physical education per week. The program lasted for six years and focused on learning motor skills, developing cardio-respiratory and muscular endurance, and introduction to a variety of sports. The control group of students consisted of the classes immediately preceding and succeeding the class that received the enhanced program. The control group received the school's standard physical education program which included 40 minutes of physical activity per week. The experimental group showed cardiovascular gains and muscle strength gains. Notably, there was no difference in body-fat content between the experimental and control groups, particularly among children of normal weight (Shephard \& Trudeau, 2005). 
Another notable study of increased physical activity effects in children was a 500 student trial in South Australia. Over an hour per day of endurance training was added to the physical education curriculum of 10 year old school children (Dwyer, Coonan, Leitch, Hetzel, \& Baghurst, 1983). In the first fourteen weeks, there were gains in physical work capacity and decreases in body-fat percentages. A follow-up investigation demonstrated that these benefits were maintained over the next two years (Dwyer et al. 1983; Shephard \& Trudeau, 2008).

In order to maintain a healthy weight and overall health, it is currently recommended that children and adolescents engage in 60 minutes of moderate to vigorous physical activity daily (Centers for Disease Control, 2011). Regrettably, more than $80 \%$ of adolescents do not participate in enough physical activity to meet these guidelines (U.S. Department of Health and Human Services, 2012). Adolescents who do not participate in habitual physical activity are losing out on more than just physical health benefits. Physical activity positively impacts several other areas of overall wellness as well.

\section{Physical Activity and Mental Health/Emotional Well-Being}

Research also supports the hypothesis that physical activity is beneficial for the mental health and emotional well-being of children and adolescents. Studies have linked physical activity to reduced levels of anxiety and depression, as well as improved selfesteem and self-efficacy (Desha, Ziviani, Nicholson, Martin, \& Darnell, 2007; Lagerberg, 2005; Parfitt \& Eston, 2005; Sagatun, Sogaard, Bjertness, Selmer, \& Heyerdahl, 2007; Valois, Umstattd, Zullig, \& Paxton, 2008; Wiles, Jones, Haase, Lawlor, Macfarlane, \& Lewis, 2008). 
Relationship. Several studies have investigated the relationship between participation in physical activity and symptoms of depression and anxiety. Parfitt \& Eston (2005) explored the relationship between physical activity and psychological wellbeing in children through a study in which 70 children ( 35 boys, 35 girls) with a mean age of 10.4 wore pedometers for seven days and were assessed for symptoms of anxiety and depression and for self-esteem levels with three self-report questionnaires; the StateTrait Anxiety Inventory for Children (STAIC), the Childhood Depression Inventory (CDI), and the Children and Youth's Physical Self-perception Profile (CY-PSPP). Correlational analyses on the data revealed that physical activity had a negative relationship with depression $(\mathrm{r}=-0.66)$ and anxiety $(\mathrm{r}=-0.48)$, as well as a positive relationship with global self-esteem $(\mathrm{r}=0.66)$. These data indicate that, as physical activity increases, symptoms of depression and anxiety decrease while self-esteem increases. Notably, when partial correlations were computed for depression, controlling for anxiety and self-esteem, and anxiety, controlling for depression and self-esteem, statistical significance disappeared, but remained for self-esteem, controlling for depression and anxiety $(\mathrm{r}=0.36)$. These results can be explained by high intercorrelations between anxiety and depression $(r=0.68)$, anxiety and self-esteem $(r=$ $0.71)$ and depression and self-esteem $(r=0.80)$. Three of the items on the STAIC are also reflected in items on the CDI and five items on the CDI have a similar counterpart on the CY-PSPP. It is likely that the relationship between physical activity and global self-esteem comprehensively includes the relationship between physical activity, depression, and anxiety. Overall, children in this study who logged more than 12,000 
steps per day on their pedometers had more positive psychological profiles than the children who logged less than 9,200 steps per day.

On a broader scale, Wiles et al. (2008) conducted a longitudinal study with 1,446 children 11-14 years old from 39 schools in the North West region of England aimed at investigating the relationship between physical activity and children's mental health. Participants completed self-report surveys listing the total number of sessions of physical activity (over 20 minutes) that they participated in during the previous week. This total was then averaged for the week to determine if the child could be classified as physically active (one hour or more of physical activity per day). Childhood emotional problems were measured using the Strengths and Difficulties Questionnaire (SDQ) at baseline and again one year later. Results showed that children who were defined as physically active had fewer emotional problems at the one year follow-up. Wiles et al. (2008) suggested that future research needs to involve longitudinal studies that record both physical activity and emotional problems more frequently and over a longer period so the effects of maintaining a healthy lifestyle can be determined more clearly.

In a similar study, Sagatun et al. (2007) used data from 2,489 adolescent participants of the Oslo Health Study in Norway to determine the association between weekly hours of physical activity at age 15-16 and mental health three years later at age 18-19. Mental health was measured by the Strengths and Difficulties Questionnaire with an impact supplement (a follow-up survey to determine if symptoms are causing significant impairment). Physical activity was measured by a survey question on weekly hours of physical activity outside school, defined as exercise 'that made you sweat or out of breath'. They found that, for boys, the number of hours spent on physical activity per 
week at age 15-16 was negatively correlated with emotional symptoms and peer problems at age 18-19. This indicates that physical activity can act as a protective factor for adolescent males. However, for girls, there were no statistically significant differences in the Strengths and Difficulties subscales at age 18-19 based on weekly hours of physical activity at 15-16. The authors hypothesize that these gender differences exist because sports hold a higher social significance for boys. Boys who participate in sports have the opportunity to be socially interactive with teammates and may appear more socially desirable to all peers. Girls tend to be naturally more socially interactive and may create more social opportunities for themselves outside sports. Positive social interactions with peers may be a protective factor for adolescents. Yet, for both boys and girls who reported participating in 5 to 7 hours of physical activity weekly at age 15-16, lower mental health difficulties at age 18-19 years were found.

The findings of Sagatun et al. (2007) suggest that physical activity participation at age 15-16 can continue to have positive impacts on the individual through ages 18-19 are interesting when considered in context with a study by Downs and Ashton (2010). Downs and Ashton (2010) conducted a survey of 395 college students at two American universities to examine how physical activity habits change during the transition from high school to college and to examine the effects of these changes. Participants selfreported their vigorous physical activity and sports participation for each year of high school and completed psychological measures assessing their athletic identity and physical and mental health. The majority of participants reported significantly less vigorous physical activity and sports participation, as well as a weaker athletic identity in college compared to high school. Moreover, the participants who reported consistent or 
current engagement in vigorous physical activity at recommended levels also reported better mental and physical health across several variables than their less active peers. Downs and Ashton's (2010) results suggest that college students often cease their participation in sports and reduce the amount of vigorous physical activity they engage in. This trend is unfortunate because consistent engagement in vigorous physical activity could help protect their mental and physical health in college and beyond. In fact, Nguyen-Michel and colleagues (2006) conducted a self-report survey of 814 ethnically diverse college students from three types of colleges in Southern California in order to examine the associations between physical activity and perceived stress and hassles of college life. Hierarchical linear model analyses revealed a statistically significant negative relationship between physical activity and perceived hassles. This reveals that, as participation in physical activity decreased, stress and perceived hassles of college life increased. Since both stress and a sedentary lifestyle are detrimental to health, it would be beneficial for college age students to be educated on ways to incorporating physical activity into college life as a strategy to reduce stress.

Physical activity may also be related to self-esteem and self-efficacy. Nelson and Gordon-Larsen (2006) analyzed data from waves I and II of the Add Health data set, which included data from 11,957 adolescents in $7^{\text {th }}$ through $12^{\text {th }}$ grades. They discovered that students who engaged in sports had the lowest risk for poor self-esteem.

Additionally, Valois et al. (2008) explored the relationships between physical activity and emotional self- efficacy in a statewide sample of 2,566 public high school adolescents in South Carolina who had participated in the Center for Disease Control's 2003 Youth Risk Behavior Study. Items related to physical activity and items from an adolescent 
emotional self-efficacy scale were used. Logistic regression and separate multivariate models were used to analyze the data. Results of the analyses suggested that low levels of vigorous physical activity (in the past 7 days), moderate physical activity (in the past 7 days), strengthening/toning exercises (past 7 days), and playing on sport teams (past 12 months) were associated with low levels of emotional self-efficacy. Specifically, black females who reported not engaging in physical activity behaviors or not meeting minimum CDC physical activity recommendations had a $1.87-2.13$ increased odds of reporting low emotional self-efficacy versus those who reported engaging in recommended levels of physical activity. Similarly, white females, black males, and white males who reported not engaging in physical activity or not meeting minimum physical activity recommendations had $4.1-6.62,1.65-1.97$, and $1.97-3.16$ increased odds respectively of reporting low emotional self-efficacy versus those who reported engaging in recommended levels of physical activity (Valois et al., 2008). These results indicated that across all groups low levels of physical activity were associated with low levels of emotional self-efficacy. In particular, white females who reported not engaging in physical activity or not meeting CDC physical activity recommendations had the largest increased odds $(4.1-6.62)$ of reporting low emotional self-efficacy. This finding is one example of the variety of demographic variables that can influence the relationship between physical activity and mental health.

Confounding and moderator variables. It is important to remember that the relationship between physical activity and mental health can be complicated and influenced by a variety of other variables (Desha et al., 2007; Lagerberg, 2005). In a 2005 review of literature, Lagerberg emphasized that the relationship is not clear cut and 
that physical activity does not directly lead to improved mental health. Additionally, he made the point that the correlations found between physical activity and mental health likely go in both directions, meaning children and adolescents with strong and stable levels of mental health are more likely to participate in physical activity. Desha et al. (2007) used data from the second Child Developmental Supplement to the Panel Study of Income Dynamics (CDS II) to determine the relationship between physical activity and depressive symptomatology in adolescents. Participants in this study were 72713 to 18 year old American adolescents. It was found that fewer than $60 \%$ of these adolescents met the 60 minutes of moderate to vigorous physical activity per day that is currently recommended by the Center for Disease Control. Interestingly, they did not find a statistically significant association between the duration of participation in physical activity and severity of depressive symptoms. They did find that male adolescents not involved in school sports or sports clubs were more likely than involved males to experience a higher amount of depressive symptoms. However, they were unable to determine if these effects were due directly to the physical activity or due to the positive psychosocial aspects of being a part of an athletic team. Desha and his colleagues (2007) recommend that more research needs to be done to pinpoint the specific aspects of sports participation that appear to be protective factors. Similarly, Taliaferro, Rienzo, Miller, Pigg, Dodd (2008) examined how the relative risk of hopelessness and suicide is associated with physical activity and sport participation by analyzing data from the Center for Disease Control's 2005 Youth Risk Behavior Study. Data from 13,857 adolescent participants from 12 to 18 years old was analyzed using logistic regression modeling to compare the odds of hopelessness and suicide in students who engaged in 
various levels of physical activity to inactive students. Similar analyses were used to compare the risks of school athletes to non-athletes. Results revealed that frequent, vigorous activity reduced the risk of hopelessness and suicide among male adolescents. Additionally, data showed that low levels of activity actually increased the risk of feeling hopeless among young females. For both genders, participation in school sports protected against hopelessness and suicide. Taliaferro et al.'s (2008) findings indicated that the psychosocial benefits that come from involvement in school sports protect adolescents from hopelessness and suicide more than physical activity alone. These data allude to the complexity of the factors that may work with physical activity to contribute to protective mental health benefits. In addition to these confounding variables, there are also demographic variables that may impact the relationship between physical activity and mental health. The most examined of these variables is gender.

Gender. During their study investigating the relationship between the physical activity and mental health of 1,446 children aged 11-14 years, Wiles et al. (2008) found gender to be a confounding variable. When their analyses included both boys and girls, the results indicated a strong negative relationship between physical activity and the total difficulties score on the Strengths and Difficulties Questionnaire (SDQ). It was discovered that girls, as a whole, engaged in less physical activity and had higher total difficulties scores on the SDQ than boys. Therefore, when separate analyses were conducted for boys and girls, the negative relationship still existed, but its strength was diminished.

Goodwin (2006) analyzed data from the Health Behavior in School-Aged Children in the United States survey, which included 9,938 youth in $6^{\text {th }}$ through $10^{\text {th }}$ 
grades in 1998, to examine the associations between coping behaviors when angry and depression. It was discovered that substance use, emotional coping strategies (i.e., praying, talking to someone, listening to music), and aggressive behavior (i.e., physical fighting, verbal arguing) were associated with increased likelihood of depression, while physical activity (i.e., exercising, bike riding, taking a walk) was associated with decreased likelihood of depression. She also found several gender-specific differences. Females were more likely to report feelings of depression and also less likely to use physical activity as a coping strategy. They were more likely to use emotional coping strategies and to verbally argue. Males were more likely to fight physically and to use substances and physical activity as coping strategies. Interestingly, Robinson et al. (2011) analyzed data from the 14-year follow-up of the Raine study, including physical activity self-reports and Child Behavior Checklist (CBCL) scores from 1,598 14 year-old adolescents living in Western Australia. It was found that adolescents who exercised rarely were more likely to be in the last t-score quartiles of the $\mathrm{CBCL}$, indicating poor mental health. Additionally, this was discovered to be particularly true for females. Conversely, Sagatun et al. (2007) analyzed data from 2,489 adolescent (aged 15-16 at baseline, and 18-19 at follow-up) participants of the Oslo Health Study including a selfreport of physical activity and scores on the Self Report Questionnaire. It was found that, for boys, the number of hours spent on physical activity per week was negatively associated with emotional symptoms and peer problems, but there were no associations for girls. The data from these studies indicate that, while males tend to be more inclined to engage in physical activity for emotional coping, this strategy can be effective for both sexes. 


\section{Physical Activity and Behavior}

Relationship between classroom behavior and physical activity. When considering the implementation of a physical activity initiative in a school system, the impact of physical activity on student behavior in the classroom is an important factor to examine. Barros, Silver, and Stein (2009) examined the relationship between school recess and classroom behavior by analyzing data from the Early Childhood Longitudinal Study. The third grade data set of Kindergarten Class 1998-1999 was used $(n=11,624)$. Children were categorized into two levels of recess participation (i.e., none $/ \mathrm{minimal}=<$ one fifteen minute break; or some). Next "some" recess was categorized into five levels based on the frequency and duration of the recess. It was found that teachers' ratings of classroom behavior scores were better for children who participated in some recess than for those who participated in no or minimal recess. This finding was statistically maintained by multivariate regression analysis. Interestingly, among the children who received some daily recess, the behavior scores did not differ due to the amount of recess the children participated in. This study demonstrated that 8-9 year old children receive better teacher behavior ratings when they are provided with at least one physical activity break daily.

Additional support for the hypothesis that participation in physical activity improves classroom behavior can be found in the studies by Jarrett, Maxwell, Dickerson, Hoge, Davies, and Yetley (1998) and Ridgway, Northup, Pellegrin, LaRue, and Hightshoe (2003). Jarrett et al. (1998) conducted a study with 43 children in fourth grade to determine the effect of a recess break on classroom behavior, including working, fidgeting, and listlessness. The children attended a southern urban elementary school 
with a district policy against recess. The school granted permission to the researchers for two 4th grade classes to have recess once per week so their behavior on recess and nonrecess days could be compared. Participants were used as their own controls and multivariate analyses were used to test hypotheses. Results demonstrated that the children were more on-task and less fidgety on days they had recess. Sixty percent of the children, both boys and girls (including the five children diagnosed with ADHD) experienced significant behavior improvement on recess days. Ridgway et al. (2003) used single case designs to evaluate the effects of traditional recess on classroom behavior of children with and without ADHD. Findings demonstrated that levels of inappropriate behavior were consistently higher on days when the participants did not have recess and these inappropriate behaviors progressively increased throughout the day.

Physical activity as a protective factor. It has been hypothesized that participation in regular physical activity reduces the likelihood that children and adolescents will engage in high-risk behaviors such as substance abuse. Taliaferro, Rienzo, and Donovan (2010) investigated the relationships between sport participation and several high risk behaviors among high school students using data from the Centers for Disease Control's Youth Risk Behavior Surveys from 1999 to 2007. Multiple logistic regression analyses were used to examine relationships between sport participation and behaviors such as sexual activity, interpersonal violence, suicidality, and substance abuse. They found that male and female students who were on an athletic team engaged in more vigorous activity than non-athletes. Additionally, male athletes were more likely to consume fruit and less likely to report trying to lose weight, to smoke cigarettes, to use 
marijuana, cocaine or other illegal drugs, to carry a weapon, to consider suicide, and to attempt suicide than non-athletes. Both male and female athletes were more likely than non-athletes to report using a condom during their last sexual encounter. On the other hand, male athletes were more likely to use alcohol and chewing tobacco and to vomit, use laxatives or take pills for quick weight loss than non-athletes. Overall, the findings of this study indicated that student athletes engaged in more positive and fewer negative health behaviors.

Nelson and Gordon-Larsen (2006) analyzed data from waves I and II of the Add Health data set to examine relationships between physical activity, sedentary behavior, and health risk behavior patterns. Data from 11,957 adolescents in $7^{\text {th }}$ to $12^{\text {th }}$ grade were included in this study. It was found that adolescents who engaged in sports were less likely to engage in risky sexual behaviors, to smoke cigarettes, to use alcohol, and to be truant. They were more likely to wear a seat belt. Students who reported logging five or more hours of physical activity were less likely to have sexual intercourse, smoke cigarettes, get drunk or drive drunk, use illegal drugs, be truant, and fail to wear a seat belt.

Additionally, Cohen, Taylor, Zonta, Vestal, and Schuster (2007) examined the relationship between the availability of and participation in extracurricular sports and high risk behavior by surveying 175 Los Angeles County public high schools in 2002. The schools self-reported the number of extracurricular sports programs offered and the percentage of students who participated in the programs. These reports were compared to community data on rates of youth arrests, teen pregnancies, and sexually transmitted diseases. It was found that the average school offered 14 sports programs and the 
average student participation rate in these programs was 39\% for boys and $30 \%$ for girls. It was also noted that schools offering fewer than 13 programs only had $14 \%$ of its students participating while schools that offered more than 16 programs had $31 \%$ of its students participating. Moreover, after controlling for area level demographics such as socioeconomic status, it was discovered that juvenile arrest rates and teen birth rates were lower in areas where the schools offered more extracurricular sports. The results of this study support the hypothesis that sports participation offers adolescents protection from high risk behaviors. However, it is unclear if these protective factors come from the engagement in physical activity, the psychosocial benefits of participating on a sports team, or a combination of the two.

Moderator variables. There are several moderator variables that influence the relationship between physical activity and student behavior. Analogous to the relationship between physical activity and children's mental health, the most researched of these moderator variables include gender and race.

Gender. Taliaferro, Rienzo, and Donovan (2010) discovered gender differences in the relationships between sports participation and high risk behaviors during their analysis of data from the 1999-2007 Youth Risk Behavior Surveys. Female athletes across races/ethnicities were less likely than female non-athletes to report having sexual intercourse and having multiple sexual partners during the past three months.

Additionally, White female athletes were less likely than non-athletes to report ever having sexual intercourse. On the other hand, minority male athletes were more likely than non-athletes to report ever having sexual intercourse and having sexual intercourse in the past three months. 
Race. Interestingly, the results of Taliaferro, Rienzo, and Donovan's (2010) analysis of data from the 1999-2007 Youth Risk Behavior Surveys indicated that, among Caucasian students, sports participation was related to multiple positive health behaviors, but African-American and Hispanic athletes reported fewer positive health behaviors and, in some cases, negative behaviors were associated with minority students who participated in sports. White female athletes reported more fruit and vegetable consumption than White female non-athletes and White male athletes reported more vegetable consumption than White male non-athletes. However, among minority males and females, there were no consistent relationships between sports participation and fruit or vegetable consumption.

Race/ethnicity also influenced the interactions between sports participation and interpersonal violence. Hispanic male athletes were more likely than Hispanic male nonathletes to be hit by a romantic partner, to get in a physical fight at school, and to be injured in a physical fight. African American male athletes were more likely to get into a physical fight at school than African American male non-athletes. These interactions were not present for White male athletes. Additionally, White female athletes were less likely than non-athletes to report experiencing forced sexual intercourse, being in a physical fight, feeling unsafe at school, considering suicide, and attempting suicide. No consistent relationships were found between these variables and sports participation among minority females. It could be that minority adolescent's higher exposure to less favorable social and environmental influences offsets the protective factors of sports participation (Pate, Health, Dowda, \& Trost, 1996; Taliferro, Rienzo, \& Donovan, 2010). 


\section{Physical Activity and Educational Achievement}

Recently, physical activity has been linked to improved cognitive performance and academic achievement (Chomitz et al., 2009; Coe et al., 2006; Fedewa \& Ahn, 2011; Fox et al., 2010; Raspberry et al., 2011; Ratey, 2008; Stevens et al., 2010; Tomporowski et al., 2007; VanDusen et al., 2011). Since school administrators face many pressures to maintain high standards of student academic achievement, this body of literature may be most likely to convince stakeholders of the benefits of increasing physical activity opportunities for students. When addressing this line of research, it is also important to examine the moderator variables that may impact this relationship. The relationship between physical activity and achievement outcomes, the moderator variables that influence this relationship, and the methods used for studying these relationship will be addressed.

\section{Relationship between physical activity and cognitive functioning. Brain-} derived neurotrophic factor (BDNF) is a family of proteins that build and maintain the neural cell circuitry in the brain. It is present in the hippocampus and is a needed ingredient for learning and memory. It has been demonstrated that when mice run regularly, they have an increase of BDNF especially in the hippocampus. Additionally, the farther the mice run, the higher their levels of BDNF (Ratey, 2008). BDNF has been likened to "miracle-grow" for the brain. It is a logical conclusion that if exercise increases the amount of BDNF in the brain, then individuals who engage in frequent physical activity will have a more extensive and finely tuned neural circuitry leading to increased brain function and higher levels of cognition. 
Tomporowski, Davis, Miller, and Naglieri (2008) reviewed the results of studies that examined the effects of exercise on children's intelligence and cognition. In the studies they reviewed, exercise interventions such as aerobic training, strength training, and balance were implemented and then improvements on cognitive tests were measured. Three of the ten exercise interventions had no effect on cognitive measures, two produced inconclusive results, and five produced improvement on the cognitive tests. The total number of children in these various studies was 442 and their age ranges from 8 to 16 years old. This study demonstrates the possibility that exercise can be a factor in cognitive gains during childhood. However, since the studies used different types of exercise interventions as well as different types of cognitive tests, it is unclear which forms of physical activity are affecting which components of cognition. The results of this review indicate that physical activity plays a role in children's cognition, but do not clarify exactly what that role is. The specific biological role that physical activity plays in cognition is just beginning to be studied. It is often impossible to do studies of chemical and electrical brain activity on humans; so many researchers are dependent upon the use of laboratory animals. Since it is easier to measure academic achievement, many more studies have made comparisons between physical activity and academic achievement.

\section{Relationship between physical activity and academic performance. Public} school environments provide a wonderful opportunity to increase the physical activity levels of children and adolescents. Additionally, working towards decreasing the obesity epidemic faced by the youth of our country is a worthy social goal. However, schools do not get evaluated or funded based on how physically fit students are. They are evaluated 
and funded based on students' academic performance. Therefore, research that evaluates the connections between physical activity and academic achievement is critical to justify resource allocations for improving physical education programs.

There have been meta-analyses and systematic reviews to assess the effects of physical activity on children's achievement. One such review completed by Raspberry, Lee, Robin, Laris, Russell, Coyle, and Nihiser (2011) summarized the literature examining the association between school-based physical activity and academic achievement. Forty-three articles containing a total of fifty studies were included in their review. It was found that there were 251 total associations between physical activity and academic performance. More than half $(50.5 \%)$ of these associations were positive, $48 \%$ were not significant, and only $1.5 \%$ were negative. These results demonstrate that physical activity in the school curriculum is beneficial to academic performance the majority of the time. When it is not beneficial, it is usually because no relationship can be established and very rarely because it is negatively correlated to academic performance. It appears there is much to gain and little risk in developing more comprehensive physical education. These results help inform school policies surrounding physical education. Additionally, a meta-analysis completed by Fedewa and Ahn (2011) examined the effects of physical activity on children's achievement outcomes. This analysis quantitatively synthesized 59 studies from 1949 to 2009 . There were 129 independent samples from the 59 studies and samples sizes of the individual studies ranged from 6 to 3,226. The mean age of participants in the studies ranged from 5.77 to 16 years old. Results indicated a significant positive effect of physical activity on children's academic achievement. Furthermore, the use of ANOVA-like categorical 
models and additional post hoc tests demonstrated that aerobic exercise had the greatest effect on children's academic performance and cognitive abilities (Fedewa \& Ahn, 2011). Individual studies also demonstrate the positive correlations often found between physical activity and academic achievement. Stevens, To, Stevenson, and Lochbaum (2010) selected more than 6,000 participants from the Early Childhood Longitudinal Study-Kindergarten data base and constructed structural equation models to determine the independent contributions of physical activity not associated with physical education curriculum and structured physical education to children's academic achievement. Results indicated that physical activity was significantly and positively related to math and reading achievement in both boys and girls, while physical education participation was not significantly related to achievement. This indicates the need for physical education programs to be updated to focus more on physical activity participation and education for all children.

VanDusen, Kelder, Kohl, Ranuit, and Perry (2011) analyzed the scores of 254,743 Texas children in grades 3-11 on a standardized academic test, the Texas Assessment of Knowledge and Skills (TAKS), and on a test of fitness, the FITNESSGRAM, which is criterion-based and measures aerobic capacity, body composition, abdominal strength, trunk strength, upper-body strength and flexibility. The authors discovered that all fitness variables except body mass index (BMI) were positively correlated to academic performance. Cardiovascular fitness was correlated to the largest difference in the TAKS score, but all of the fitness factors had positive linear associations with academic test scores. Additionally, cardiovascular fitness showed a dose-response association with 
academic performance; meaning that each additional unit of cardiovascular fitness is associated with an additional increase in the TAKS score.

Fox, Barr-Anderson, Neumark-Sztainer, and Wall (2010) investigated whether the associations found between physical activity and academic achievement could be explained by the physical activity itself or by participation in sports teams which may come with academic requirements. In order to separate these two variables, data were drawn from Project EAT (Eating Among Teens), a survey in which 4,746 middle and high school aged students self-reported their physical activity levels, sports team participation, and academic letter grades. Regression analyses were conducted with the variables of interest. It was found that, for high-school girls, both physical activity and sports team participation were independently positively correlated with GPA. For high school boys, only sports team participation was significantly positively correlated with GPA. For middle school students of both genders, the two variables of physical activity and sports participation could not be separated, but overall physical activity involvement was associated with higher GPA.

Coe, Pivarnik, Womack, Reeves, and Malina (2006) investigated the effect of physical education class enrollment and physical activity participation on academic achievement by randomly assigning 214 sixth-grade students to physical education either during the first or second school semester. They also measured the amount of moderate to vigorous physical activity the students completed outside of school using the 3-d physical activity recall (3DPAR) which breaks time outside of school into 30-minute time blocks and then gives each block an ordinal rating based the amount and intensity of physical activity completed. Academic achievement was assessed using class grades. It 
was found that physical education enrollment had no impact on academic achievement, but that students who engaged in vigorous physical activity had higher academic achievement than those who did not.

Finally, Chomitz, Slining, McGowan, Mitchell, Dawson, and Hacker (2009) sought to determine the relationship between physical fitness and academic achievement in diverse urban students in the Northeastern United States. They created a crosssectional study using data from public schools on the Massachusetts Comprehensive Assessment System (MCAS) academic achievement tests and the physical fitness tests used in physical education classes. It was determined that the odds of passing the MCAS math test and the MCAS English test increased as the student's level of physical fitness increased. While this study demonstrates a link between physical fitness and academic achievement, it does not demonstrate that physical education is directly linked to academic achievement. It is unclear how physically "fit" students in this study achieved their levels of fitness. This study does, however, confirm other studies' findings with respect to the link between a student's physical fitness level and achievement outcomes. In order to improve students' academic achievement, school should promote physical activity opportunities through physical education, recess, and extracurricular activities.

Based on the findings of these studies, it is highly recommended that school administrators consider increasing physical activity during the school day. It is also recommended that physical education adjusts its focus to increasing the amount of physical activity students engage in and improving student's understanding of and appreciation for the need of physical activity. 
Moderator variables. It is worth noting that not all studies examining the relationship between physical activity and academic achievement find positive correlations. As was the case for the relationships between physical activity and children's mental health and behavioral outcomes, there are also several moderator variables that influence the relationship between physical activity and academic performance. These moderator variables include gender, age, race, and intensity of the activity.

Gender. When measuring the effects of physical activity on standardized academic test scores, VanDusen et al. (2011) stratified their results by gender, ethnicity, grade level, and economic disadvantage. It was found that girls had a stronger readingfitness association than boys, especially in the cardiovascular, curl-ups, and push-ups tests.

During their analyses of the Project EAT data, Fox et al. (2010) found gender differences in the relationships among physical activity, sports participation, and academic grades. The mean GPA for middle school boys who participated in sports was significantly higher than the GPA of those who did not participate in sports, but this relationship did not exist for middle school girls. After controlling for sports participation, the association between engaging in more hours of moderate to vigorous physical activity and GPA was only statistically significant for high school females and not high school males.

Hanson and Kraus (1998) used data from the 1980 and 1982 High School and Beyond data sets to examine the relationship between sports and science in a nationally representative longitudinal sample of 11,683 high school students during their sophomore 
and senior years. They found that, while males were more likely to participate in varsity sports than females, involvement in sports was more likely to have a significant effect on the science experiences of females. During their sophomore year, young women's participation in sports had a significant positive effect on their access to science but a significant negative effect on their attitudes towards science. During their senior year, sports participation had a significant positive effect on the females' access to and attitudes toward science. Conversely, participation in sports had a significant negative effect on males' science achievement during their sophomore year and no significant impacts during their senior year.

Videon (2002) analyzed Wave 1 data from the National Longitudinal Study of Adolescent Health (Add Health) data set to determine if sports participation was associated with academic outcomes and if it had different impacts for boys and girls. Contradictory to what Fox (2010), Hanson and Kraus (1998), and VanDusen et al. (2011), Videon (2002) discovered that, while sports participation had a positive effect on the academic outcomes of boys and girls, it had a more positive impact on boys' academic performance than on girls. These contradictory findings indicate that, while gender is a confounding variable in the relationship between physical activity and academic performance, the effects of this confounding variable are not completely clear.

Age. VanDusen et al. (2011) found significant differences by grade level in the correlations between cardiovascular fitness and academic performance. A positive correlation between cardiovascular fitness and academic performance peaked between seventh and tenth grade for both genders. Conversely, Fedewa and Ahn (2011) found in their meta-analysis of the effects of physical activity on children's cognitive performance 
and academic achievement that the highest mean Effect Size (ES) was found from children at the elementary school level, while the ESs from the middle and high school levels were similar but smaller. The limited amount of research in this area and the differing results indicate more studies need to be conducted to explore the moderating effects of age.

Race and culture. Yu, Chan, Cheng, Sung, and Hau (2006) noticed that education is strongly emphasized in the Chinese culture and, for many, is the primary indicator of success. Other activities, including physical activity, are often viewed as distractions that waste energy and time and take away from academic achievement. Curious as to whether this was an appropriate attitude, Yu et al. (2006) investigated the relationships among academic achievement, self-esteem, school conduct, and physical activity by collecting data from 333 Chinese students aged 8-12 years. Grades and conduct data were obtained from school records, self-esteem was measured using the Physical Self-Description Questionnaire (PSDQ), and physical activity was measured with the Physical Activity Questionnaire for Children (PAQ-C). Results demonstrated that physical activity level was not related to either academic achievement or school conduct. Boys with higher physical activity levels did demonstrate higher levels of selfesteem. These results could be explained by a cultural emphasis on high grades and academic performance. It is possible that students who are not physically active are spending that extra time studying, thus negating the achievement differences between themselves and those who study less, but are more physical active.

During their analysis of High School and Beyond data, Hanson and Kraus (1998) discovered that the influence of sports activities on science access, attitudes, and 
achievement varied substantially among racial subgroups. White young women's science experiences benefited the most from sports participation. African American young women's sports participation had a negative effect on their science experiences and no relationship was present for young Hispanic women.

Socioeconomic status. When examining the relationships between physical activity, physical education, and academic achievement from data from the Early Childhood Longitudinal Study, Stevens et al. (2010) discovered that socioeconomic status (SES) accounted for about $26 \%$ of the physical activity that was not associated with school based physical education. Therefore, it is more likely that children from homes and neighborhoods with higher SES would participate in physical activity; thus, SES may serve as a moderator variable given that a child's SES may also account for higher academic achievement in childhood. In fact, Basch (2011a) reviewed and synthesized literature on the health problems that affect school-aged youth and found that several health issues, including low levels of physical activity, disproportionately impact urban minority youth. Health disparities among this group may adversely affect academic achievement due to absenteeism or inability to focus on school work due to the need to deal with more pressing health, family, or nutrition matters. Unfortunately, this can create a reciprocal causal relationship between health, education, and poverty (Basch, 2011a). Poor health leads to low educational attainment, which leads to poverty, which leads to poor health.

There is evidence that suggests it may be possible to use physical activity interventions as a tool to break this cycle. Hollar et al. (2010) assessed the effects of a school-based obesity prevention intervention that included dietary, curricula, and 
physical activity components on the BMI percentiles and academic performance among elementary children in Florida with low socioeconomic status. The study had a quasiexperimental design and there were four intervention schools and one control school. The intervention was conducted over a two-year period. The data analyzed for this study were from the cohort of children at the schools who were low socioeconomic status, defined as qualifying for free or reduced lunch $(n=1,197)$. Significantly more intervention than control children stayed within normal BMI percentiles and more obese children in the intervention than the in the control groups decreased their BMI percentiles. Additionally, children in the intervention group had higher math scores both years. This research indicates that physical activity interventions might be particular beneficial for children in a low socioeconomic demographic.

Race and socioeconomic status. Several studies address socioeconomic status and race as intertwined factors that impact levels of physical activity. Since minority races are disproportionately represented in groups with a low socioeconomic status it becomes difficult to separate the influences of each factor. One literature review completed by Basch (2011b) determined that African American and Hispanic youth are less physically active than White youth and that this difference is particularly evident among female adolescents. However, the majority of the studies reviewed involved minority participants from urban, low socioeconomic status areas, so it is hard to say whether the lack of involvement in physical activity was due to socioeconomic factors or social and cultural factors linked to the race of the participants. Regardless, the study still offers support for the establishment of school or community based programs to increase 
the physical activity levels of urban minority youth and to educate them about the lifelong benefits of regular exercise.

Eugeni, Baxter, Mama, and Lee (2011) completed interviews with twenty-two African American individuals with a mean age of 43.9 years living in public housing. These individuals had some awareness of health recommendations, but indicated limited adherence to them. Participation in physical activity for recreation was largely viewed as an activity for children. Additionally, the majority of residents were not aware of local opportunities for physical activity or healthy eating. This study reinforces the reciprocal relationship as outlined by Basch (2011a). The residents who live in an area of poverty have or are aware of few healthful opportunities, which contribute to poor health, which then contributes to the inability to focus on other subjects, such as educational attainment, which then, in turn, increases the cycle of poverty.

Intensity and amount of activity. During their investigation of the effects of physical education class enrollment and physical activity participation on $6^{\text {th }}$ graders academic achievement, Coe et al. (2006) discovered that during the 55-minute physical education classes, students averaged only 19 minutes of moderate to vigorous physical activity. They found that physical education enrollment had no impact on academic achievement, but meeting the Healthy People 2010 guideline for physical activity (30 minutes of moderate activity 5 times per week and 20 minutes of vigorous activity 3 times per week) did improve academic achievement. These findings appear to be related to the amount of moderate to vigorous activity in physical education being less than the Healthy People 2010 guideline. It is possible that physical education could have a more 
profound impact on academic achievement if physical education incorporated more vigorous physical activity.

\section{Physical Activity and Educational Attainment}

Relationship. A less studied area of physical activity research is how physical activity participation in childhood and adolescence impacts educational and career aspirations and attainment. There was some research in this area over 35 years ago, but this is a topic that needs updated studies. Recent research in this area is focused on how extra-curricular activities impact educational attainment (Feldman and Matjasko, 2005; Kjonniksen, Fjortoft, and Wold, 2009). While sports are one category of extra-curricular activity included in this research, the research pertains more specifically to how being involved with a school-related team or club impacts educational attainment. More research regarding how physical activity itself, regardless of whether or not the physical activity is completed through participation in school activities, associates with educational attainment is warranted.

Two early studies on this topic were completed by Otto and Alwin (1977) and Picou (1978). Otto and Alwin (1977) attempted to determine the effect participation in athletics and peer status had on occupational aspirations, occupational attainments, and income. They gathered data from 340 male adolescents aged 17 years who were enrolled in high schools in Lenawee County, Michigan in 1957. A follow-up survey was conducted with participants 15 years later in 1972. The researchers found support for the hypothesis that athletics has a positive effect on academic aspirations and attainment. They also found support for the idea that athletics affects occupational aspirations and attainment and income. These effects were present even when variables such as 
socioeconomic status, cognitive ability, academic performance, and the influence of significant others was controlled for. In 1978, Picou conducted a similar study to investigate the relationship between athletic achievement and educational aspiration. Picou conducted his study with data from 299 African-American and 1,207 Caucasian male adolescents who participated in a November 1970 study of the achievement behaviors and social mobility attitudes of Louisiana high school students. He also used race as a factor and separately analyzed the results of Caucasian males and the results of African-American males. He found that athletic behavior facilitates the association of Caucasian males with a college-oriented peer group, producing an indirect impact on educational aspiration. On the other hand, he found that for African-American males, athletic behavior does not put them in contact with a college-oriented group of peers. It must be noted that these studies were completed over 30 years ago and in the case of Otto and Alwin (1977) data collection began over 50 years ago. Due to the age of these studies, caution needs to be used when generalizing their results until more recent studies along these lines are completed. This is particularly true for the Picou (1978) study since it used race as a variable and race relations in this country have changed significantly over the past 35 years.

More recently, Feldman and Matjasko (2005) conducted a review of more contemporary literature regarding the impacts of participation in school-based physical activity on a variety of factors. Research included in this review was narrowed down to those involving school-based activities, United States participants, quantitative data, and in which participation in a school-based activity was identified as an independent variable. The studies included in the review were longitudinal and cross sectional. 
Number of participants in the studies ranges from 237 to 43,832. Participants ages ranged from 12 years to 21 years. It was noted that the majority of the identified activities involved participation in a sport. Findings indicated that participation in an extracurricular activity (usually a sport) was associated with 1) higher academic performance, 2) reduced rates of dropout, 3) slightly lower rates of substance use, 4) less sexual activity among females, 5) better psychological adjustment (i.e., higher selfesteem, less worry about the future, reduced feelings of social isolation), and 6) reduced rates of delinquency. The studies reviewed by Feldman and Matjasko (2005) focused on the psychosocial benefits of extra-curricular participation. However, there is a distinct need in the literature for an examination of how physical activity itself, separate from extra-curricular participation, influences educational attainment. Additionally, the studies focused on the benefits of extra-curricular activities during adolescence. More research is needed that explores how certain activities during adolescence are related to achievements in adulthood.

Moderator variables. An interesting variable that may become a mediator variable when investigating the impact of youth physical activity on adult achievement outcomes is the extent to which physical activity participation in youth leads to physical activity participation in adulthood. Even if research demonstrates that high levels of youth physical activity leads to high achievement outcomes in adulthood, the mechanism for exactly how this occurs is unclear. Just as Basch (2011a) and Eugeni et al. (2011) suggested a reciprocal relationship between poverty and unhealthy living, there may be a similar relationship between physical activity and achievement. Physical activity in youth can lead to higher academic achievement (Chomitz et al., 2009; Coe et al., 2006; 
Fedewa \& Ahn, 2011; Fox et al., 2010; Raspberry et al., 2011; Stevens et al., 2010; \& Van Dusen et al., 2008) which, in turn, can lead to higher academic attainment in adulthood. Typically, higher academic achievement and attainment is associated with higher economic status. High socioeconomic status may provide an individual with more time and opportunity for lifelong recreational physical activity. In turn, high levels of physical activity in adulthood positively impact physical and mental health, thus allowing the individual to continue to achieve at a high level.

Several studies support the idea that participation in physical activity during youth is associated with a higher likelihood of participation in physical activity as an adult. Kjonniksen, Fjortoft, and Wold (2009) surveyed 630 participants over a 10-year period to examine the relationship between attitude to physical education and participation in organized sports at age 13 to participation in physical activity at age 23 . It was found that youth participation in organized sport was the strongest predictor of physical activity in males at age 23 and youth attitude toward physical education was the strongest predictor of physical activity in females at age 23. Additionally, Matton et al. (2006) conducted a longitudinal study to evaluate the stability of physical activity patterns in females from adolescence to middle adulthood. They used participants from a previous study who had been examined on lifestyle, fitness, and health dimensions at a mean age of 16.6. At the time of this study, these participants had a mean age of 40.5 . They were found by the researchers and participated in measures of body dimensions and motor fitness tests. It was determined that physical fitness characteristics remained stable from adolescence to adulthood, that weight during adolescence was indicative of weight during adulthood, and that amount of participation in physical activity was likely to remain fairly consistent 
particularly when the participation rates were low. These studies demonstrate the likelihood that increased physical activity rates in adolescence contribute to increased physical activity rates in adulthood.

Physical activity habit formation could impact a study attempting to analyze the relationships between physical activity in youth and adult achievement. It will be necessary to take into account the current physical activity participation and perhaps the physical fitness of the adults.

\section{Habitual Physical Activity}

Habitual physical activity can be defined as engaging in recommended levels of physical activity on a regular basis. Physical activity is most beneficial when it is done on a regular and consistent basis (Centers for Disease Control, 2011). Habit formation can help an individual establish regular physical activity patterns (Gardner, de Bruijn, \& Lally, 2011; Lally, Wardle, \& Gardner, 2011).

Habit formation. Habit formation is an important goal for individuals attempting to change their behaviors. Lally, Wardle, and Gardner (2011) recorded the habit formation experiences of 10 participants ( 3 men and 7 women) aged 24-59 years enrolled in weight loss intervention that specifically focused on habit formation. The major themes of this intervention included strategies to support initial engagement in novel behaviors, development of automatic behaviors, and establishing effective cues to support repeated behavior. Results indicated that the participants experienced the initial behavior change as something that required substantial cognitive effort. However, as automaticity increased and was supported, the cognitive effort required to maintain the behaviors 
decreased. These findings demonstrate the necessity for behaviors to become habit in order to continue on a regular and consistent basis.

Gardner, de Bruijn, and Lally (2011) conducted a meta-analysis to review relationships among habit strength, habit-behavior correlations, habit $\mathrm{x}$ intention interactions, and dietary, physical activity, and active travel behavior. An electronic database search was used to identify papers that met the following criteria: reporting primary data in which the Self-Report Habit Index (SRHI) was used to operationalize habits related to diet, physical activity, inactivity, or physically active travel (i.e., walking, cycling). Twenty-two studies were included and their data were expressed in a standardized form. Meta-analysis of the SRHI scores revealed that the strongest habits were reported in relation to physical activity and physically active travel. Habits moderated the intention-behavior relationship in such a way that as habit strength increased, intention on behavior decreased. Additionally, the grand weighted mean habitbehavior correlation $(\mathrm{r} \approx 0.45)$ suggests that habit accounts for approximately $20 \%\left(\mathrm{R}^{2} \approx\right.$ 0.02 ) of variation in nutrition and physical activity related behaviors. These results demonstrate the importance of habit formation on long-term behavior change.

Rhodes, de Bruijn, and Matheson (2010) explored the role of habit in predicting physical activity by examining 153 undergraduate students who completed a habit measure and measures of the theory of planned behavior (TPB) and then completed measures of intention and behavior two weeks later. Regression analysis of data revealed that, after accounting for the TPB and temporal stability of intention, habit still explained $7 \%$ of the variance in physical activity behaviors. These findings suggest that physical 
activity behaviors may have an automatic component and that establishing habits can lead to more physical activity.

Habits established in youth. Behaviors that are established at a young age may impact later habits. Hallal, Wells, Reichert, Anselmi, and Victora (2006) examined the effects of early social and behavioral variables on physical activity in adolescence. They used data from 4,453 adolescents in southern Brazil aged 10-12 years who participated in the Pelotas 1993 birth cohort study. For the purposes of their study, sedentary lifestyle was defined as self-reporting less than 300 minutes of physical activity per week. It was found that $58.2 \%$ of the participants had a sedentary lifestyle at age $10-12$ years. Risk factors for a sedentary lifestyle included being female, high family income, high maternal education, and low birth order. Interestingly, levels of physical activity at age 4 years (as reported by parents) were inversely related to a sedentary lifestyle at age 10-12 years. This finding indicates that behavior patterns established early in life could have a lasting effect on future behavioral patterns.

\section{Previous ADD Health Physical Activity Research}

The Adolescent Health (ADD Health) Study created a prominent data set of the opinions, attitudes, beliefs, and behaviors of American adolescents and young adults (specific details regarding the ADD Health Study will be found in subsequent sections). A few researchers have used the ADD Health data set to examine how physical activity behaviors in adolescence is related to a variety of other variables and behaviors (BooneHeinonen, Evenson, Song, \& Gordon-Larsen, 2010; Boone-Heinonen \& Gordon-Larsen, 2012; Boone-Heinonen, Guilkey, Evenson, \& Gordon-Larson, 2010; Gordon-Larsen, 
McMurray, \& Popkin, 1999, 2000; Gordon-Larsen, Nelson, \& Popkin, 2004; Guo, North, Gordon-Larsen, Bulik, \& Choi, 2007; Ornelas, Perreira, \& Ayala, 2007).

Gordon-Larsen, McMurray, \& Popkin (1999) used the ADD Health data set to determine the extent to which physical activity and inactivity patterns vary by ethnicity. They used multinomial logistic regression to adjust for sociodemographic factors. They discovered large ethnic differences for amount of inactivity, particularly in the variable relating to television viewing. Non-Hispanic black adolescents spent the most time watching TV (mean $=20.4$ hours per week), while non-Hispanic white adolescents watched the least amount of TV (mean $=13.1$ hours per week). They found fewer ethnic differences in the amount of physical activity the adolescents engaged in. However, it was noted that female minority adolescents participated in least amount of physical activity per week.

Guo, North, Gorden-Larsen, Bulik, \& Choi (2007) used the ADD Health data set to investigate the joint role of a dopamine receptor gene (DRD4) and environmental factors in the body mass of adolescents. Dopamine is a neurotransmitter that has been found to help regulate food intake by modulating food reward. There are five types of dopamine receptors and the receptors that are associated with the 7-repeat allele and 5repeat allele of the DRD4 gene have previously been linked to obesity. In this study, it was found that the 7-repeat and 5-repeat alleles of the DRD4 gene were associated with body mass in African-American participants. Interestingly, these two alleles occur more frequently in African-American (12\%) and Hispanic-American (11\%) populations than in European-American (5\%) populations. Neither physical activity nor sedentary behavior was found to be associated with body mass index. Family socio-economic status (SES) 
was associated with body mass index in the European-American sample. The lower the family's SES, the more likely it was the adolescent had a higher body mass index.

Boone-Heinonen, Evenson, Song, and Gordon-Larsen (2010) investigated the relationships among the built and socioeconomic environmental characteristics and physical activity. They identified three built environment constructs (homogenous landscape, pay workout facility count, and public workout facility count) and two socioeconomic constructs (advantageous social environment and disadvantageous social environment). It was found that, overall, both built and socioeconomic environmental constructs impacted physical activity levels in adolescents. Additionally, they discovered that the socioeconomic constructs acted as a confounder of the built environment and physical activity association. It was recommended that future research in the built environment and physical activity area address the possibility of socioeconomic complexities. Gordon-Larsen, McMurray, and Popkin (2000) also used ADD Health data to assess the impact of environmental and sociodemographic determinants on physical activity and inactivity patterns in United States adolescents. For the purposes of this study, environmental determinants were defined as modifiable factors in the physical environment that have a direct influence on the opportunity to engage in physical activity. Results indicated that overall rates of moderate to vigorous physical activity were lower and rates of inactivity higher for non-Hispanic black and Hispanic adolescents than for non-Hispanic white adolescents. Additionally, participation in school physical education programs was lower for these groups of adolescents and decreased with age. For all adolescents, participation in daily school physical education programs and the use of a community recreation center were associated with an increased likelihood of engaging in 
higher levels of moderate to vigorous physical activity. High family income was associated with increased levels of physical activity and decreased inactivity. High neighborhood crime rates were associated with decreased levels of physical activity. In addition, it was noted that despite the impact of school physical education programs on physical activity levels few adolescents (21.3\%) participated in one or more days a week of physical activity at school.

In order to further explore the relationship between the built environment and physical activity, Boone-Heinonen, Guilkey, Evenson, and Gordon-Larsen (2010) used data from Wave I (1994-1995) and Wave III (2001) to estimate longitudinal relationships among these variables between adolescence and adulthood. The majority of results from this study yielded null or counter-intuitive associations, but it was discovered that for both males and females as crime rates dropped physical activity increased and for males as the number of physical activity pay facilities increased, physical activity increased.

There is little research on the longitudinal patterns of physical activity as individuals transition from adolescence into adulthood. One study completed by GordonLarsen, Nelson, and Popkin (2004) used Add Heath data from Wave I (1994-1995) and Wave III (2001) to determine the incidence, reversal, and maintenance rates of completing five or more weekly sessions of moderate to vigorous physical activity (MVPA). Additionally, these researchers also examined the incidence, reversal, and maintenance rates of engaging in less than 14 hours of screen time (television or moving watching, video or computer game playing). It was discovered that of the adolescents who achieved five or more sessions of weekly MVPA and engaged in less than 14 hours of screen time during Wave I, only $4.4 \%$ continued to achieve this amount of physical 
activity into adulthood (Wave III) and $37.0 \%$ continued to maintain these low levels of screen time. Additionally, it was determined that African-American females were more likely to maintain physical activity levels than white females and that African-Americans of both genders were more likely to maintain low levels of screen time than white individuals.

Another examination of Add Health data by Ornelas, Perreira, and Ayala (2007) explored the longitudinal relationship between parental influence and physical activity. It was found that family cohesion, parent-child communication, and parental engagement during Wave I (1994-1995) positively predicted five or more sessions of physical activity one year later during Wave II (1995-1996). Self-esteem and depressive symptoms were found to mediate these results.

The majority of research surrounding physical activity that has come out of the ADD Health data set seeks to determine what demographic or behavioral factors contribute to the physical activity levels of adolescents. The current study instead seeks to use adolescent physical activity levels as a predictor of future physical and educational behavior. Although the ADD Health data set is longitudinal, there is very little research on how physical activity behavior during adolescence impacts future physical activity behavior particularly that includes the most recent Wave IV (2008). Longitudinal research that has been done focuses on factors that may impact physical activity rather than what physical activity impacts. Additionally, there is no ADD Health research that addresses how physical activity behavior in adolescence impacts educational ambition or future educational attainment. 


\section{Summary}

Current research indicates habitual participation in physical activity has physical health, mental health, behavioral, and academic benefits for children and adolescents. Unfortunately, many children are leading a sedentary lifestyle both at home and at school. Schools are overwhelmed with obligations to perform on standardized tests of reading and math. As a result, schools often add curriculum time to academic areas and take out classes and activities that are considered "extras," including time for physical activity. However, there is a growing body of research discovering that quality physical education programs can go a long way towards shaping children and adolescents into well-rounded and successful individuals. Since research regarding the long-term educational impacts of participation in physical activity during youth is limited, the secondary analysis of this comprehensive longitudinal study will aid in addressing some of the current gaps in physical activity research.

\section{Research Questions}

Current research suggests that physical activity plays a role in the physical, emotional, academic, and social development of children and adolescents. The long-term effects of physical activity that may continue into adulthood are less studied. The theory of reasoned action and planned behavior helps conceptualization of how physical activity during youth could be related to long-term health and life outcomes. If an individual is exposed to physical activity during youth, they will become aware of its benefits at a time when habits and attitudes are likely to be formed. As a result, they will believe in the important results and benefits of physical activity, which will lead them to be more likely to engage in the act of physical activity on a voluntary basis. Additionally, the ecological 
framework suggests that if individuals are surrounded by an environment that provides opportunities for physical activity, physical activity is likely to become a normative and habitual behavior.

This study will address several research questions relating to the long-term impacts of habitual physical activity in adolescence. The research questions are: a) Do physical activity levels in adolescence (Wave I) grow into continued or increased physical activity levels in later adolescence and young adulthood (Wave II, III, IV) and do gender and ethnicity impact this growth? b) Do physical activity levels in adolescence (Wave I) predict levels of educational ambition (Wave I and Wave II)? c) Do physical activity levels in adolescence (Wave I) predict educational attainment in young adulthood (Wave III and Wave IV)?

The hypotheses for the research questions are based upon literature focused on physical activity in childhood and adolescence. The hypotheses are: a) habitual physical activity levels in adolescence (Wave I) will grow into continued habitual physical activity levels in later adolescence and young adulthood (Wave II, III, IV) and gender and ethnicity will impact this growth; b) higher levels of habitual physical activity in adolescence (Wave I) will predict higher educational ambition (Wave I and Wave II); c) higher levels of habitual physical activity in adolescence (Wave I) will predict higher educational attainment in young adulthood (Wave III and Wave IV).

Copyright (C) Frances Jillian Priesmeyer 2014 


\section{Chapter Three: Methodology}

The purpose of this study is to identify the long-term educational benefits of habitual physical activity in adolescence. Data from the National Longitudinal Study of Adolescent Health (here-in referred to as the Add Health Study) was chosen for analysis

due to the large number of participants, the quantity of information that was obtained, and the longitudinal nature of the data. Secondary analysis of data from the Add Health Study was conducted. The Add Health study was commissioned by the U.S. Congress to collect data for the purpose of learning more about how the social environment affects adolescent health. The two major areas of research targeted by the Add Health Study were 1) the behaviors that encourage health and the behaviors that are detrimental to health; and 2) the connections that individual and community variables have on the health of adolescents (e.g., diet, nutrition, physical activity, depression, and violent behavior; (Bearman, Jones, \& Udry, 1997; Harris et al., 2009). There were four waves of data collection for this study: Wave I (1994-1995), Wave II (1996), Wave III (2000), and Wave IV (2008).

\section{Participants}

The Add Health study is a nationally representative, probability-based survey of adolescents in the seventh through twelfth grade. High schools were eligible for the study if they had an eleventh grade and at least 30 students. Participant schools provided a student roster and administered an in-school questionnaire during class time. The sample consisted of 80 high schools randomly selected from a national roster of high schools. The selected high schools were stratified by region (Northeast, Midwest, South, West), population density (urban, suburban, rural), school size (125 or less, 126-350, 
$351-775,776$ or more students), school type (public, private, parochial), grade span (kindergarten through 12th grade, 7th grade through 12th grade, and 10th through 12th grade) and ethnicity (Bearman et al., 1997; Harris et al., 2009). Eighty high schools were identified to participate from the national list of 26,666 schools. Of those, 52 high schools were eligible and agreed to participate. Replacement schools were selected from the list for the schools that declined participation. Each replacement school was chosen from a predefined list to match the characteristics of the originally selected school (Bearman et al., 1997; Harris et al., 2009). Demographic characteristics for the 80 participating high schools are summarized in Table 3.1.

Table 3.1

Characteristics of Participating High Schools

Number of Participating High Schools

$\underline{\text { Region }}$

Northeast 17

South

27

Midwest

19

West

17

Total

80

$\underline{\text { School Type }}$

Public 71

Catholic

3

Other Private

Total 80

Population Density

Urban 24

Suburban

42

Rural 14

Total

80


For each selected high school, a feeder high school was also selected from the junior high or middle schools (including 7th grade) that provided students to the high school. The largest feeder school was selected when one was present. The 80 high schools plus the identified feeder schools created a total of 145 schools that participated in the study.

During Stage 1 of Wave I, 90,118 students in grades 7th through 12th completed a 45 to 60 minute questionnaire (In-School Questionnaire). Additionally, each school completed a school administrator questionnaire. Next, a random sample of approximately 200 students from each pair of schools was selected for participation in the In-Home components of the survey. These selected students created the core group of approximately 12,000 students. The core sample is nationally representative of adolescents in grades 7 th through 12th throughout the United States. Additionally, a supplemental group was chosen to complete the In-Home Questionnaire. The supplemental group was oversampled on the basis of ethnicity, disability status, and genetic differences (i.e., twins, full-siblings, half-siblings, non-related adolescents living in the same household). The core group and the supplemental group resulted in a total of 20,745 participants for the Wave I In-Home Questionnaire. Nine thousand one hundred forty-one members of the core group participated in the next In-Home Questionnaire during Wave II. Including the supplemental groups, a total of 14,738 students completed the Wave II In-Home Questionnaire. A total of 15,170 participants from Wave I completed the Wave III In-Home Questionnaire. A total of 15,701 participants from Wave I completed the Wave IV In-Home Questionnaire. 
An unspecified monetary incentive and an individualized report from results of the data were given to each school that participated in the study. Families were not given any incentive to participate. Parental consent was usually obtained by the school through passive parental consent. The final decision on how to collect parent consent forms was left up to the individual schools. In order to protect the identity of participants, the data do not contain names or other individual identifiers. Each participant was given a random identification number that was used to track responses at each wave.

\section{Add Health Instruments}

Students attending schools participating in the Add Health study were eligible for selection into several methods of data collection: the Wave I In-School Questionnaire (1994-1995), the Wave I In-Home Questionnaire (1995), the Wave II In-Home Questionnaire (1996), the Wave III In-Home Questionnaire (2001-2002), and the Wave IV In-Home Questionnaire (2008). The Picture Vocabulary Test, which is an abridged version of the Peabody Picture Vocabulary Test, was administered at the same time as the Wave I In-Home Questionnaire. Other forms of data collection included the Wave I School Administrator Questionnaire (1994-1995), the Wave I Parent Questionnaire (1995), the Wave II School Administrator Questionnaire (1996), the friendship nominations and network databases that were created from In-School data, the Wave III Partner Sample (2001-2002), the Wave III Partner In-Home Interview (2001-2002), the Wave IV Biological Data (2007-2008), the Wave IV Genome Wide Association Study (2007-2008), and the Wave IV Intra-Individual Variation Study (2007-2008).

This study will utilize data from all four waves (1995-2008) of the Add Health study. All data that will be analyzed will be taken from the In-Home Questionnaires. 
Most of the interviews for each of these questionnaires were completed in the home setting. Screenings were completed and factors such as age, gender, and past experiences were taken into account so that all questions were not administered to every respondent (Bearman et al., 1997; Harris et al., 2009). Details of the data collection waves are summarized in Table 3.2 .

Table 3.2

Age and Number of Participants at Each Data Collection Point

Wave $\quad \underline{\text { Year }} \quad \underline{\text { Number of Participants }}$ Age of Participants

Wave I -In

School Survey

1994-1995

90,118

12-19 years

Wave I - In

Home Survey

1995

20,745

12-19 years

Wave II - In

1996

14,738

13-19 years

Home Survey

Wave III- In

2001-2002

15,170

18-26 years

Home Survey

Wave IV- In

Home Survey

2008

15,701

24-32 years

Wave-I In-School Questionnaire. The Wave-I In-School Questionnaire was a self-administered, self-report survey completed by more than 90,000 students in grades 7th through 12th during a 45 to 60 minute class period between September 1994 and 
April 1995. There were no makeup dates for the absent students and parents were informed about the survey beforehand, so they could choose for their children not to participate. The questionnaire contained topics such as social and demographic information, education and occupation of parents, household structure, risk behaviors, expectations for the future, self-esteem, health status, friendships, and school-year extracurricular activities.

Wave-I In-Home Questionnaire. The Wave-I In-Home Questionnaire consisted of responses to a lengthy and detailed interview completed by a subset of students from the school rosters and those who filled out the In-School Questionnaire. Data were collected between April and December of 1995. This questionnaire took between 60 and 120 minutes to complete and collected information regarding the adolescent's health and health-related behaviors, peers, neighborhood, emotional well-being, family environment, and school environment. The Wave-I In-Home Questionnaire consisted of 2,820 variables and was completed by 20,745 students.

Wave-II In-Home Questionnaire. The Wave-II In-Home Questionnaires took place between April and August of 1996. The questions asked were similar to the questions that were included in the Wave-I In-Home Questionnaire. Demographic information and other information that was not subject to change were not asked again. Notably, respondents who were in grade 12 at the time they completed the Wave-I questionnaires and were not a part of the genetic sample (i.e., identical twins, fraternal twins, siblings, half-siblings, step-siblings, etc.) were not interviewed again at Wave-II. An additional sample of 65 adolescents who did not complete the Wave-I questionnaires were recruited to be a part of the genetic sample during Wave-II. Wave-II questions 
included more detailed questions related to nutrition and questions about sun exposure were added. The Wave-II In-Home Questionnaire consisted of 2,540 variables and was completed by 14,738 students.

Wave-III In-Home Questionnaire. Wave III data collection occurred between August 2001 and April 2002 when respondents were between 18 and 26 years old. Inhome interviews with 15,170 respondent from Wave-I were completed during Wave-III. The Wave-III questionnaire was designed to obtain relationship, marital, childbearing, educational experiences, and career experiences of the respondents. While the Wave-III Questionnaire asked similar questions from Waves I and II, it also included new sections with a focus on topics more relevant to young adulthood. The average length of interview completion was 134 minutes. Additionally, the high school transcripts of participants were collected as part of the education data component.

Wave-IV In-Home Questionnaire. A fourth in-home interview was conducted in 2007 and 2008 with 15,701 of the original Wave-I respondents. At the time of data collection, respondents were 24 to 32 years old. The questions at Wave-IV focused on adult roles, career responsibilities, current health habits (i.e., sleep patterns, nutrition, physical activity), and life-style choices. A forty-one question inventory regarding personality dimensions was added. Additionally, there were physical measurements of height, weight, waist circumference, blood pressure, and pulse rate as well as biospecimen collections measuring lipid levels, blood glucose levels, and immune system functioning included in Wave IV. The interview took an average of 90 minutes and the physical measurement and biospecimen collection took an additional 30 minutes. 
Data collection. The Wave I In-School Questionnaire was conducted in the classroom setting with teacher assistance. The Wave I, Wave II, Wave III, and Wave IV In-Home Questionnaires were conducted at the adolescent or young adult's home. A Computer-assisted Personal Interview (CAPI) was utilized by the interviewer during the administration of the In-Home Questionnaires. The CAPI was used to modify the questionnaire for each participant by branching subsequent questions based on responses (Bearman et al., 1997; Harris et al., 2009). For example, if the respondent indicated they had never drank alcohol, the computer would code "non-applicable" for all subsequent related questions and branch away to the next set of questions. Additionally, for more sensitive segments related to illegal or undesirable risk behavior, an Audio Computerassisted Self Interview (ACASI) was utilized. When using the ACASI respondents listened to questions with headphones and entered responses directly into the computer. The screen and keyboard was not visible to anyone else. These techniques were used as an attempt to increase the validity of the self-reporting of sensitive personal data.

\section{Measures}

Physical activity at Wave I. All three research questions address levels of physical activity during adolescence (Wave I). The items presented in Appendix A were taken from the Wave I In-Home Questionnaire for the purpose of determining Wave I physical activity levels.

Physical activity at Waves II, III, and IV. The first research question addresses how levels of physical activity at Wave I influences physical activity patterns later in life (Waves II, III, and IV). The items in Appendix B were taken from the Wave II In-Home Questionnaire for the purpose of determining Wave II physical activity levels, the items 
in Appendix C were taken from the Wave III In-Home Questionnaire for the purpose of determining Wave III physical activity levels, and the items in Appendix D were taken from the Wave-IV In-Home Questionnaire for the purpose of determining Wave IV physical activity levels.

Educational ambition at Waves I and II. The second research question addresses how physical activity in adolescence (Wave I) predicts educational ambition in adolescence (Wave I and II). The items in Appendix E were taken from the Wave I InHome Questionnaire and used as variables of participants' educational ambition at Wave I. The items in Appendix F were taken from the Wave II In-Home Questionnaire and used as variables of participants' educational ambition at Wave II.

Educational attainment at Waves III and IV. The third research question addresses how physical activity in adolescence (Wave I) predicts educational attainment in young adulthood (Waves III and IV). The item in Appendix G was taken from the Wave III In-Home Questionnaire and used as a measure of participants' educational attainment at Wave III. The item in Appendix $\mathrm{H}$ was taken from the Wave IV In-Home Questionnaire and used as a measure of participants' educational attainment at Wave IV.

\section{Data Analysis}

Data preparation. In the Add Health survey, the survey questions related to physical activity changed with each wave. The amount and variety of activities queried about as well as the Likert scale response categories changed across waves. In order to longitudinally assess physical activity across waves, data were converted into a format that was identical across waves. The responses to the identified physical activity items in Waves I through IV were collapsed to produce one item at each wave that was a sum of 
the physical activity at reported during that wave. An ordinal variable was then created from the sum of the reported physical activity at each wave. This new variable was based on current Center for Disease Control (CDC) recommendations that adolescents and adults engage in 60 minutes of moderate to vigorous activity per day (Centers for Disease Control, 2011). The Add Health survey asked individuals to report the number of times per week they engaged in a specific set of physical activities. The duration of each activity was not measured. Due to the impossibility of retroactively determining how long each physical activity session was, it was decided that each reported physical activity session would represent 60 minutes of physical activity. The number of questions about physical activity also varied across waves. Due to this discrepancy in the data collection, the questions regarding physical activity were collapsed into one universal physical activity variable that would be comparable across waves. In order to accomplish this, the number of reported physical activity sessions across all physical activity questions in each wave was tallied. Since it was decided that each physical activity session equaled 60 minutes of physical activity, a tally $\geq 7$ indicated that the individual met the CDC guidelines for physical activity. The new variables were ordinal and indicated how physically active each individual was at each wave on a scale of 0 to 2 with 0 indicating no physical activity, 1 indicating some physical activity but not enough to meet $\mathrm{CDC}$ guidelines, and 2 indicating the individual met $\mathrm{CDC}$ guidelines for physical activity. In the new variables, a tally $\geq 7$ was represented by a 2 , a tally of 1-6 was represented by a 1 , and a tally of 0 was represented by a 0 . In order to determine if these new variables were representative of the items they combined, exploratory factor analysis was conducted. Eigenvalues were found to determine if the vector of the combined items 
remained parallel to the vectors of the individual items. Following the 3:1 rule $\left(\lambda_{1}: \lambda_{2}\right)$ proposed by Gorsuch (1983), if the first eigenvalue is at least three times the size of the second then there is strong evidence of unidimensionality or general factor.

Wave I. In Wave I data, three items were identified as variables reflecting levels of physical activity (Appendix A). The largest eigenvalue was 1.430, which is greater than one and provides evidence to support that these factors are measuring similar constructs. Although the ratio of the 1 st to 2 nd eigenvalues did not exceed the criterion (3:1) set by Gorsuch (1983), the first eigenvalue is greater than 1 and explains almost half the variability in the set of items (47.7\%), which suggests the set of items covariation is explained by one common factor. The factor pattern loadings of all three original variables were moderately to highly correlated to the single factor solution. The question regarding playing an active sport had the highest correlation $(r=0.771)$, the question regarding exercise had the next highest correlation $(r=0.669)$, and the question regarding rollerblading and bicycling had a moderate correlation $(r=0.589)$. Additionally, the scree plot was a shape that indicated one factor could be extracted (Figure 3.1). 
Figure 3.1

Scree Plot of Items Measuring Physical Activity at Wave I

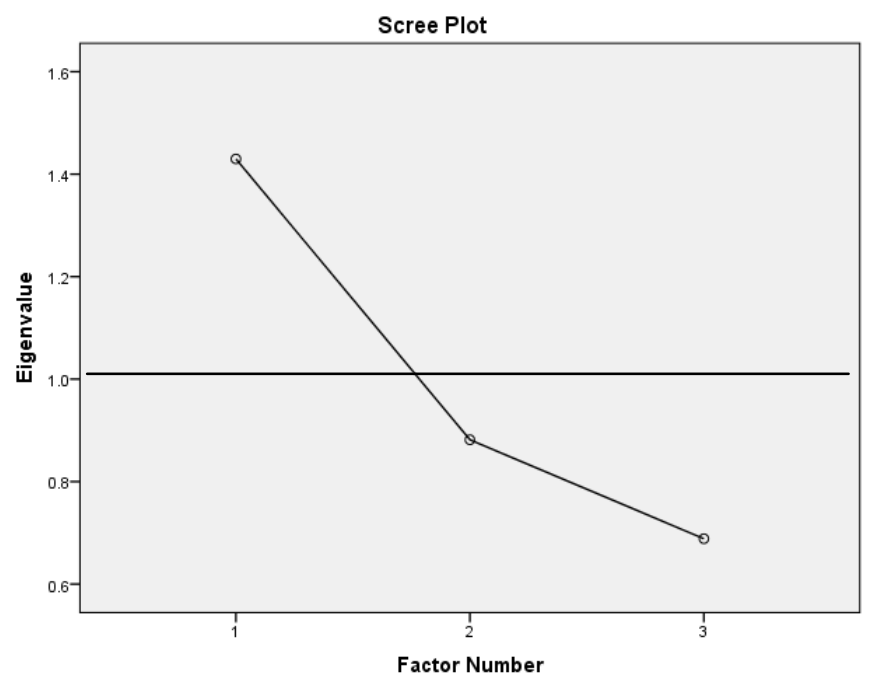

Wave II. In Wave II data, three items were identified as variables reflecting levels of physical activity (Appendix B). The largest eigenvalue was 1.4, which is greater than one and provides evidence to support that these factors are measuring similar constructs. Although the ratio of the 1 st to 2 nd eigenvalues did not exceed the criterion $(3: 1)$ set by Gorsuch (1983), the first eigenvalue is greater than 1 and explains close to half of the variability in the set of items $(46.7 \%)$, which suggests the set of items covariation is explained by one common factor. The factor pattern loadings of all three original variables were moderately to highly correlated to the single factor solution. The question regarding playing an active sport had the highest correlation $(r=0.762)$, the question regarding exercise had the next highest correlation $(r=0.693)$, and the question regarding rollerblading and bicycling had a moderate correlation $(r=0.582)$. Additionally, the scree plot was a shape that indicated one factor could be extracted (Figure 3.2). 
Figure 3.2

Scree Plot of Items Measuring Physical Activity at Wave II

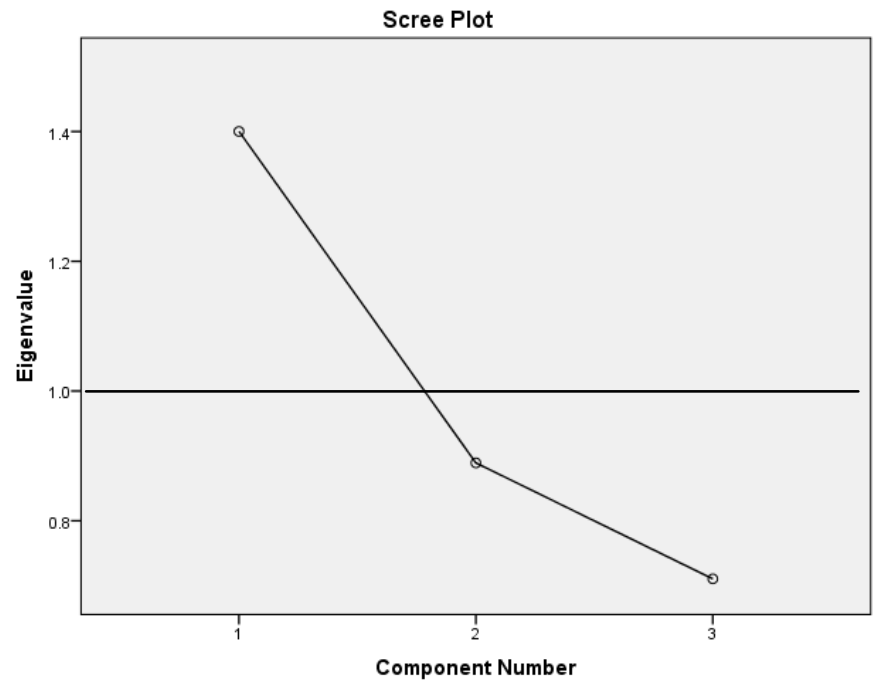

Wave III. In Wave III data, seven items were identified as variables reflecting levels of physical activity (Appendix C). The largest eigenvalue was 6.1, which is greater than one and provides evidence to support that these factors are measuring similar constructs. The ratio of the 1 st to 2 nd eigenvalues (6.1:0.3) exceeds the criterion (3:1) set by Gorsuch (1983). The first eigenvalue explains $86.9 \%$ of the variability in the set of items, which suggests the set of items covariation is explained by one common factor. The factor pattern loadings of all seven original items were moderately to highly correlated to the single factor solution. The item regarding playing golf, baseball, fishing, or bowling had the highest correlation $(r=0.959)$ with the correlations of the other six items following in this descending order: playing a strenuous sport $(r=0.954)$, participating in gymnastics or strength training $(r=0.953)$, playing an individual sport ( $r$ $=0.947)$, participating in rollerblading, roller-skating, skiing, or aerobics $(r=0.937)$, participating in bicycling, skateboarding, dancing, hunting, or hiking $(r=0.904)$, and 
walking for exercise $(r=0.867)$. Additionally, the scree plot was a shape that indicated one factor could be extracted (Figure 3.3).

Figure 3.3

Scree Plot of Items Measuring Physical Activity at Wave III

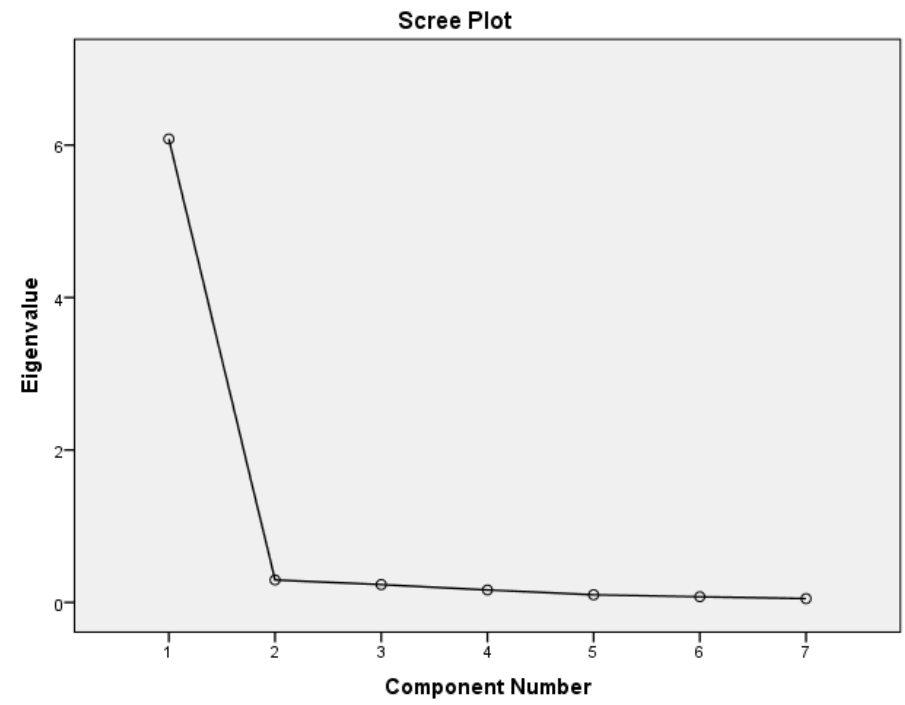

Wave IV. In Wave IV data, six items were identified as variables reflecting levels of physical activity (Appendix D). The largest eigenvalue was 4.8 , which is greater than one and provides evidence to support that these factors are measuring similar constructs. The ratio of the 1 st to 2 nd eigenvalues (4.8:0.4) exceeds the criterion (3:1) set by Gorsuch (1983). The first eigenvalue explains $80.5 \%$ of the variability in the set of items, which suggests the set of items covariation is explained by one common factor. The factor pattern loadings of all six original items were highly correlated to the single factor solution. The item regarding participating in rollerblading, roller-skating, skiing, or aerobics had the highest correlation $(r=0.931)$ with the correlations of the other five items following in this descending order: playing an individual sport $(r=0.928)$, playing golf, baseball, fishing, or bowling ( $r=0.927)$, participating in gymnastics or strength 
training $(r=0.925)$, walking for exercise $(r=0.838)$, and participating in bicycling, skateboarding, dancing, hunting, or hiking $(r=0.827)$. Additionally, the scree plot was a shape that indicated one factor could be extracted (Figure 3.4).

Figure 3.4

Scree Plot of Items Measuring Physical Activity at Wave IV

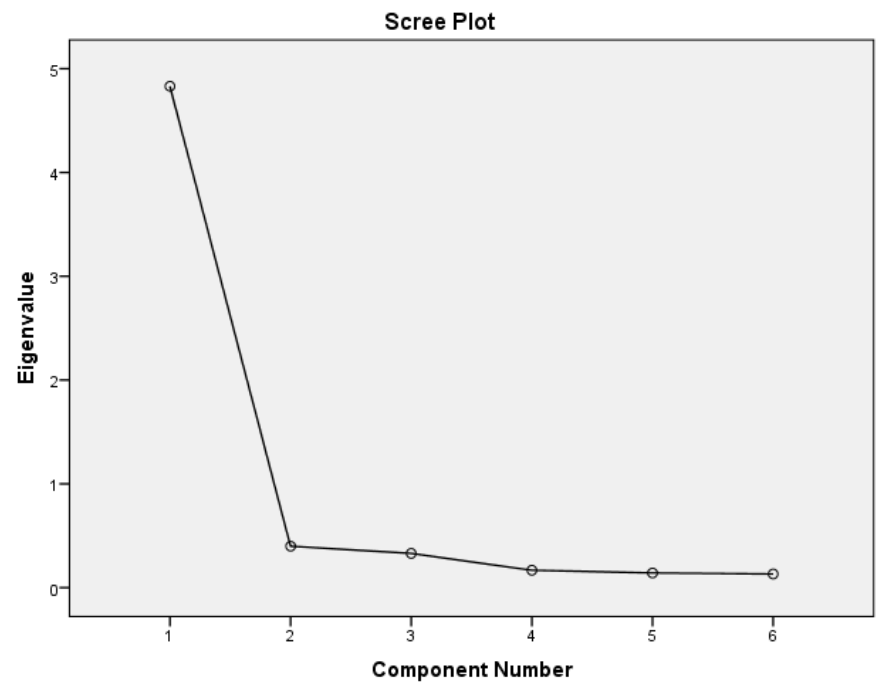

Data weights. Several sampling weights are available for use with the Add Health data set. These weights are used to turn the sample of adolescents interviewed into a sample that is more representative of the entire population of adolescents that was enrolled in secondary school at the time each wave was collected (Chantala, 2006). Several weights are available for use with each wave and a weight is chosen based on the type of analysis that is needed to investigate each hypothesis. In the current study, data weights specified for use in longitudinal analyses were used. Specifically, GSWGT4_2 was used in research question 1, GSWGT1 and GSWGT2 were used in research question 2, and GSWGT3_2 and GSWGT4_2 were used in research question 3. These weights were chosen based on the Carolina Population Center's Guidelines for Analyzing Add Health Data (Chantala, 2006). The weights provided were sampling or probability 
weights. Due to the fact that the SPSS software used for the analyses does not allow for type of weight to by uniquely defined, the population weights were converted to frequency weights, which is the type of weight recognized by SPSS. The conversions were done by rounding the probability weight to the nearest decimal place (i.e., the nearest 100 -th) and then multiplying by $100^{\wedge} \mathrm{k}$. The result was an integer that could be used as a frequency weight (Maletta, 2007; Samuels, 2009; Treiman, 2009).

Data analysis of research question one. The first research question explored the potential growth relationship between physical activity in early adolescence (Wave I) and physical activity in later adolescence and young adulthood (Wave II, III, IV). How gender and ethnicity impacted this growth relationship was also explored. In order to determine the relationships between these variables, a generalized linear mixed model (GLMM) was used. GLMM was chosen because it provided a means of incorporating a longitudinal design with categorical outcomes (Heck, Thomas, \& Tabata, 2012) and allowed the trajectory of physical activity from adolescence to adulthood to be explored. The specific GLMM approach used was the generalized estimated equation (GEE) approach. The GEE approach was chosen because it extends GLMM further by accommodating repeated categorical measures where relationships between successive measurements on the same individual likely influence the model (Heck, Thomas, \& Tabata 2012). GEE is usually used when the repeated observations are nested in individuals over time and the individuals are a random sample of a population. These parameters were an ideal fit for the physical activity variables created in the current study from the longitudinal ADD Health data set. 
Data analysis of research question two. The second research question addressed the potential relationship between physical activity in adolescence (Wave I) and educational ambition (Wave I and Wave II). The created physical activity variable from Wave I was used as the independent variable. Identified educational ambition items from Waves I and II were used as dependent variables (Appendices E and F). Ordinal linear regression was conducted to examine the potential relationships between physical activity in Wave I and the identified educational ambition items in Waves I and II (i.e., desire to go to college and likelihood of going to college).

PACategories 1 (coded $0=$ no reported physical activity, $1=$ reported physical activity not at levels that meet $\mathrm{CDC}$ recommendations, $2=$ reported physical activity levels meet $\mathrm{CDC}$ recommendations) is the independent variable in this model. It is being compared to the dependent variable hleel which is based on a question that asks, "On a scale of one to five (one being low, five being high), how much do you want to go to college?" (Appendix E). PACategories1 was also compared to the dependent variable hlee 2 which is based on a question that asks, "On a scale of one to five (one being low, five being high), how likely is it that you will go to college?" (Appendix E).

In order to examine some long-term educational impacts of physical activity during adolescence, reported levels of physical activity in Wave I were also compared to questions of educational ambition gathered during Wave II. PACategories 1 (coded $0=$ no reported physical activity, $1=$ reported physical activity not at levels that meet CDC recommendations, 2 = reported physical activity levels meet $\mathrm{CDC}$ recommendations) is also the independent variable in this model. 
Data analysis of research question three. The third research question addressed the potential relationship between physical activity in adolescence (Wave I) and educational attainment (Wave III and Wave IV). The created physical activity variable from Wave I was used as the independent variable. Identified educational attainment items from Waves III and IV were used as dependent variables (Appendices $\mathrm{G}$ and $\mathrm{H}$ ). Ordinal linear regression was conducted to explore the potential relationships between the independent variable, physical activity in Wave I, and the identified educational attainment items in Waves III and IV (i.e., the highest level of education attained and degrees received). PACategories 1 (coded $0=$ no reported physical activity, $1=$ reported physical activity not at levels that meet $\mathrm{CDC}$ recommendations, $2=$ reported physical activity levels meet $\mathrm{CDC}$ recommendations) is the independent variable in this model. PACategories 1 was correlated to the dependent variables H3EDI and H4ED2 which were items that asked, "What is the highest grade or year of regular school you completed?" in Wave III and "What is the highest level of education that you have achieved to date?" in Wave IV. Answer choices ranged from $6=6^{\text {th }}$ grade to $22=$ five or more years of graduate school in Wave III and $1=8$ th grade or less to $13=$ professional education (i.e., medical school, law school, etc) in Wave IV (Appendices G and H). In order to make the answer categories offered in Wave IV ordinal rather than categorical two of the categories were collapsed before analysis was conducted. Category 12 (some post baccalaureate professional education) was combined with category Category 8 (some graduate school) and Category 13 (completed post baccalaureate professional education) was combined with Category 9 (completed a master's degree).

Copyright (C) Frances Jillian Priesmeyer 2014 


\section{Chapter Four: Results}

\section{Research Question One: Growth in Physical Activity}

The hypothesis for research question one was that higher levels of physical activity in adolescence (Wave I) would grow into continued higher levels of physical activity into later adolescence (Wave II) and adulthood (Wave III and Wave IV) and gender and ethnicity would impact this growth. Generalized estimated equations (GEE) were used to analyze growth in physical activity.

The physical activity category of each participant was coded as a binary variable where $0=$ no reported physical activity and $1=$ either some physical activity or physical activity at $\mathrm{CDC}$ recommended levels (i.e., at least some physical activity). Age was used as the time variable and it was centered around the mean age, 16 years old, so that time 0 $=16$ years old. It was determined that the predicted log odds of reporting at least some physical activity vs. no physical activity at time 0 (16 years old) was positive and statistically significant, $\beta=2.30, p<.001, O R=9.93$. The odds ratio indicates that adolescents were about 9 times more likely to report at least some physical activity vs. no physical activity at time 0 (16 years old), holding all other variables constant. There was a small statistically significant finding for age at time of response. That is, as adolescents' age increased, their likelihood of reporting at least some physical activity decreased by a $\log$ odds of $-0.08, p<.001, O R=0.92$. The odds ratio suggests that the odds of an adolescent reporting at least some physical activity are multiplied by 0.91 (or reduced by $8 \%$ ) over the first interval (between age 0 and age 1 (i.e., between 16 years old and 17 years old). Using this model, there was also a statistically significant finding for gender at age $16, \beta=0.5, p<.001, O R=1.65$. This indicates that the odds of males 
reporting at least some physical activity were $65 \%$ higher than the odds of females reporting at least some physical activity. Additionally, there were small yet significant changes in physical activity level due to ethnicity and age by ethnicity interaction variables. Given that the majority of odds ratios of these interactions were between 1.01 and 1.10, this suggests small differences that are likely not of substantive importance and were only statistically significant given the large sample size. It is also worth noting that the language used to describe the ethnicity categories from this point forward is used because it is the specific language used on the surveys taken by the participants. A discussion of the limitations of this language is included in the discussion section.

The interactions that had odds ratios larger than 1.1 were White vs. Native American $(\beta=0.16, p<.001, O R=1.17)$, Hispanic vs. Native American $(\beta=0.17, p<$ $.001, O R=1.19)$, Black or African- American vs. White $(\beta=0.16, p<.001, O R=1.18)$, Black or African American vs. Native American $(\beta=0.2, p<.001, O R=1.22)$, Black or African American vs. Asian or Pacific Islander $(\beta=0.12, p<.001, O R=1.13)$, Asian or Pacific Islander vs. Native American $(\beta=0.16, p<.001, O R=1.18)$, and Multiracial vs. Native American $(\beta=0.14, p<.001, O R=1.15)$. This indicates individuals who identified as Native American were $17 \%$ more likely than those who identified as White, $19 \%$ more likely than those who identified as Hispanic, $22 \%$ more likely than those who identified as Black or African American, and 15\% more likely than those who identified as Multiracial to report at least some physical activity. Additionally, individuals who identified as White were $18 \%$ more likely than those who identified as Black or AfricanAmerican to report at least some physical activity and individuals who identified as Asian or Pacific Islander were 13\% more likely than those who identified as Black or African- 
American to report at least some physical activity. It is important to keep in mind that these interactions are still rather small and likely only statistically significant due to the large sample size.

Finally, the correlation between the age variable and the intercept at time 0 (16 years old) was negative $(r=.26)$. This small positive correlation indicates that adolescents who reported at least some physical activity initially experienced slightly more growth in the amount of physical activity reported over the course of the study than those who reported no physical activity initially. All log odds and odds ratios from the growth analysis are reported in Table 4.1.

Table 4.1

Predicted Log Odds of Reporting Physical Activity within Specific Age, Gender, and Ethnicity Parameters with Data Set Weights

\begin{tabular}{|c|c|c|c|c|c|}
\hline Parameter & $\beta$ & $S E$ & $p$ & OR & $95 \% \mathrm{CI}$ \\
\hline (Intercept) & 2.3 & $<.001$ & $<.001$ & 9.93 & {$[9.93,9.93]$} \\
\hline Age $($ Time $0=16$ years $)$ & -0.08 & $<.001$ & $<.001$ & 0.92 & {$[0.92,0.92]$} \\
\hline Sex $(0=$ Female, $1=$ Male $)$ & 0.5 & $<.001$ & $<.001$ & 1.65 & {$[1.65,1.65]$} \\
\hline Age by Sex & 0.01 & $<.001$ & $<.001$ & 1.01 & {$[1.01,1.01]$} \\
\hline White vs. Native American & 0.16 & $<.001$ & $<.001$ & 1.17 & {$[1.17,1.17]$} \\
\hline Hispanic vs. White & 0.07 & $<.001$ & $<.001$ & 1.08 & {$[1.08,1.08]$} \\
\hline Hispanic vs. Native American & 0.17 & $<.001$ & $<.001$ & 1.19 & {$[1.19,1.19]$} \\
\hline $\begin{array}{l}\text { Hispanic vs. Asian or Pacific } \\
\text { Islander }\end{array}$ & 0.04 & $<.001$ & $<.001$ & 1.04 & {$[1.04,1.04]$} \\
\hline $\begin{array}{l}\text { Black or African American vs. } \\
\text { Hispanic }\end{array}$ & 0.1 & .001 & $<.001$ & 1.01 & {$[1.01,1.01]$} \\
\hline $\begin{array}{l}\text { Black or African American vs. } \\
\text { White }\end{array}$ & 0.16 & $<.001$ & $<.001$ & 1.18 & {$[1.18,1.18]$} \\
\hline
\end{tabular}


Table 4.1 (continued)

Black or African American

$0.2 \quad-.001<.001 \quad 1.22$

$[1.22,1.22]$

vs. Native American

Black or African American

$0.12<.001<.001<1.13$

$[1.13,1.13]$

vs. Asian or Pacific Islander

Asian or Pacific Islander

$0.16<.001<.001 \quad 1.18$

$[1.18,1.18]$

vs. Native American

Asian or Pacific Islander

$0.03<.001<.001<1.03$

$[1.03,1.03]$

vs. White

Multiracial vs. Native American

$0.14<.001<.001 \quad 1.15$

$[1.14,1.15]$

Multiracial vs. White

$0.02<.001<.001<1.02$

$[1.02,1.02]$

Age by White vs. Age by Asian

or Pacific Islander

$0.01<.001<.001<1.01$

$[1.01,1.01]$

Age by White vs. Age by

0.06

$<.001<.001$

1.06

$[1.06,1.06]$

Multiracial

Age by Hispanic vs. Age by

0.01

Asian or Pacific Islander

Age by Hispanic vs. Age by Multiracial

$\begin{array}{llll}0.06<.001<.001 & 1.07\end{array}$

Age by Black or African

American vs. Age by Hispanic

$0.004<.001<.001<1.004 \quad[1.004,1.004]$

Age by Black or African

$0.01<.001<.001<1.01$

$[1.01,1.01]$

American vs. Age by White

Age by Black or African

0.0

American vs. Age by Asian or

Pacific Islander

Age by Black or African

0.05

American vs. Age by

Multiracial

Age by Native American vs.

Age by Asian or Pacific

Islander

$0.01<.001<.001<1.01$

$[1.01,1.01]$ 
Table 4.1 (continued)

Age by Native American vs.

0.05

$<.00$

$<.001$

1.05

$[1.05,1.05]$

Age by Multiracial

Age by Asian or Pacific

0.07

$<.001<.001$

1.08

$[1.08,1.08]$

Islander vs. Age by

Multiracial

Note: The first category listed was the category used as the comparison category. The interactions are listed as their positive iterations, while the inverse negative iterations are not included. For example, the Black vs. White interaction had a log odds of 0.16 and an odds ratio of 1.18 indicating an individual who identified as White was $18 \%$ more likely to report physical activity than an individual who identified as Black. The inverse White vs. Black interaction had a log odds of -0.21 and an odds ratio of 0.82. This odds ratio indicates an individual who identified as Black was $18 \%$ less likely to report physical activity than an individual who identified as White and was not reported due to redundancy.

Due to the very large data set size, particularly when weights were added to the data, all interactions came back as statistically significant regardless of how small the interaction was. This is a common statistical error that occurs with large data sets. In order to provide a frame of reference in regards to more appropriate $p$-values, standard errors, and confidence intervals, some unweighted interactions are presented in Table 4.2.

Table 4.2

Predicted Log Odds of Reporting Physical Activity within Specific Age, Gender, and Ethnicity Parameters without Data Set Weights

\begin{tabular}{lccccc}
\hline Parameter & $\beta$ & $S E$ & $p$ & OR & $95 \%$ CI \\
\hline (Intercept) & 2.28 & .038 & $<.001$ & 9.74 & {$[9.04,10.5]$} \\
Age (Time 0 = 16 years) & -0.08 & .004 & $<.001$ & 0.92 & {$[0.92,0.93]$} \\
Sex (0=Female, 1=Male) & 0.53 & .052 & $<.001$ & 1.70 & {$[1.54,1.88]$} \\
Age by Sex & 0.01 & .004 & .017 & 1.01 & {$[1.00,1.02]$} \\
White vs. Native American & 0.12 & .149 & .433 & 1.12 & {$[0.84,1.5]$}
\end{tabular}


Table 4.2 (continued)

$\begin{array}{llllll}\text { Hispanic vs. Native American } & 0.13 & .150 & .399 & 1.13 & {[0.85,1.52]} \\ \begin{array}{l}\text { Black or African American } \\ \text { vs. White }\end{array} & 0.08 & .055 & .134 & 1.09 & {[0.98,1.21]} \\ \begin{array}{l}\text { Black or African American } \\ \text { vs. Native American }\end{array} & 0.14 & .150 & .346 & 1.15 & {[0.86,1.55]} \\ \begin{array}{l}\text { Black or African American } \\ \begin{array}{l}\text { vs. Asian or Pacific Islander } \\ \text { Asian or Pacific Islander }\end{array}\end{array} & 0.19 & .110 & .093 & 1.2 & {[0.97,1.5]} \\ \begin{array}{l}\text { vs. Native American } \\ \text { Multiracial vs. Native American }\end{array} & 0.10 & .149 & .497 & 1.11 & {[0.83,1.48]} \\ \end{array}$

When comparing the unweighted data to the weighted data, it is noticeable that fewer of the unweighted interactions are of statistical significance. It is also noticeable that the standard errors are larger in the unweighted data, thus the confidence intervals are wider. However, the $\log$ odds $(\beta)$ and odds ratios values only slightly differ between the two data sets. For these reasons, the current analysis, as well as the analyses of research questions two and three, uses weighted data, but focus on the interpretation of interaction variables rather than on significance levels and standard errors which are interpreted with caution.

\section{Research Question Two: Physical Activity as a Predictor of Educational Ambition}

Hypothesis two predicted that higher levels of physical activity in adolescence (Wave I) would predict higher educational ambition at both Wave I and Wave II after controlling for age (centered at age 16), biological gender, and ethnicity. Ordinal logistic 
regression was used to test this hypothesis for each outcome variable at each wave of data collection.

\section{Physical activity (Wave I) and educational ambition (Wave I). PACategories I}

was used to predict the dependent variables hleel ("On a scale of one to five, where one is low and five is high, how much do you want to go to college?") and hlee2 ("On a scale of one to five, where one is low and five is high, how likely is it that you will go to college?"). Overall model fit results showed the ordinal logistic regression model predicting hleel at Wave 1 fit the data better than a null model, $-2 * \log$ likelihood (-2LL) $=331235777.7, \chi^{2}(9, N=2,226,114,415)=69015401.78, p<.001$, McFadden's pseudo $R^{2}=.016$, Nagelkerke's pseudo $R^{2}=.036$. It is important to keep in mind that pseudo $R^{2}$ should not be interpreted independently or compared across data sets. It is reported in this context only to serve as a comparison for the other pseudo $R^{2}$ in the current analysis of this data set. Results for the model predicting hleel at Wave 1 are provided in Table 4.3 .

\section{Table 4.3}

Proportional Odds (Ordinal Logistic Regression) Model Predicting Desire to go to College (hleel) at Wave I from Physical Activity at Wave 1, Gender, Age, and Ethnicity: Coefficients, Standard Errors for Coefficients (SE), Odds Ratios (ORs), and 95\% Confidence Intervals (CIs) of Odds Ratios

$\begin{array}{llllll}\text { Variable } & \text { Coefficient } & S E & p & O R & 95 \% \mathrm{CI}\end{array}$

Threshold

$\begin{array}{lccccc}{[\text { hleel }=1.00]} & -2.5 & <.001 & <.001 & 0.08 & {[0.08,0.08]} \\ {[\text { hleel }=2.00]} & -1.89 & <.001 & <.001 & 0.15 & {[0.15,0.15]} \\ {[\text { hleel }=3.00]} & -0.80 & <.001 & <.001 & 0.45 & {[0.45,0.45]} \\ {[\text { hleel }=4.00]} & -0.06 & <.001 & <.001 & 0.94 & {[0.94,0.94]}\end{array}$


Table 4.3 (continued)

\begin{tabular}{|c|c|c|c|c|c|}
\hline Age Centered (Age - 16) & -0.11 & $<.001$ & $<.001$ & 0.9 & {$[0.9,0.9]$} \\
\hline Female & 0.46 & $<.001$ & $<.001$ & 1.58 & {$[1.58,1.58]$} \\
\hline \multicolumn{6}{|l|}{$\begin{array}{l}\text { Race/Ethnicity (reference } \\
\text { category 'White') }\end{array}$} \\
\hline Hispanic & -0.26 & $<.001$ & $<.001$ & 0.77 & {$[0.77,0.77]$} \\
\hline $\begin{array}{l}\text { Black or African } \\
\text { American }\end{array}$ & 0.09 & $<.001$ & $<.001$ & 1.09 & {$[1.09,1.09]$} \\
\hline Native American & -0.11 & $<.001$ & $<.001$ & 0.9 & {$[0.9,0.9]$} \\
\hline Asian or Pacific Islander & 0.4 & $<.001$ & $<.001$ & 1.49 & {$[1.49,1.49]$} \\
\hline $\begin{array}{l}\text { Identified with two or } \\
\text { more racial/ethnic } \\
\text { groups }\end{array}$ & -0.65 & .001 & $<.001$ & 0.52 & {$[0.52,0.52]$} \\
\hline \multicolumn{6}{|l|}{$\begin{array}{l}\text { Physical activity during } \\
\text { Adolescence (reference } \\
\text { category 'No physical } \\
\text { activity') }\end{array}$} \\
\hline Some physical activity & 0.48 & $<.001$ & $<.001$ & 1.62 & {$[1.62,1.62]$} \\
\hline $\begin{array}{l}\text { Physical activity at CDC } \\
\text { recommended levels }\end{array}$ & 0.99 & $<.001$ & $<.001$ & 2.69 & {$[2.69,2.69]$} \\
\hline
\end{tabular}

In general, results showed higher levels of physical activity during adolescence was associated with higher desire to go to college (hleel), increased age was associated with reduced to hleel, being female was associated with increased hleel, and ethnicity was related to hleel. For instance, given that an adolescent was female vs. male, we expect a 0.46 ordered log odds of being in a higher level of hleel, after holding constant (at zero) all other predictors in the model. If we take the exponential of the coefficient, we can get the proportional odds ratios, which suggests that being a female vs. male, the 
odds of reporting the highest category hleel vs. the combined other four categories is 1.58 times greater, given all other variables in the model are held constant. Since this odds ratio is greater than one, it indicates that being female is related to increased odds of reporting a desire to attend college at Wave I. Also, for each 1-unit increase in age, we can expect a -0.11 ordered log odds of being in a lower level of hleel, after holding constant (at zero) all other predictors in the model. Given an increase in age of 1 year, the odds of being in a higher hleel category rather than a lower category are 0.9 , given all other variables in the model are held constant. This odds ratio is less than one, indicating that an increase in age is related to reduced odds of reporting a desire to attend college at Wave I. Given that an adolescent identified as Asian or Pacific Islander vs. White, we expect a 0.4 ordered log odds of being in a higher level of hleel, after holding constant (at zero) all other predictors in the model. Given identification as Asian, the odds of being in a higher hleel category rather than a lower category are 1.49, given all other variables in the model are held constant. Interestingly, given an adolescent identified as Black or African American vs. White, we expect a 0.09 ordered log odds of being in a higher level of hleel, after holding constant (at zero) all other predictors in the model. Given identification as Black, the odds of being in a higher hleel category rather than a lower category are 1.09 , given all other variables in the model are held constant. These odds ratios are greater than one, indicating identification as either Asian or Pacific Islander or Black or African American vs. White is related to increased odds of reporting a higher level of desire to attend college at Wave I. On the other hand, given that an adolescent identified as Hispanic vs. White, we expect a -0.26 ordered log odds of being in a higher level of hleel, after holding constant (at zero) all other predictors in the 
model. Given identification as Hispanic, the odds of being in a higher hleel category rather than a lower category are 0.77 , given all other variables in the model are held constant. Additionally, given that an adolescent identified either as Native American vs. White or as Multiracial vs. White, we respectively expect -0.11 and -0.65 ordered log odds of being in a higher level of hleel, after holding constant (at zero) all other predictors in the model. The odds of being in a higher hleel category rather than a lower category are 0.9 given identification as Native American and 0.52 given identification as Multiracial when all other variables in the model are held constant. Since these odds ratios are less than one, it indicates identification as Hispanic vs. White, Native American vs. White, or Multiracial vs. White are related to decreased odds of reporting a higher level of desire to attend college at Wave I.

As hypothesized, physical activity during adolescence was positively related with desire to go to college. Specifically, results showed increased PACategories1 was associated with increased hleel. That is, going from no physical activity to some physical activity, we can expect a 0.48 ordered log odds of being in a higher level of hleel, after holding constant (at zero) all other predictors in the model. Moreover, the odds of being in a higher hleel category rather than a lower category are 1.62, given all other variables in the model are held constant. Since this odds ratio is greater than one, it indicates participation in some physical activity rather than no physical activity at Wave I is related to increased odds of reporting a stronger desire to attend college at Wave I. Additionally, going from no physical activity to physical activity at CDC recommended levels, we can expect a 0.99 ordered log odds of being in a higher level of hleel, after holding constant (at zero) all other predictors in the model. So, the odds of being in a 
higher hleel category rather than a lower category are 2.69 , given all other variables in the model are held constant. This odds ratio is also greater than one, indicating participation in physical activity at CDC recommended levels is also related to increased odds of reporting a stronger desire to attend college at Wave I. Finally, a Spearman's Rank Order correlation was also run to determine the strength of the bivariate relationship between physical activity at Wave I and desire to attend college at Wave I. There was a small positive correlation between physical activity and desire to attend college, which was statistically significant, $r_{s}=.087, p<.001$.

Also at Wave I, a model was developed to predict the dependent variable hlee2 ("On a scale of one to five, where one is low and five is high, how likely is it that you will go to college?"). Overall, model fit results showed the ordinal logistic regression model predicting hlee 2 at Wave 1 fit the data better than a null model, $-2 * \log$ likelihood $(-2 \mathrm{LL})=443940391.8, \chi^{2}(9, N=2,226,114,415)=75275105.45, p<.001$, McFadden's pseudo $R^{2}=.015$, Nagelkerke's pseudo $R^{2}=.036$. It is important to keep in mind that pseudo $R^{2}$ should not be interpreted independently or compared across data sets. It is reported in this context only to serve as a comparison for the other pseudo $R^{2}$ in the current analysis of this data set. Results for the model predicting hlee 2 at Wave 1 are provided in Table 4.4 .

Table 4.4 Proportional Odds (Ordinal Logistic Regression) Model Predicting Reported Likelihood of Attending College (hlee2) at Wave I from Physical Activity at Wave 1, Gender, Age, and Ethnicity: Coefficients, Standard Errors for Coefficients (SE), Odds Ratios (ORs), and $95 \%$ Confidence Intervals (CIs) of Odds Ratios

$\begin{array}{llllll}\text { Variable } & \text { Coefficient } & S E & p & O R & 95 \% \mathrm{CI}\end{array}$

\section{Threshold}


Table 4.4 (continued)

\begin{tabular}{|c|c|c|c|c|c|}
\hline$[$ hlee2 $=1.00]$ & -2.1 & $<.001$ & $<.001$ & 0.12 & {$[0.12,0.12]$} \\
\hline$[$ hlee2 $=2.00]$ & -1.41 & $<.001$ & $<.001$ & 0.24 & {$[0.24,0.24]$} \\
\hline$[$ hlee $2=3.00]$ & -0.38 & $<.001$ & $<.001$ & 0.68 & {$[0.68,0.68]$} \\
\hline$[$ hlee2 $=4.00]$ & 0.57 & $<.001$ & $<.001$ & 1.77 & {$[1.77,1.77]$} \\
\hline Age Centered (Age - 16) & 0.0 & $<.001$ & $<.001$ & 1.0 & {$[1.0,1.0]$} \\
\hline Female & 0.51 & $<.001$ & $<.001$ & 1.67 & {$[1.67,1.67]$} \\
\hline \multicolumn{6}{|l|}{$\begin{array}{l}\text { Race/Ethnicity (reference } \\
\text { category 'White') }\end{array}$} \\
\hline Hispanic & -0.48 & $<.001$ & $<.001$ & 0.62 & {$[0.62,0.62]$} \\
\hline $\begin{array}{l}\text { Black or African } \\
\text { American }\end{array}$ & -0.12 & $<.001$ & $<.001$ & 0.89 & {$[0.89,0.89]$} \\
\hline Native American & -0.28 & $<.001$ & $<.001$ & 0.76 & {$[0.76,0.76]$} \\
\hline Asian or Pacific Islander & 0.38 & $<.001$ & $<.001$ & 1.46 & {$[1.46,1.46]$} \\
\hline $\begin{array}{l}\text { Identified with two or } \\
\text { more racial/ethnic } \\
\text { groups }\end{array}$ & -0.33 & .001 & $<.001$ & 0.72 & {$[0.72,0.72]$} \\
\hline \multicolumn{6}{|l|}{$\begin{array}{l}\text { Physical activity during } \\
\text { Adolescence (reference } \\
\text { category 'No physical } \\
\text { activity') }\end{array}$} \\
\hline Some physical activity & 0.52 & $<.001$ & $<.001$ & 1.68 & {$[1.68,1.68]$} \\
\hline $\begin{array}{l}\text { Physical activity at CDC } \\
\text { recommended levels }\end{array}$ & 0.95 & $<.001$ & $<.001$ & 2.59 & {$[2.59,2.59]$} \\
\hline
\end{tabular}

In general, results showed higher physical activity levels during adolescence were associated with increased $h 1 e e 2$, being female was associated with greater reported likelihood of attending college (hlee2), and ethnicity was related to hlee2. For instance, given that an adolescent was female vs. male, we expect a 0.51 ordered log odds of being 
in a higher level of hlee2, after holding constant (at zero) all other predictors in the model. If we take the exponential of the coefficient, we can get the proportional odds ratios, which suggests that being a female vs. male, the odds of reporting the highest category hlee 2 vs. the combined other 4 categories is 1.67 times greater, given all other variables in the model are held constant. Since this odds ratio is greater than one, it indicates that being female is related to increased odds of reporting a higher level of likelihood of attending college at Wave I. Also, given that an adolescent identified as Asian or Pacific Islander vs. White, we expect a 0.32 ordered log odds of being in a higher level of hlee2, after holding constant (at zero) all other predictors in the model. Given identification as Asian, the odds of being in a higher hlee 2 category rather than a lower category are 1.46, given all other variables in the model are held constant. This odds ratio is greater than one, indicating identification as Asian or Pacific Islander vs. White is related to increased odds of reporting a higher level of likelihood of attending college at Wave I. On the other hand, given that an adolescent identified as Hispanic vs. White, we expect a -0.48 ordered log odds of being in a higher level of hlee 2 , after holding constant (at zero) all other predictors in the model. Given identification as Hispanic, the odds of being in a higher hlee2 category rather than a lower category are 0.62 , given all other variables in the model are held constant. Additionally, given that an adolescent identified as Multiracial vs. White, Native American vs. White, or Black or African American vs. White, we relatively expect $-0.33,-0.28$, and -0.12 ordered log odds of being in a higher level of hlee2, after holding constant (at zero) all other predictors in the model. The odds of being in a higher hlee 2 category rather than a lower category are 0.72 given identification as Multiracial, 0.76 given identification as Native 
American, and 0.89 given identification as Black or African American when all other variables in the model are held constant. Since these odds ratios are less than one, it indicates identification as Hispanic, Multiracial, Native American, or Black or African American vs. White is related to decreased odds of reporting a higher level of desire to attend college at Wave I.

As hypothesized, physical activity during adolescence was positively related with reported likelihood of attending college. Specifically, results showed increased PACategories1 was associated with increased hlee2. That is, going from no physical activity to some physical activity, we can expect a 0.52 ordered log odds of being in a higher level of hlee2, after holding constant (at zero) all other predictors in the model. Moreover, the odds of being in a higher hlee 2 category rather than a lower category are 1.68 , given all other variables in the model are held constant. Since this odds ratio is greater than one, it indicates participation in some physical activity rather than no physical activity at Wave I is related to increased odds of reporting a higher likelihood of attending college at Wave I. Additionally, for going from no physical activity to physical activity at CDC recommended levels, we can expect a 0.95 ordered log odds of being in a higher level of hlee2, after holding constant (at zero) all other predictors in the model. So, the odds of being in a higher hlee 2 category rather than a lower category are 2.59 , given all other variables in the model are held constant. This odds ratio is also greater than one, indicating participation in physical activity at CDC recommended levels is also related to increased odds of reporting a higher likelihood of attending college at Wave I. Finally, a Spearman's Rank Order correlation was also run to determine the strength of the bivariate relationship between physical activity at Wave I and reported likelihood of 
attending college at Wave I. There was a small positive correlation between physical activity and desire to attend college, which was statistically significant, $r_{s}=.089, p<$ .001 .

\section{Physical activity (Wave I) and educational ambition (Wave II).}

PACategories 1 was used to predict the dependent variables h2eel ("On a scale of one to five, where one is low and five is high, how much do you want to go to college?") and h2ee2 ("On a scale of one to five, where one is low and five is high, how likely is it that you will go to college?"). Overall, model fit results showed the ordinal logistic regression model predicting $h 2 e e l$ at Wave II fit the data better than a null model, $-2 * \log$ likelihood $(-2 \mathrm{LL})=355748869.0, \chi^{2}(9, N=1,881,747,144)=57993361.69, p<.001$, McFadden's pseudo $R^{2}=.015$, Nagelkerke's pseudo $R^{2}=.036$. It is important to keep in mind that pseudo $R^{2}$ should not be interpreted independently or compared across data sets. It is reported in this context only to serve as a comparison for the other pseudo $R^{2}$ in the current analysis of this data set. Results for the model predicting h2eel at Wave II are provided in Table 4.5 .

Table 4.5

Proportional Odds (Ordinal Logistic Regression) Model Predicting Desire to go to College (h2eel) at Wave II from Physical Activity at Wave 1, Gender, Age, and Ethnicity: Coefficients, Standard Errors for Coefficients (SE), Odds Ratios (ORs), and 95\% Confidence Intervals (CIs) of Odds Ratios

$\begin{array}{llllll}\text { Variable } & \text { Coefficient } & S E & p & O R & 95 \% \mathrm{CI}\end{array}$

\section{Threshold}

$\begin{array}{lrrrrr}{[h 2 e e 1=1.00]} & -2.32 & <.001 & <.001 & 0.1 & {[0.08,0.12]} \\ {[h 2 e e 1=2.00]} & -1.74 & <.001 & <.001 & 0.18 & {[0.15,0.21]} \\ {[h 2 e e 1=3.00]} & -0.73 & <.001 & <.001 & 0.48 & {[0.41,0.56]}\end{array}$


Table 4.5 (continued)

\begin{tabular}{|c|c|c|c|c|c|}
\hline$[h 2 e e 1=4.00]$ & 0.03 & $<.001$ & $<.001$ & 1.03 & {$[0.89,1.2]$} \\
\hline Age Centered (Age - 16) & -0.13 & $<.001$ & $<.001$ & 0.88 & {$[0.88,0.88]$} \\
\hline Female & 0.4 & $<.001$ & $<.001$ & 1.49 & {$[1.49,1.49]$} \\
\hline \multicolumn{6}{|l|}{$\begin{array}{l}\text { Race/Ethnicity (reference } \\
\text { category 'White') }\end{array}$} \\
\hline Hispanic & -0.23 & $<.001$ & $<.001$ & 0.79 & {$[0.79,0.79]$} \\
\hline $\begin{array}{l}\text { Black or African } \\
\text { American }\end{array}$ & 0.13 & $<.001$ & $<.001$ & 1.14 & {$[1.14,1.14]$} \\
\hline Native American & -0.08 & $<.001$ & $<.001$ & 0.92 & {$[0.92,0.92]$} \\
\hline Asian or Pacific Islander & 0.5 & $<.001$ & $<.001$ & 1.65 & {$[1.65,1.65]$} \\
\hline $\begin{array}{l}\text { Identified with two or } \\
\text { more racial/ethnic } \\
\text { groups }\end{array}$ & -0.58 & .001 & $<.001$ & 0.56 & {$[0.56,0.57]$} \\
\hline \multicolumn{6}{|l|}{$\begin{array}{l}\text { Physical activity during } \\
\text { Adolescence (reference } \\
\text { category 'No physical } \\
\text { activity') }\end{array}$} \\
\hline Some physical activity & 0.52 & $<.001$ & $<.001$ & 1.68 & {$[1.68,1.68]$} \\
\hline $\begin{array}{l}\text { Physical activity at CDC } \\
\text { recommended levels }\end{array}$ & 0.99 & $<.001$ & $<.001$ & 2.69 & {$[2.69,2.69]$} \\
\hline
\end{tabular}

In general, results showed higher levels of physical activity during adolescence was associated with increased desire to go to college (h2eel), increased age was associated with reduced $h 2 e e 1$, being female was associated to increased $h 2 e e 1$, and ethnicity was related to h2eel. For instance, given that an adolescent was female vs. male, we expect a 0.4 ordered log odds of being in a higher level of $h 2 e e 1$, after holding constant (at zero) all other predictors in the model. If we take the exponential of the coefficient, we can get the proportional odds ratios, which suggests that being a female 
vs. male, the odds of reporting the highest category h2eel vs. the combined other 4 categories is 1.49 times greater, given all other variables in the model are held constant. Since this odds ratio is greater than one, it indicates that being female is related to increased odds of reporting a desire to attend college at Wave II. Also, for each 1-unit increase in age we can expect a -0.13 ordered log odds of being in a higher level of h2eel, after holding constant (at zero) all other predictors in the model. Given an increase in age of 1 year, the odds of being in a higher h2eel category rather than a lower category are 0.88 , given all other variables in the model are held constant. This odds ratio is less than one, indicating that an increase in age is related to reduced odds of reporting a strong desire to attend college at Wave II. Given that an adolescent identified as Asian or Pacific Islander vs. White, we expect a 0.5 ordered log odds of being in a higher level of h2eel, after holding constant (at zero) all other predictors in the model. Given identification as Asian or Pacific Islander, the odds of being in a higher h2eel category rather than a lower category are 1.65 , given all other variables in the model are held constant. Interestingly, given that an adolescent identified as Black or African American vs. White, we expect a 0.13 ordered log odds of being in a higher level of h2eel, after holding constant (at zero) all other predictors in the model. Given identification as Black, the odds of being in a higher h2eel category rather than a lower category are 1.14, given all other variables in the model are held constant. These odds ratios are greater than one, indicating identification as either Asian or Pacific Islander or Black or African American vs. White is related to increased odds of reporting a higher level of desire to attend college at Wave II. On the other hand, given that an adolescent identified as Multiracial vs. White, Hispanic vs. White, or Native American vs. White, 
we relatively expect $-0.58,-0.23$, and -0.08 ordered log odds of being in a higher level of h2eel, after holding constant (at zero) all other predictors in the model. The odds of being in a higher $h 2 e e 1$ category rather than a lower category are 0.56 given identification as Multiracial, 0.79 given identification as Hispanic, and 0.92 given identification as Native American when all other variables in the model are held constant. Since these odds ratio are less than one, it indicates identification as Multiracial vs. White, Hispanic vs. White, or Native American vs. White are related to decreased odds of reporting a higher level of desire to attend college at Wave II.

As hypothesized, physical activity during adolescence was positively related with desire to go to college. Specifically, results showed increased PACategories1 was associated with increased h2eel. That is, going from no physical activity to some physical activity, we can expect a 0.52 ordered log odds of being in a higher level of h2eel, after holding constant (at zero) all other predictors in the model. Moreover, the odds of being in a higher $h 2 e e l$ category rather than a lower category are 1.68 , given all other variables in the model are held constant. Since this odds ratio is greater than one, it indicates participation in some physical activity rather than no physical activity at Wave I is related to increased odds of reporting a stronger desire to attend college at Wave II. Additionally, going from no physical activity to physical activity at CDC recommended levels, we can expect a 0.99 ordered log odds of being in a higher level of h2eel, after holding constant (at zero) all other predictors in the model. So, the odds of being in a higher $h 2 e e 1$ category rather than a lower category are 2.69 , given all other variables in the model are held constant. This odds ratio is also greater than one, indicating participation in physical activity at CDC recommended levels is also related to increased 
odds of reporting a stronger desire to attend college at Wave II. Moreover, the odds ratio for a 2-unit increase in physical activity is larger than the odds ratio for a 1-unit increase in physical activity. This indicates participation in physical activity at CDC

recommended levels is related to a larger increase in the odds of reporting a higher level of desire to attend college than participation in some physical activity. Finally, a Spearman's Rank Order correlation was also run to determine the strength of the bivariate relationship between physical activity at Wave I and desire to attend college at Wave II. There was a small positive correlation between physical activity and desire to attend college, which was statistically significant, $r_{s}=.091, p<.001$.

Also at Wave II, a model was developed to predict the dependent variable $h 2 e e 2$ ("On a scale of one to five, where one is low and five is high, how likely is it that you will go to college?"). Overall model fit results showed the ordinal logistic regression model predicting $h 2 e e 2$ at Wave 1 fit the data better than a null model, $-2 * \log$ likelihood $(-2 \mathrm{LL})=408273740.1, \chi^{2}(9, N=1,881,747,144)=77492485.35, p<.001$, McFadden's pseudo $R^{2}=.016$, Nagelkerke's pseudo $R^{2}=.045$. It is important to keep in mind that pseudo $R^{2}$ should not be interpreted independently or compared across data sets. It is reported in this context only to serve as a comparison for the other pseudo $R^{2}$ in the current analysis of this data set. Results for the model predicting $h 2 e e 2$ at Wave II are provided in Table 4.6.

Table 4.6

Proportional Odds (Ordinal Logistic Regression) Model Predicting Reported Likelihood of Attending College (h2ee2) at Wave II from Physical Activity at Wave 1, Gender, Age, and Ethnicity: Coefficients, Standard Errors for Coefficients (SE), Odds Ratios (ORs), and 95\% Confidence Intervals (CIs) of Odds Ratios

$\begin{array}{llllll}\text { Variable } & \text { Coefficient } & S E & p & O R & 95 \% \mathrm{CI}\end{array}$


Table 4.6 (continued)

\begin{tabular}{|c|c|c|c|c|c|}
\hline \multicolumn{6}{|l|}{ Threshold } \\
\hline$[h 2 e e 2=1.00]$ & -1.85 & $<.001$ & $<.001$ & 0.16 & {$[0.16,0.16]$} \\
\hline$[h 2 e e 2=2.00]$ & -1.16 & $<.001$ & $<.001$ & 0.31 & {$[0.31,0.31]$} \\
\hline$[h 2 e e 2=3.00]$ & -0.19 & $<.001$ & $<.001$ & 0.83 & {$[0.83,0.83]$} \\
\hline$[h 2 e e 2=4.00]$ & 0.7 & $<.001$ & $<.001$ & 2.01 & {$[2.01,2.01]$} \\
\hline Age Centered (Age - 16) & -0.07 & $<.001$ & $<.001$ & 0.93 & {$[0.93,0.93]$} \\
\hline Female & 0.56 & $<.001$ & $<.001$ & 1.75 & {$[1.75,1.77]$} \\
\hline \multicolumn{6}{|l|}{$\begin{array}{l}\text { Race/Ethnicity (reference } \\
\text { category 'White') }\end{array}$} \\
\hline Hispanic & -0.48 & $<.001$ & $<.001$ & 0.62 & {$[0.62,0.62]$} \\
\hline $\begin{array}{l}\text { Black or African } \\
\text { American }\end{array}$ & -0.1 & $<.001$ & $<.001$ & 0.9 & {$[0.9,0.9]$} \\
\hline Native American & -0.19 & $<.001$ & $<.001$ & 0.83 & {$[0.83,0.83]$} \\
\hline Asian or Pacific Islander & 0.36 & $<.001$ & $<.001$ & 1.43 & {$[1.43,1.43]$} \\
\hline $\begin{array}{l}\text { Identified with two or } \\
\text { more racial/ethnic } \\
\text { groups }\end{array}$ & 0.02 & .001 & $<.001$ & 1.02 & {$[1.02,1.03]$} \\
\hline \multicolumn{6}{|l|}{$\begin{array}{l}\text { Physical activity during } \\
\text { Adolescence (reference } \\
\text { category 'No physical } \\
\text { activity') }\end{array}$} \\
\hline Some physical activity & 0.5 & $<.001$ & $<.001$ & 1.65 & {$[1.65,1.65]$} \\
\hline $\begin{array}{l}\text { Physical activity at CDC } \\
\text { recommended levels }\end{array}$ & 0.9 & $<.001$ & $<.001$ & 2.46 & {$[2.46,2.46]$} \\
\hline
\end{tabular}

In general, results showed higher physical activity levels during adolescence were associated with greater reported likelihood of attending college (h2ee2), being female 
was associated with increased $h 2 e e 2$, increased age was associated with reduced $h 2 e e 2$, and ethnicity was related to $h 2 e e 2$. For instance, given that an adolescent was female vs. male, we expect a 0.56 ordered log odds of being in a higher level of $h 2 e e 2$, after holding constant (at zero) all other predictors in the model. If we take the exponential of the coefficient, we can get the proportional odds ratios, which suggests that being a female vs. male, the odds of reporting the highest category $h 2 e e 2$ vs. the combined other 4 categories is 1.75 times greater, given all other variables in the model are held constant. Since this odds ratio is greater than one, it indicates that being female is related to increased odds of reporting a higher level of likelihood of attending college at Wave II. Also, for each 1-unit increase in age we can expect a -0.07 ordered log odds of being in a higher level of $h 2 e e 2$, after holding constant (at zero) all other predictors in the model. Given an increase in age of 1 year, the odds of being in a higher $h 2 e e 2$ category rather than a lower category are 0.93 , given all other variables in the model are held constant. This odds ratio is less than one, indicating that an increase in age is related to reduced odds of reporting a higher likelihood to attend college at Wave II. Also, given that an adolescent identified as Asian or Pacific Islander vs. White or as Multiracial vs. White, we relatively expect 0.36 and 0.02 ordered log odds of being in a higher level of $h 2 e e 2$, after holding constant (at zero) all other predictors in the model. The odds of being in a higher $h 2 e e 2$ category rather than a lower category are 1.43 given identification as Asian or Pacific Islander and 1.02 given identification as Multiracial when all other variables in the model are held constant. These odds ratio are greater than one, indicating identification as Asian or Pacific Islander vs. White or Multiracial vs. White are related to increased odds of reporting a higher level of likelihood of attending college at Wave II. 
On the other hand, given that an adolescent identified as Hispanic vs. White, Native American vs. White, or Black or African American vs. White, we relatively expect -0.48, -0.19 , and -0.1 ordered log odds of being in a higher level of $h 2 e e 2$, after holding constant (at zero) all other predictors in the model. The odds of being in a higher $h 2 e e 2$ category rather than a lower category are 0.62 given identification as Hispanic, 0.83 given identification as Native American, and 0.1 given identification as Black or African American when all other variables in the model are held constant. Since these odds ratios are less than one, it indicates identification as either Hispanic, Native American, or Black or African American vs. White is related to decreased odds of reporting a higher level of desire to attend college at Wave II.

As hypothesized, physical activity during adolescence was positively related with reported likelihood of attending college. Specifically, results showed increased PACategories1 was associated with increased h2ee2. That is, going from no physical activity to some physical activity, we can expect a 0.5 ordered log odds of being in a higher level of $h 2 e e 2$, after holding constant (at zero) all other predictors in the model. Moreover, the odds of being in a higher $h 2 e e 2$ category rather than a lower category are 1.65 , given all other variables in the model are held constant. Since this odds ratio is greater than one, it indicates participation in some physical activity rather than no physical activity at Wave I is related to increased odds of reporting a higher likelihood of attending college at Wave II. Additionally, for going from no physical activity to physical activity at CDC recommended levels, we can expect a 0.9 ordered log odds of being in a higher level of $h 2 e e 2$, after holding constant (at zero) all other predictors in the model. So, the odds of being in a higher $h 2 e e 2$ category rather than a lower category are 
2.46 , given all other variables in the model are held constant. This odds ratio is also greater than one, indicating participation in physical activity at CDC recommended levels during Wave I is also related to increased odds of reporting a higher likelihood of attending college at Wave II. Finally, a Spearman's Rank Order correlation was also run to determine the strength of the bivariate relationship between physical activity at Wave I and reported likelihood of attending college at Wave II. There was a small positive correlation between physical activity and desire to attend college, which was statistically significant, $r_{s}=.081, p<.001$.

\section{Research Question Three: Physical Activity as a Predictor of Educational}

\section{Achievement}

Hypothesis three predicted that higher levels of physical activity in adolescence (Wave I) would predict higher levels of educational achievement at both Wave III and Wave IV after controlling for age (centered at age 16), biological gender, and Ethnicity. Ordinal logistic regression was used to test this hypothesis for each outcome variable at each wave of data collection.

\section{Physical activity (Wave I) and educational achievement (Wave III).}

PACategories 1 was used to predict the dependent variable $h 3 e d 1$ ("What is the highest grade or year of regular school you have completed?"). Overall model fit results showed the ordinal logistic regression model predicting $h 3 e d 1$ at Wave III fit the data better than a null model, $-2 * \log$ likelihood $(-2 \mathrm{LL})=1128098842, \chi^{2}(9, N=2,210,415,337)=$ $160892432.5, p<.001$, McFadden's pseudo $R^{2}=.018$, Nagelkerke's pseudo $R^{2}=.072$. It is important to keep in mind that pseudo $R^{2}$ should not be interpreted independently or compared across data sets. It is reported in this context only to serve as a comparison for 
the other pseudo $R^{2}$ in the current analysis of this data set. Results for the model predicting $h 3 e d l$ at Wave III are provided in Table 4.7.

Table 4.7

Proportional Odds (Ordinal Logistic Regression) Model Predicting Desire to go to College (h3ed1) at Wave I from Physical Activity at Wave I, Gender, Age, and Ethnicity: Coefficients, Standard Errors for Coefficients (SE), Odds Ratios (ORs), and 95\% Confidence Intervals (CIs) of Odds Ratios

$\begin{array}{llllll}\text { Variable } & \text { Coefficient } & S E & p & O R & 95 \% \mathrm{CI}\end{array}$

\section{Threshold}

\begin{tabular}{|c|c|c|c|c|c|}
\hline$[h 3 e d 1=6]$ & -7.45 & .001 & $<.001$ & 0.0006 & {$[0.0006,0.0006]$} \\
\hline$[h 3 e d 1=7]$ & -6.2 & .001 & $<.001$ & 0.002 & {$[0.002,0.002]$} \\
\hline$[h 3 e d 1=8]$ & -4.39 & $<.001$ & $<.001$ & 0.01 & {$[0.01,0.01]$} \\
\hline$[h 3 e d 1=9]$ & -3.06 & $<.001$ & $<.001$ & 0.05 & {$[0.05,0.05]$} \\
\hline$[h 3 e d 1=10]$ & -2.08 & $<.001$ & $<.001$ & 0.12 & {$[0.12,0.12]$} \\
\hline$[h 3 e d 1=11]$ & -1.33 & $<.001$ & $<.001$ & 0.26 & {$[0.26,0.26]$} \\
\hline$[h 3 e d 1=12]$ & 0.41 & $<.001$ & $<.001$ & 1.51 & {$[1.51,1.51]$} \\
\hline$[h 3 e d 1=13]$ & 1.08 & $<.001$ & $<.001$ & 2.94 & {$[2.94,2.94]$} \\
\hline$[h 3 e d 1=14]$ & 1.8 & $<.001$ & $<.001$ & 6.05 & {$[6.05,6.05]$} \\
\hline$[h 3 e d 1=15]$ & 2.42 & $<.001$ & $<.001$ & 11.25 & {$[11.25,11.25]$} \\
\hline$[h 3 e d 1=16]$ & 3.75 & $<.001$ & $<.001$ & 42.52 & {$[42.52,42.52]$} \\
\hline$[h 3 e d 1=17]$ & 4.57 & $<.001$ & $<.001$ & 96.54 & {$[96.54,96.54]$} \\
\hline$[h 3 e d 1=18]$ & 5.22 & $<.001$ & $<.001$ & 184.93 & {$[184.93,186.79]$} \\
\hline$[h 3 e d 1=19]$ & 5.9 & $<.001$ & $<.001$ & 365.04 & {$[365.04,365.04]$} \\
\hline$[h 3 e d 1=20]$ & 7.47 & .001 & $<.001$ & 1754.61 & {$[1754.61$,} \\
\hline
\end{tabular}

$1754.61]$ 
Table 4.7 (continued)

\begin{tabular}{|c|c|c|c|c|c|}
\hline$[h 3 e d 1=21]$ & 8.18 & .001 & $<.001$ & 3568.86 & {$[3533.34$} \\
\hline & & & & & $3568.86]$ \\
\hline Age Centered (Age - 16) & 0.18 & $<.001$ & $<.001$ & 1.2 & {$[1.2,1.2]$} \\
\hline Female & 0.39 & $<.001$ & $<.001$ & 1.48 & {$[1.48,1.48]$} \\
\hline $\begin{array}{l}\text { Race/Ethnicity (reference } \\
\text { category 'White') }\end{array}$ & & & & & \\
\hline Hispanic & -0.65 & $<.001$ & $<.001$ & 0.52 & {$[0.52,0.52]$} \\
\hline $\begin{array}{l}\text { Black or African } \\
\text { American }\end{array}$ & -0.54 & $<.001$ & $<.001$ & 0.58 & {$[0.58,0.58]$} \\
\hline Native American & -0.47 & $<.001$ & $<.001$ & 0.63 & {$[0.63,0.63]$} \\
\hline Asian or Pacific Islander & 0.58 & $<.001$ & $<.001$ & 1.8 & {$[1.8,1.8]$} \\
\hline $\begin{array}{l}\text { Identified with two or } \\
\text { more racial/ethnic } \\
\text { groups }\end{array}$ & 0.8 & .001 & $<.001$ & 2.23 & {$[2.23,2.25]$} \\
\hline
\end{tabular}

Physical activity during Adolescence (reference category 'No physical activity')

$\begin{array}{lccccc}\text { Some physical activity } & 0.59 & <.001 & <.001 & 1.8 & {[1.8,1.8]} \\ \text { Physical activity at CDC } & 0.92 & <.001 & <.001 & 2.51 & {[2.51,2.51]}\end{array}$
recommended levels

In general, results showed higher physical activity levels during adolescence were associated with completing higher levels education at Wave III ( $h 3 e d 1$ ), being female was associated with increased $h 3 e d l$, increased age was associated with increased $h 3 e d l$, and ethnicity was related to $h 3 e d 1$. For instance, given that an adolescent was female vs. male, we expect a 0.39 ordered log odds of being in a higher level of $h 3 e d 1$, after holding 
constant (at zero) all other predictors in the model. If we take the exponential of the coefficient, we can get the proportional odds ratios, which suggests that being a female vs. male, the odds of reporting the highest category $h 3 e d 1$ vs. the combined other 4 categories is 1.48 times greater, given all other variables in the model are held constant. Since this odds ratio is greater than one, it indicates that being female is related to increased odds of attaining a higher level of education at Wave III. Also, for each 1-unit increase in age we can expect a 0.18 ordered log odds of being in a higher level of $h 3 e d l$, after holding constant (at zero) all other predictors in the model. Given an increase in age of 1 year, the odds of being in a higher $h 3 e d l$ category rather than a lower category are 1.2, given all other variables in the model are held constant. This odds ratio is greater than one, indicating that an increase in age is related to increased odds of attaining a higher level of education at Wave III. Given that an adolescent identified as Asian or Pacific Islander vs. White, we expect a 0.58 ordered log odds of being in a higher level of h3edl, after holding constant (at zero) all other predictors in the model. Given identification as Asian or Pacific Islander, the odds of being in a higher $h 3 e d 1$ category rather than a lower category are 1.8, given all other variables in the model are held constant. Also, given that an adolescent identified as Multiracial vs. White, we expect a 0.8 ordered log odds of being in a higher level of $h 3 e d 1$, after holding constant (at zero) all other predictors in the model. Given identification as Multiracial, the odds of being in a higher h3ed 1 category rather than a lower category are 2.23 , given all other variables in the model are held constant. These odds ratios are greater than one, indicating identification as Asian or Pacific Islander vs. White or Multiracial vs. White are related to increased odds of attaining a higher level of education at Wave III. On the other hand, 
given that an adolescent identified as Hispanic vs. White, we expect a -0.65 ordered log odds of being in a higher level of $h 3 e d 1$, after holding constant (at zero) all other predictors in the model. Given identification as Hispanic, the odds of being in a higher $h 3 e d l$ category rather than a lower category are 0.52 , given all other variables in the model are held constant. Similarly, given that an adolescent identified as Black or African American vs. White, we expect -0.54 ordered log odds of being in a higher level of $h 3 e d 1$, after holding constant (at zero) all other predictors in the model. Given identification as Black or African American, the odds of being in a higher $h 3 e d l$ category rather than a lower category are 0.58 , given all other variables in the model are held constant. Additionally, given that an adolescent identified as Native American vs. White, we expect a -0.47 ordered log odds of being in a higher level of $h 3 e d 1$, after holding constant (at zero) all other predictors in the model. Given identification as Native American, the odds of being in a higher $h 3 e d 1$ category rather than a lower category are 0.63 , given all other variables in the model are held constant. Since these odds ratios are less than one, it indicates identification as Hispanic, Black or African American, or Native American vs. White is related to decreased odds of attaining a higher level of education at Wave III.

As hypothesized, physical activity during adolescence was positively related with higher levels of attained education. Specifically, results showed increased PACategories1 was associated with increased $h 3 e d l$. That is, going from no physical activity to some physical activity, we can expect a 0.59 ordered log odds of being in a higher level of $h 3 e d 1$, after holding constant (at zero) all other predictors in the model. Moreover, the odds of being in a higher $h 3 e d 1$ category rather than a lower category are 
1.8 , given all other variables in the model are held constant. Since this odds ratio is greater than one, it indicates participation in some physical activity rather than no physical activity at Wave I is related to increased odds of attaining a higher level of education at Wave III. Additionally, for going from no physical activity to physical activity at CDC recommended levels, we can expect a 0.92 ordered log odds of being in a higher level of $h 3 e d l$, after holding constant (at zero) all other predictors in the model. So, the odds of being in a higher $h 3 e d l$ category rather than a lower category are 2.51 , given all other variables in the model are held constant. This odds ratio is also greater than one, indicating participation in physical activity at $\mathrm{CDC}$ recommended levels during Wave I is also related to increased odds of attaining a higher level of education at Wave III. Finally, a Spearman's Rank Order correlation was also run to determine the strength of the bivariate relationship between physical activity at Wave I and level of attained education at Wave III. There was a small positive correlation between physical activity and attained education, which was statistically significant, $r_{s}=.033, p<.001$.

\section{Physical activity (Wave I) and educational achievement (Wave IV).}

PACategories 1 was also used to predict the dependent variable $h 4 e d 2$ ("What is the highest level of education you have achieved to date?"). Overall model fit results showed the ordinal logistic regression model predicting $h 4 e d 2$ at Wave IV fit the data better than a null model, $-2 * \log$ likelihood $(-2 \mathrm{LL})=536150911.4, \chi^{2}(9, N=2,197,822,902)=$ 102442071.8, $p<.001$, McFadden's pseudo $R^{2}=.011$, Nagelkerke's pseudo $R^{2}=.04$. It is important to keep in mind that pseudo $R^{2}$ should not be interpreted independently or compared across data sets. It is reported in this context only to serve as a comparison for 
the other pseudo $R^{2}$ in the current analysis of this data set. Results for the model predicting $h 4 e d 2$ at Wave IV are provided in Table 4.8.

Table 4.8

Proportional Odds (Ordinal Logistic Regression) Model Predicting Desire to go to College (h4ed2) at Wave IV from Physical Activity at Wave I, Gender, Age, and Ethnicity: Coefficients, Standard Errors for Coefficients (SE), Odds Ratios (ORs), and 95\% Confidence Intervals (CIS) of Odds Ratios

$\begin{array}{llllll}\text { Variable } & \text { Coefficient } & S E & p & O R & 95 \% \mathrm{CI}\end{array}$

\begin{tabular}{lccccc}
\hline Threshold & & & & & \\
{$[h 4 e d 2=1]$} & -4.85 & $<.001$ & $<.001$ & 0.008 & {$[0.008,0.008]$} \\
{$[h 4 e d 2=2]$} & -1.85 & $<.001$ & $<.001$ & 0.16 & {$[0.16,0.16]$} \\
{$[h 4 e d 2=3]$} & -0.53 & $<.001$ & $<.001$ & 0.59 & {$[0.59,0.59]$} \\
{$[h 4 e d 2=4]$} & -0.35 & $<.001$ & $<.001$ & 0.7 & {$[0.7,0.7]$} \\
{$[h 4 e d 2=5]$} & -0.07 & $<.001$ & $<.001$ & 0.93 & {$[0.93,0.93]$} \\
{$[h 4 e d 2=6]$} & 1.38 & $<.001$ & $<.001$ & 4.0 & {$[4.0,4.0]$} \\
{$[h 4 e d 2=7]$} & 2.63 & $<.001$ & $<.001$ & 13.87 & {$[13.8713 .87]$} \\
{$[h 4 e d 2=8]$} & 3.16 & $<.001$ & $<.001$ & 23.57 & {$[23.57,23.57]$} \\
{$[h 4 e d 2=9]$} & 4.77 & $<.001$ & $<.001$ & 117.92 & {$[117.92,117.92]$} \\
{$[h 4 e d 2=10]$} & 5.65 & $<.001$ & $<.001$ & 284.29 & {$[284.29,284.29]$} \\
Age Centered (Age -16$)$ & 0.03 & $<.001$ & $<.001$ & 1.03 & {$[1.03,1.03]$} \\
Female & 0.46 & $<.001$ & $<.001$ & 1.58 & {$[1.58,1.58]$}
\end{tabular}

Race/Ethnicity (reference category 'White')

$\begin{array}{lccccc}\text { Hispanic } & -0.6 & <.001 & <.001 & 0.55 & {[0.55,0.55]} \\ \begin{array}{l}\text { Black or African } \\ \text { American }\end{array} & -0.51 & <.001 & <.001 & 0.6 & {[0.6,0.6]}\end{array}$


Table 4.8 (continued)

\begin{tabular}{|c|c|c|c|c|c|}
\hline Native American & -0.51 & $<.001$ & $<.001$ & 0.6 & {$[0.6,0.6]$} \\
\hline Asian or Pacific Islander & 0.58 & $<.001$ & $<.001$ & 1.79 & {$[1.79,1.79]$} \\
\hline $\begin{array}{l}\text { Identified with two or } \\
\text { more racial/ethnic } \\
\text { groups }\end{array}$ & 0.74 & .001 & $<.001$ & 2.1 & {$[2.1,2.1]$} \\
\hline \multicolumn{6}{|l|}{$\begin{array}{l}\text { Physical activity during } \\
\text { Adolescence (reference } \\
\text { category 'No physical } \\
\text { activity') }\end{array}$} \\
\hline Some physical activity & 0.43 & $<.001$ & $<.001$ & 1.54 & {$[1.54,1.54]$} \\
\hline $\begin{array}{l}\text { Physical activity at } \\
\text { CDC } \\
\text { recommended levels }\end{array}$ & 0.68 & $<.001$ & $<.001$ & 1.97 & {$[1.97,1.97]$} \\
\hline
\end{tabular}

In general, results showed higher physical activity levels during adolescence were associated with completing higher levels education at Wave IV ( h4ed2), being female was associated with increased $h 4 e d 2$, and ethnicity was related to $h 4 e d 2$. For instance, given that an adolescent was female vs. male, we expect a 0.46 ordered log odds of being in a higher level of $h 4 e d 2$, after holding constant (at zero) all other predictors in the model. If we take the exponential of the coefficient, we can get the proportional odds ratios, which suggests that being a female vs. male, the odds of reporting the highest category $h 4 e d 2$ vs. the combined other 4 categories is 1.58 times greater, given all other variables in the model are held constant. Since this odds ratio is greater than one, it indicates that being female is related to increased odds of attaining a higher level of education at Wave IV. Also, for each 1-unit increase in age we can expect a 0.03 ordered $\log$ odds of being in a higher level of $h 3 e d 1$, after holding constant (at zero) all other 
predictors in the model. Given an increase in age of 1 year, the odds of being in a higher $h 3 e d 1$ category rather than a lower category are 1.03 , given all other variables in the model are held constant. Ethnicity was also related to educational attainment. Given that an adolescent identified as Asian or Pacific Islander vs. White, we expect a 0.58 ordered $\log$ odds of being in a higher level of $h 4 e d 2$, after holding constant (at zero) all other predictors in the model. Given identification as Asian or Pacific Islander, the odds of being in a higher $h 4 e d 2$ category rather than a lower category are 1.79 , given all other variables in the model are held constant. Additionally, given that an adolescent identified as Multiracial vs. White, we expect a 0.74 ordered log odds of being in a higher level of $h 4 e d 2$, after holding constant (at zero) all other predictors in the model. Given identification as Multiracial, the odds of being in a higher $h 4 e d 2$ category rather than a lower category are 2.1, given all other variables in the model are held constant. These odds ratios are greater than one, indicating identification as Asian or Pacific Islander vs. White is related to increased odds of attaining a higher level of education at Wave IV. On the other hand, given that an adolescent identified as Hispanic vs. White, we expect a -0.6 ordered log odds of being in a higher level of $h 4 e d 2$, after holding constant (at zero) all other predictors in the model. Given identification as Hispanic, the odds of being in a higher $h 4 e d 2$ category rather than a lower category are 0.55 , given all other variables in the model are held constant. Similarly, given that an adolescent identified as Black or African American vs. White, we expect a -0.51 ordered log odds of being in a higher level of $h 4 e d 2$, after holding constant (at zero) all other predictors in the model. Given identification as Black or African American, the odds of being in a higher $h 4 e d 2$ category rather than a lower category are 0.6 , given all other variables in the model are held 
constant. Additionally, given that an adolescent identified as Native American vs. White, we expect a -0.51 ordered log odds of being in a higher level of $h 4 e d 2$, after holding constant (at zero) all other predictors in the model. Given identification as Native American, the odds of being in a higher $h 4 e d 2$ category rather than a lower category are 0.6 , given all other variables in the model are held constant. Since these odds ratios are less than one, it indicates identification as Hispanic, Black or African American, or Native American vs. White is related to decreased odds of attaining a higher level of education at Wave IV.

As hypothesized, physical activity during adolescence was positively related with higher levels of attained education. Specifically, results showed increased PACategories1 was associated with increased $h 4 e d 2$. That is, going from no physical activity to some physical activity, we can expect a 0.43 ordered log odds of being in a higher level of $h 4 e d 2$, after holding constant (at zero) all other predictors in the model. Moreover, the odds of being in a higher $h 4 e d 2$ category rather than a lower category are 1.54 , given all other variables in the model are held constant. Since this odds ratio is greater than one, it indicates participation in some physical activity rather than no physical activity at Wave I is related to increased odds of attaining a higher level of education at Wave IV. Additionally, for going from no physical activity to physical activity at CDC recommended levels, we can expect a 0.68 ordered log odds of being in a higher level of $h 4 e d 2$, after holding constant (at zero) all other predictors in the model. So, the odds of being in a higher $h 4 e d 2$ category rather than a lower category are 1.97 , given all other variables in the model are held constant. This odds ratio is also greater than one, indicating participation in physical activity at CDC recommended levels during 
Wave I is also related to increased odds of attaining a higher level of education at Wave IV. Finally, a Spearman's Rank Order correlation was also run to determine the strength of the bivariate relationship between physical activity at Wave I and level of attained education at Wave IV. There was a small positive correlation between physical activity and attained education, which was statistically significant, $r_{s}=.051, p<.001$.

Copyright (C) Frances Jillian Priesmeyer 2014 


\section{Chapter Five: Discussion}

The final section discusses the implications of the results and links them to previous literature. The results are summarized and discussed by research question. Additionally, the research contributions of the current study as well as its limitations are also summarized and discussed.

\section{Research Question One}

A growth curve analysis was conducted in order to determine the growth of physical activity over time. The correlation between the age variable and the intercept at time 0 (mean age -16 years old) was positive but weak $(r=.26)$, indicating that adolescents who reported some physical activity initially experienced slightly more growth in the amount of physical activity over time than those who reported no physical activity initially. The weak positive correlation is a common growth curve analysis result with large data sets when the time 0 intercept is set around a mean. Considering this, the positive correlation may be only slightly meaningful in this scenario. However, these results do not fully align with the hypothesis that reported levels of physical activity at Wave I would be strongly positively correlated with the reported levels of physical activity at Waves II, III, and IV. The correlation was weaker than what was expected given prior research in this area that shows a more consistent relationship across time for habitual physical activity (Gardner, de Bruijn, \& Lally, 2011; Hallal et al., 2006; Lally, Wardle, \& Gardner 2011; Rhodes, de Bruijn, \& Matheson, 2010).

Additionally, results of the growth curve analysis indicated that several demographic variables impacted growth in participation in physical activity. For instance, males were $65 \%$ more likely than females to report participation in at least some 
physical activity. This could be explained by males being more likely to engage in physically active hobbies, more likely to join sports teams, or more likely to view physical activity as a desirable pass time and inflate self-reports of how much time spent being physically active. Previous studies have also found males to be more physically active than females (Goodwin, 2006; Wiles et al., 2008). Additionally, as an adolescent's age increased, there was an $8 \%$ reduction in the odds of reporting physical activity. This interaction could be explained by the fact that, as adolescents age and turn into young adults, they typically take on greater responsibilities (i.e., increased amounts of school work, jobs, family responsibilities) as well as have increased access to forms of sedentary entertainment (i.e., less regulated access to TV, video games, and internet). Previous studies have also found that as the age of children and adolescents increase, levels of physical activity decrease (Downs \& Ashton, 2010; VanDusen et al., 2011). Finally, the odds of reporting participation in physical activity changed slightly based on ethnicity. Individuals who identified as Native American were more likely to report physical activity than individuals who identified as White, Hispanic, Black or African American, Asian or Pacific Islander, or Multiracial. Individuals who identified as White or Asian or Pacific Islander were more likely to report physical activity than individuals who identified as Black or African American. However, these differences were small and likely statistically negligible. Demographic differences in physical activity participation are supported by previous research (Basch, 2011a; Desha et al., 2007; Eugeni, Baxter, Mama, \& Lee, 2011; Fox et al., 2010; Goodwin, 2006; Hanson \& Kraus, 1998; Hollar et al., 2010; Lagerberg, 2005; Pate, Health, Dowda, \& Trost, 1996; Stevens et al., 2010; Taliaferro, Rienzo, \& Donovan, 2010; VanDusen et al., 2011; Videon, 2002; Wiles et al., 
2008; Yu, Chan, Cheng, Sung, \& Hau, 2006) and it is somewhat surprising that larger interactions between ethnicity and physical activity were not found in the current study.

\section{Research Question Two}

It was determined through ordinal linear regression that higher reported levels of physical activity during Wave I was associated with higher desires to go to college during Waves I and II, as well as higher reported likelihood of attending college during Waves I and II. The odds that an individual endorsed a level 5 (highest) versus a level 1 (lowest) on desire to attend college and likelihood of attending college increased as the amount of physical activity they engaged in during Wave I increased. These results align well with the hypothesis that higher levels of reported physical activity during Wave I would be associated with higher desires to go to college and higher likelihood of attending college during Waves I and II.

Higher levels of physical activity at Wave I was associated with higher desire to go to college at Waves I and II and higher reported likelihood of attending college at Waves I and II. This result could be explained by several factors. First, past research has indicated that increased levels of physical activity are associated with higher academic performance (Fedewa \& Ahn, 2011; Stevens et al., 2010; Raspberry et al., 2011;

VanDusen et al. 2011). Increased levels of physical activity have been associated with higher levels of academic performance for several reasons. On a biological level, there is research indicating that exercise increases levels of Brain-derived neurotrophic factor (BDNF), a family of proteins that build and maintain the neural cell circuitry in the brain (Ratey, 2008). BNDF is critical for learning, so adolescents with higher levels of BDNF would likely have an increased potential for learning and retaining academic material, 
leading to higher academic achievement. It would stand to reason that individuals with higher academic achievement during adolescence would be more likely to be placed in college prepatory classes, be encouraged by adults to pursue college, have a greater desire to continue academic studies, and receive more academic scholarship activities.

Additionally, past studies have indicated that increased levels of sports participation leads to higher academic performance (Fox et al., 2010). On a social level, sports participation may be beneficial for adolescents not only for the physical activity but also for the team building and positive social interaction sports offer. Playing sports may make an adolescent feel more connected to her school, motivate her to maintain certain academic standards, and introduce her to a goal oriented group of peers (Fox et al., 2010). These social factors could contribute to the reason why adolescents with higher levels of reported physical activity also reported higher levels of desire to go to college and higher likelihood of attending college.

On an emotional level, several studies have investigated the relationship between participation in physical activity and symptoms of depression and anxiety and determined that an increased level of physical activity is correlated with decreased levels of anxiety and depression (Parfitt \& Eston, 2005; Sagatun et al., 2007; Wiles et al., 2008). It can be very difficult for adolescents who are struggling with anxiety or depression to be emotionally available to learn. It stands to reason that if physical activity helps to lower symptoms of anxiety and depression, it would make it easier for adolescents who struggle with emotional disorders to engage in and focus on academic tasks. Once they are more available for learning, they will likely experience an increase in academic success. As stated earlier, it stands to reason that adolescents who experience higher levels of 
academic success will be more likely to be placed in college prepatory classes, be encouraged by adults to pursue college, and receive more academic scholarship activities. Thus, they are more likely to indicate a greater desire and a higher likelihood of obtaining post-secondary education.

On the other hand, it could be that there is a common-causal variable, such as parent expectations, parent education, or availability of opportunities to engage in extracurricular activities. In this scenario, the common-causal environmental factor variable could simultaneously impact both levels of physical activity participation and reported desire to go to college.

\section{Research Question Three}

It was determined through ordinal linear regression that reporting CDC recommended levels of physical activity during Wave I was associated with higher levels of completed higher education by both Wave III and Wave IV. The association was stronger during Wave III than it was during Wave IV. The odds that an individual obtained a higher level of education by Waves III or IV increased as the amount of physical activity they engaged in during Wave I increased. Those who engaged in CDC recommended levels of physical activity vs. no physical activity had higher odds of obtaining more post-secondary education than those who engaged in some physical activity vs. no physical activity.

Similar to the results from the second research question, these results could also be explained by the previously mentioned studies indicating that both physical activity and sports participation lead to higher academic achievement (Fedewa \& Ahn, 2011; Fox et al., 2010; Stevens et al., 2010; Raspberry et al., 2011; VanDusen et al., 2011). On 
biological, social, and emotional levels, physical activity can help improve academic performance (Fox et al., 2010; Parfitt \& Eston, 2005; Ratey, 2008; Sagatun et al., 2007; Wiles et al., 2008). It would be reasonable to expect adolescents with higher levels of academic achievement to be more likely to pursue and complete more years of higher education. The findings of the current study support the findings of earlier research stating adolescents who engage in higher levels of physical activity are also more academically successful (Fedewa \& Ahn, 2011; Stevens et al., 2010; Raspberry et al., 2011; VanDusen et al., 2011). Again, it is likely that adolescents with higher levels of academic performance will be more likely to complete advanced post-secondary education. The correlation found in the current study between physical activity during adolescence and educational attainment by young adulthood suggests that the benefits of physical activity are not short term. Adolescents who are physically active do experience the short-term benefit of increased levels of academic success (Fedewa \& Ahn, 2011; Fox et al., 2010; Stevens et al., 2010; Raspberry et al., 2011; VanDusen, et al., 2011), but arguably it is the long term impact of this academic success that is the most beneficial for the individual. In the long-term, higher levels of academic success can lead to more years of completed post-secondary education, higher likelihood of obtaining a career of choice, and higher income.

Previous research was focused on the immediate links between physical activity and behavior, mental health, and academic achievement during childhood and adolescence. Few previous studies addressed the longitudinal educational impacts of physical activity during adolescence. The notable exceptions were two studies conducted in the 1970's (Otto \& Alwin, 1977; Picou, 1978). The findings of the current study 
indicated that higher levels of physical activity in adolescence is weakly to negligibly associated with higher academic achievement goals and higher levels of educational attainment by young adulthood. The findings of the current study slightly diverge from the earlier studies of physical activity and educational attainment. Otto and Alwin (1977) and Picou (1978) found that participation in athletics was moderately positively correlated with occupational aspiration, educational ambition, and educational attainment, particularly for Caucasian males. The current findings indicated the positive correlations between reported physical activity and educational ambition and educational attainment were only weak to negligible positive correlations. The difference could be explained by several factors. In their studies, Otto and Alwin (1977) and Picou (1978) defined physical activity as participation in athletics. It is possible that serious participation in an athletic sport led some participants in those studies to pursue higher education for athletics related purposes. On the other hand, in the current study, physical activity is defined as reporting engaging in moderate to vigorous movement activities. While participation in traditional sports such as basketball, soccer, and football certainly counted, so did participation in activities such as bowling, rollerblading, jogging, and aerobics. Broadening the category of physical activity participation to include many more people than just serious athletes may have weakened the correlation. Also, the rates of college completion in the United States rose steadily between the years of 1950, when $6.2 \%$ of the U.S. population had bachelor's degrees, and 2000 , when $24.4 \%$ of the U.S. population had bachelor's degrees (Bureau of the Census, 1957; U.S. Census Bureau, 2000). Each of the three studies being compared used educational ambition and attainment data gathered at different points during this 50 year time period. Otto and 
Alwin (1977) used data gathered in 1957, Picou (1978) used data gathered in 1970, and the current study used data gathered between 1994 and 2008. Society's changing expectations of the amount of education the typical individual should acquire could also contribute to the weakened correlation. In the culture of today's society vs. the culture of society between 1957 and 1970, it is more likely that a larger number of individuals, regardless of levels of physical activity or sports participation, will desire or complete post-secondary education.

Additionally, the current study included individuals of many races and both genders while the previous studies examined only Caucasian and African-American males. Race and gender are demographic variables known to influence levels of both physical activity and educational attainment (Bureau of the Census, 1957; U.S. Census Bureau, 2000). Males are more likely than females to be involved in higher levels of physical activity (Wiles et al., 2008). Caucasian individuals are more likely than AfricanAmerican or Hispanic individuals to be involved in higher levels of physical activity (Taliaferro, Rienzo, \& Donovan, 2010). When the data for the earlier studies was gathered in 1957 and 1970, males were also more likely to complete higher levels of education. In 1957, 13.7\% of males between the ages of 25-34 had a Bachelor's degree, while only $6.6 \%$ of women in the same age range had a Bachelor's degree (Bureau of the Census, 1957). However, this gender gap began rapidly closing between the years of 1950 and 2000. By the time the data for the current study was collected between 1994 and 2008, females were more likely than males to enroll in college (U.S. Department of Education, 2012). In 2000, 26.1\% of U.S. males (of all ages) had a Bachelor's degree, while $22.8 \%$ of U.S. females had a Bachelor's degree (U.S. Census Bureau, 2000). Race 
also influences educational attainment. In 1957, 10.1\% of "white" males over age 25 had completed at least four years of college, while only $2.6 \%$ of "non-white" males over age 25 had completed the same amount of education (Bureau of the Census, 1957).

Similarly, in the same year $6.0 \%$ of "white" females over age 25 had completed at least four years of college, while $2.9 \%$ of "non-white" females of the same age had completed the same amount of education (Bureau of the Census, 1957). When the data for the current study was gathered, race was still a factor influencing educational attainment. In $2000,44.1 \%$ of Asian-American, $27.0 \%$ of Caucasian, $14.3 \%$ of African-American, $11.5 \%$ of American Indian, and 10.4\% of Hispanic people over age 25 had completed Bachelor's degrees (U.S. Census Bureau, 2000). By including a more representative sample of the population, the current study is impacted more by potentially confounding and moderating demographic variables than the previous studies. Finally, while the correlation found between physical activity and educational attainment in the current study was weaker than the correlations found in the previous studies, it is likely a more accurate representation of the actual correlation in the general population.

\section{Limitations}

The current study has several limitations. The survey from the longitudinal data set was designed in such a way that the questions regarding physical activity changed slightly at each wave of data collection. The response options also changed at each wave making a secondary collapsing of data necessary. Due to this instrumentation difficulty, no core set of items was measurable across time. Although attempts were made to create and measure the same construct over time, complete equity was not possible. As a result, the internal validity of the current study is weakened. Specifically, the internal validity of 
research question one was threatened by not being able to use the same survey items across times.

Additionally, construct validity is threatened in research questions two and three because single item questions were used to measure educational ambition and educational attainment outcomes. When a single item is used is used to measure constructs, particularly higher-order constructs such as educational ambition, it is likely that the item is too narrow to completely account for every facet of the construct. It is likely that not every aspect of educational ambition and educational attainment was measured by the single items chosen to represent these constructs. As a result, the construct validity of the current study is weakened. The use of single items as outcome measures may also impact statistical conclusion validity. The reduced reliability of single items as outcome measures lowers the powers and effect sizes of statistical outcomes.

Also, the longitudinal nature of the survey resulted in significant amounts of missing data, particularly at later Waves after participants had dropped out. As a result, once the data set was treated for missing data each analysis had a different number of participants. Therefore, the results of each analysis conducted in this study can only be applied to the particular group of individuals captured in that analysis. This also may weaken the validity of the current study and makes it less applicable to the population as a whole. Another threat to the validity of the current study is that the data set used is very large and therefore is susceptible to producing results that are statistically significant, yet have little to no meaning. With large data sets, the risk for false positive results rises and it is important to keep this in mind when interpreting the results of this study. In future studies using the Add Health data set, particularly in a longitudinal capacity, it may be 
beneficial to run analyses through software that has more advanced capabilities of correcting for sampling errors and handling large amounts of data while keeping standard errors and significance levels accurate.

Related to the large sample size, it should be noted that data weights were used in these analyses in order to make the survey sample more nationally representative of adolescents enrolled in secondary school at the time the data was collected. However, the weights further inflated the sample size and resulted in standard errors and significance levels that were misleadingly small. An alternative would have been to not use weights and interpret the results as results representing only the individuals who participated in the survey and not as nationally representative. If this had been done, the specific demographics that were related to adolescents being more likely to be selected for the study, such as being from a high SES African-American household, would need to be carefully examined and discussed (Chantala, 2006; Johnson, 2008; Maletta, 2007; Treiman, 2009). Another alternative would have been to use different software for the statistical analyses such as STATA, which is more advanced than SPSS in the way it adjusts for clustering and uses weights to compute standard errors (Chantala, 2006; Johnson, 2008; Maletta, 2007; Treiman, 2009).

Additionally, demographic data on the ethnicity of participants was collected in such a way that it is likely many participants were unsure which group to identify with. The choices included broad categories such as 'White,' 'Hispanic,' 'Black or African American,' 'Native American,' and 'Asian or Pacific Islander.' These categories do not take into consideration that some individuals identify most strongly with a group based on physical appearance, while others identify with a group based on a shared culture. For 
example, individuals who identified as 'Hispanic' or 'Asian or Pacific Islander' based on culture or heritage could also have identified as 'White' or 'Black' based on skin color. Participants were allowed to identify with more than one category, which is a design strength. Due to the small number of individuals who identified with more than one category, they were grouped together into one 'Multiracial' category for the purposes of this analysis. As a result, there are a variety of differences among and between the individuals within the 'Multiracial' group that the current analyses were not able to capture.

Finally, the way physical activity was measured in the Add Health data set created some obstacles. The constructs of physical activity and participation in group sports were not separated in the survey questions surrounding physical activity. Previous literature has identified both physical activity and sports team participation as two separate factors that impact social, behavioral, and academic success during adolescence. Due to the fact that the longitudinal data set used in the current study did not differentiate between these two constructs, it is unclear which of these factors contributed most significantly to the results of this study. Also, the only measure of physical activity participation in the current study was through self-report. It has been demonstrated through previous research that the most accurate way to determine levels of physical activity participation is with biofeedback devices such as heart rate monitors and pedometers. Therefore, the current study may be suffering from response bias errors that commonly result from selfreport survey data due to the perceived social desirability of physical activity participation. 


\section{Conclusion}

Overall, the findings of the current study imply that physical activity during adolescence may have more than just short term benefits. In fact, higher levels of participation in physical activity during adolescence might contribute to continued higher levels of physical activity, increased levels of educational ambition, and higher levels of academic attainment through young adulthood. This adds to the growing body of literature that indicates physical activity is a critical piece of development that contributes to physical, emotional, and academic well-being. This information should be taken into consideration by individuals who develop educational and community programs for children. Providing opportunities for children and adolescents to participate in and learn about physical activity should be viewed as a necessity, rather than as an option. According to current research, if communities and educational systems increase the amount of physical activity their youth engage in, they will be contributing to the creation of a generation of individuals who are more physically fit throughout life, are more emotionally healthy, and have better academic outcomes in both the short and long term. Encouraging physical fitness in youth can be an important preventative measure schools and communities can take to ensure a healthy and successful future generation.

It is also important that research of the benefits of physical activity during youth continues. Additional studies that focus on the long term impacts of physical activity should be conducted. Future studies could continue to explore the long term academic impacts of physical activity or explore the potential long term behavioral and emotional impacts of physical activity. Studies with randomized controlled clinical trials or case controls are also needed in order to further strengthen the known relationship between 
physical activity and academic outcomes. Additionally, future studies should be designed with the specific needs of accurately measuring physical activity in mind. In addition to self-report questionnaires, biofeedback devices such as pedometers, heart rate monitors, and accelerometers should be used. When self-report questionnaires are used longitudinally, they should be designed to ask identical questions at each point of data collection.

Copyright (C) Frances Jillian Priesmeyer 2014 


\section{Appendix A}

\section{Wave I Physical Activity Items}

During the past week, how many times did you go roller-blading, roller-skating, skateboarding, or bicycling?

\begin{tabular}{l|l}
\hline 0 & Not at all \\
\hline 1 & 1 or 2 times \\
\hline 2 & 3 or 4 times \\
\hline 3 & 5 or more times \\
\hline 6 & Refused \\
\hline 8 & Don't Know \\
\hline
\end{tabular}

During the past week, how many times did you play an active sport, such as baseball, softball, basketball, soccer, swimming, or football?

\begin{tabular}{l|l}
\hline 0 & Not at all \\
\hline 1 & 1 or 2 times \\
\hline 2 & 3 or 4 times \\
\hline 3 & 5 or more times \\
\hline 6 & Refused \\
\hline 8 & Don't Know \\
\hline
\end{tabular}

During the past week, how many times did you do exercise, such as jogging, walking, karate, jumping rope, gymnastics, or dancing?

\begin{tabular}{l|l}
\hline 0 & Not at all \\
\hline 1 & 1 or 2 times \\
\hline 2 & 3 or 4 times \\
\hline 3 & 5 or more times \\
\hline 6 & Refused \\
\hline 8 & Don't Know \\
\hline
\end{tabular}




\section{Appendix B}

Wave II Physical Activity Items

During the past week, how many times did you go roller-blading, roller-skating, skateboarding, or bicycling?

\begin{tabular}{l|l}
\hline 0 & Not at all \\
\hline 1 & 1 or 2 times \\
\hline 2 & 3 or 4 times \\
\hline 3 & 5 or more times \\
\hline 6 & Refused \\
\hline 8 & Don't Know \\
\hline
\end{tabular}

During the past week, how many times did you play an active sport, such as baseball, softball, basketball, soccer, swimming, or football?

\begin{tabular}{l|l}
\hline 0 & Not at all \\
\hline 1 & 1 or 2 times \\
\hline 2 & 3 or 4 times \\
\hline 3 & 5 or more times \\
\hline 6 & Refused \\
\hline 8 & Don't Know \\
\hline
\end{tabular}

During the past week, how many times did you do exercise, such as jogging, walking, karate, jumping rope, gymnastics, or dancing?

\begin{tabular}{l|l}
\hline 0 & Not at all \\
\hline 1 & 1 or 2 times \\
\hline 2 & 3 or 4 times \\
\hline 3 & 5 or more times \\
\hline 6 & Refused \\
\hline 8 & Don't Know \\
\hline
\end{tabular}




\section{Appendix C}

Wave III Physical Activity Items

In the past seven days, how many times did you bicycle, skateboard, dance, hike, hunt, or do yard work?

\begin{tabular}{l|l}
\hline 0 & Not at all \\
\hline 1 & 1 times \\
\hline 2 & 2 times \\
\hline 3 & 3 times \\
\hline 4 & 4 times \\
\hline 5 & 5 times \\
\hline 6 & 6 times \\
\hline 7 & 7 or more times \\
\hline 96 & Refused \\
\hline 98 & Don't Know \\
\hline
\end{tabular}

In the past seven days, how many times did you roller blade, roller skate, downhill snow ski, snow board, play racquet ball sports, or do aerobics?

\begin{tabular}{l|l}
\hline 0 & Not at all \\
\hline 1 & 1 times \\
\hline 2 & 2 times \\
\hline 3 & 3 times \\
\hline 4 & 4 times \\
\hline 5 & 5 times \\
\hline 6 & 6 times \\
\hline 7 & 7 or more times \\
\hline 96 & Refused \\
\hline
\end{tabular}




\begin{tabular}{l|l}
\hline 98 & Don't Know \\
\hline $\begin{array}{l}\text { In the past seven days, how many times did you participate in strenuous team sports, such } \\
\text { as football, soccer, basketball, lacrosse, rugby, field hockey, or ice hockey? }\end{array}$ \\
\hline 0 & Not at all \\
\hline 1 & 1 time \\
\hline 2 & 2 times \\
\hline 3 & 3 times \\
\hline 4 & 4 times \\
\hline 5 & 5 times \\
\hline 6 & 6 times \\
\hline 7 & 7 or more times \\
\hline 96 & Refused \\
\hline
\end{tabular}

In the past 7 days, how many times did you participate in individual sports such as running, wrestling, swimming, cross-country skiing, cycle racing, or martial arts?

\begin{tabular}{l|l}
\hline 0 & Not at all \\
\hline 1 & 1 time \\
\hline 2 & 2 times \\
\hline 3 & 3 times \\
\hline 4 & 4 times \\
\hline 5 & 5 times \\
\hline 6 & 6 times \\
\hline 7 & 7 times \\
\hline 96 & Refused \\
\hline 98 & Don't Know \\
\hline
\end{tabular}


In the past seven days, how many times did you participate in gymnastics, weight lifting, or strength training?

\begin{tabular}{l|l}
\hline 0 & Not at all \\
\hline 1 & 1 times \\
\hline 2 & 2 times \\
\hline 3 & 3 times \\
\hline 4 & 4 times \\
\hline 5 & 5 times \\
\hline 6 & 6 times \\
\hline 7 & 7 or more times \\
\hline 96 & Refused \\
\hline 98 & Don't Know \\
\hline
\end{tabular}

In the past seven days, how many times did you play golf, go fishing or bowling, or play softball or baseball?

\begin{tabular}{l|l}
\hline 0 & Not at all \\
\hline 1 & 1 times \\
\hline 2 & 2 times \\
\hline 3 & 3 times \\
\hline 4 & 4 times \\
\hline 5 & 5 times \\
\hline 6 & 6 times \\
\hline 7 & 7 or more times \\
\hline 96 & Refused \\
\hline 98 & Don't Know \\
\hline
\end{tabular}

In the past seven days, how many times did you walk for exercise? 


\begin{tabular}{l|l}
\hline 0 & Not at all \\
\hline 1 & 1 times \\
\hline 2 & 2 times \\
\hline 3 & 3 times \\
\hline 4 & 4 times \\
\hline 5 & 5 times \\
\hline 6 & 6 times \\
\hline 7 & 7 or more times \\
\hline 96 & Refused \\
\hline 98 & Don't Know \\
\hline
\end{tabular}




\section{Appendix D}

Wave IV Physical Activity Items

In the past seven days, how many times did you bicycle, skateboard, dance, hike, hunt, or do yard work?

\begin{tabular}{l|l}
\hline 0 & Not at all \\
\hline 1 & 1 times \\
\hline 2 & 2 times \\
\hline 3 & 3 times \\
\hline 4 & 4 times \\
\hline 5 & 5 times \\
\hline 6 & 6 times \\
\hline 7 & 7 or more times \\
\hline 96 & Refused \\
\hline 98 & Don't Know \\
\hline
\end{tabular}

In the past seven days, how many times did you roller blade, roller skate, downhill snow ski, snow board, play racquet ball sports, or do aerobics?

\begin{tabular}{l|l}
\hline 0 & Not at all \\
\hline 1 & 1 times \\
\hline 2 & 2 times \\
\hline 3 & 3 times \\
\hline 4 & 4 times \\
\hline 5 & 5 times \\
\hline 6 & 6 times \\
\hline 7 & 7 or more times \\
\hline 96 & Refused \\
\hline
\end{tabular}




\begin{tabular}{l|l}
\hline 98 & Don't Know \\
\hline $\begin{array}{l}\text { In the past seven days, how many times did you participate in strenuous team sports, such } \\
\text { as football, soccer, basketball, lacrosse, rugby, field hockey, or ice hockey? }\end{array}$ \\
\hline 0 & Not at all \\
\hline 1 & 1 time \\
\hline 2 & 2 times \\
\hline 3 & 3 times \\
\hline 4 & 4 times \\
\hline 5 & 5 times \\
\hline 6 & 6 times \\
\hline 7 & 7 or more times \\
\hline 96 & Refused \\
\hline
\end{tabular}

In the past 7 days, how many times did you participate in individual sports such as running, wrestling, swimming, cross-country skiing, cycle racing, or martial arts?

\begin{tabular}{l|l}
\hline 0 & Not at all \\
\hline 1 & 1 time \\
\hline 2 & 2 times \\
\hline 3 & 3 times \\
\hline 4 & 4 times \\
\hline 5 & 5 times \\
\hline 6 & 6 times \\
\hline 7 & 7 times \\
\hline 96 & Refused \\
\hline 98 & Don't Know \\
\hline
\end{tabular}


In the past seven days, how many times did you participate in gymnastics, weight lifting, or strength training?

\begin{tabular}{l|l}
\hline 0 & Not at all \\
\hline 1 & 1 times \\
\hline 2 & 2 times \\
\hline 3 & 3 times \\
\hline 4 & 4 times \\
\hline 5 & 5 times \\
\hline 6 & 6 times \\
\hline 7 & 7 or more times \\
\hline 96 & Refused \\
\hline 98 & Don't Know \\
\hline
\end{tabular}

In the past seven days, how many times did you play golf, go fishing or bowling, or play softball or baseball?

\begin{tabular}{l|l}
\hline 0 & Not at all \\
\hline 1 & 1 times \\
\hline 2 & 2 times \\
\hline 3 & 3 times \\
\hline 4 & 4 times \\
\hline 5 & 5 times \\
\hline 6 & 6 times \\
\hline 7 & 7 or more times \\
\hline 96 & Refused \\
\hline 98 & Don't Know \\
\hline
\end{tabular}

In the past seven days, how many times did you walk for exercise? 


\begin{tabular}{l|l}
\hline 0 & Not at all \\
\hline 1 & 1 times \\
\hline 2 & 2 times \\
\hline 3 & 3 times \\
\hline 4 & 4 times \\
\hline 5 & 5 times \\
\hline 6 & 6 times \\
\hline 7 & 7 or more times \\
\hline 96 & Refused \\
\hline 98 & Don't Know \\
\hline
\end{tabular}




\section{Appendix E}

\section{Wave I Educational Ambition Questions}

On a scale of 1 to 5 , where 1 is low and 5 is high, how much do you want to go to college?

\begin{tabular}{l|l}
\hline 1 & 1 \\
\hline 2 & 2 \\
\hline 3 & 3 \\
\hline 4 & 4 \\
\hline 5 & 5 \\
\hline 6 & Refused \\
\hline 8 & Don't Know \\
\hline
\end{tabular}

On a scale of 1 to 5 , where 1 is low and 5 is high, how likely is it that you will go to college?

\begin{tabular}{l|l}
\hline 1 & 1 \\
\hline 2 & 2 \\
\hline 3 & 3 \\
\hline 4 & 4 \\
\hline 5 & 5 \\
\hline 6 & Refused \\
\hline 8 & Don't Know \\
\hline
\end{tabular}




\section{Appendix F}

\section{Wave II Educational Ambition Questions}

On a scale of 1 to 5 , where 1 is low and 5 is high, how much do you want to go to college?

\begin{tabular}{l|l}
\hline 1 & 1 \\
\hline 2 & 2 \\
\hline 3 & 3 \\
\hline 4 & 4 \\
\hline 5 & 5 \\
\hline 6 & Refused \\
\hline 8 & Don't Know \\
\hline
\end{tabular}

On a scale of 1 to 5 , where 1 is low and 5 is high, how likely is it that you will go to college?

\begin{tabular}{l|l}
\hline 1 & 1 \\
\hline 2 & 2 \\
\hline 3 & 3 \\
\hline 4 & 4 \\
\hline 5 & 5 \\
\hline 6 & Refused \\
\hline 8 & Don't Know \\
\hline
\end{tabular}




\section{Appendix G}

\section{Wave III Educational Attainment Questions}

What is the highest grade or year of regular school you completed?

\begin{tabular}{|c|c|}
\hline 6 & $6^{\text {th }}$ grade \\
\hline 7 & $7^{\text {th }}$ grade \\
\hline 8 & $8^{\text {th }}$ grade \\
\hline 9 & $9^{\text {th }}$ grade \\
\hline 10 & $10^{\text {th }}$ grade \\
\hline 11 & $11^{\text {th }}$ grade \\
\hline 12 & $12^{\text {th }}$ grade \\
\hline 13 & 1 year of college \\
\hline 14 & 2 years of college \\
\hline 15 & 3 years of college \\
\hline 16 & 4 years of college \\
\hline 17 & 5 or more years of college \\
\hline 18 & 1 year of graduate school \\
\hline 19 & 2 years of graduate school \\
\hline 20 & 3 years of graduate school \\
\hline 21 & 4 years of graduate school \\
\hline 22 & 5 or more years of graduate school \\
\hline 96 & Refused \\
\hline 98 & Don't Know \\
\hline 99 & Not Applicable \\
\hline
\end{tabular}




\section{Appendix $\mathbf{H}$}

Wave IV Educational Attainment Question

What is the highest level of education that you have achieved to date?

\begin{tabular}{|c|c|}
\hline 1 & $8^{\text {th }}$ grade or less \\
\hline 2 & Some high school \\
\hline 3 & High school graduate \\
\hline 4 & Some vocational or technical training after high school \\
\hline 5 & $\begin{array}{l}\text { Completed vocational or technical training after high } \\
\text { school }\end{array}$ \\
\hline 6 & Some college \\
\hline 7 & Completed college \\
\hline 8 & Some graduate school \\
\hline 9 & Completed a master's degree \\
\hline 10 & Some graduate training beyond a master's degree \\
\hline 11 & Completed a doctoral degree \\
\hline 12 & $\begin{array}{l}\text { Some post baccalaureate professional education (e.g., law } \\
\text { school, medical school, nurse) }\end{array}$ \\
\hline 13 & $\begin{array}{l}\text { Completed post baccalaureate professional education } \\
\text { (e.g., law school, medical school, nurse) }\end{array}$ \\
\hline 96 & Refused \\
\hline 98 & Don't Know \\
\hline
\end{tabular}




\section{References}

Ajzen, I. (1991). The theory of planned behavior. Organizational Behavior and Human Decision Processes, 50, 179-211. Retrieved from http://eds.a.ebscohost.com.ezproxy.uky.edu/

Barros, R.M., Silver, E.J., \& Stein, R.E.K. (2009). School recess and group classroom behavior. Pediatrics, 123(2), 431-436. doi: 10.1542/peds.2007-2825

Basch, C.E. (2011a). Healthier students are better learners: A missing link in school reforms to close the achievement gap. Journal of School Health, 81(10), 593-598. doi: 10.1111/j.1746-1561.2011.00640.x

Basch, C.E. (2011b). Physical activity and the achievement gap among urban minority youth. Journal of School Health, 81(10), 626-634. doi: 10.1111/j.17461561.2011.00637.x

Bearman, P., Jones, J., \& Udry, J.R. (1997). The National Longitudinal Study of Adolescent Health: Research Design. Chapel Hill, NC: Carolina Population Center. Available at http://www.cpc.unc.edu/projects/addhealth/design.html

Boone-Heinonen, J., Evenson, K.R., Song, Y., \& Gordon-Larsen, P. (2010). Built and socioeconomic environments: patterning and associations with physical activity in US adolescents. International Journal of Behavioral Nutrition \& Physical Activity, 7, 45-60. doi: 10.1186/1479-5868-7-45

Boone-Heinonen, J. \& Gordon-Larsen, P. (2012). Obesogenic environments in youth: concepts and methods from a longitudinal national sample. American Journal of Preventive Medicine, 42(5), 37-46. doi: 10.1016/j.amepre.2012.02.005 
Boone-Heinonen, J., Guilkey, D.K., Evenson, K.R., \& Gordon-Larsen, P. (2010).

Residential self-selection bias in the estimation of built environment effects on physical activity between adolescence and young adulthood. International Journal of Behavioral Nutrition \& Physical Activity, 7, 70-80. doi:

$10.1186 / 1479-5868-7-70$

Bureau of the Census. (1957). Educational attainment: March 1957. Current Population Reports: Population Characteristics, Series P-20, No. 77. Accessed March 1, 2014. Available at $<$ http://www.census.gov/hhes/socdemo/education/data/cps/1957/p20-77.pdf $>$

Centers for Disease Control and Prevention. (2011). Accessed November 26, 2011. Available at $<$ http://www.cdc.gov/healthyyouth/obesity/facts.htm>

Chantala, K. (2006). Guidelines for Analyzing Add Health Data. Carolina Population Center: University of North Carolina at Chapel Hill. Accessed July 1, 2012. Available at $<$ http://www.cpc.unc.edu/projects/addhealth/data/guides/wtguidelines.pdf $>$

Chomitz, V.R., Slining, M.M., McGowan, R.J., Mitchell, S.E., Dawson, G.F., \& Hacker, K.A. (2009). Is there a relationship between physical fitness and academic achievement? Positive results from public school children in the Northeastern United States. Journal of School Health, 79(1), 30-37. doi: 10.1111/j.17461561.2008.00371.x

Coe, D.P., Pivarnik, J.M., Womack, C.J., Reeves, M.J. \& Malina, R.M. (2006). Effect of physical education and activity levels on academic achievement in children. 
Medicine \& Science in Sports \& Exercise, 38(8), 1515-1519. doi:

10.1249/01.mss.0000227537.13175.lb

Cohen, D.A., Taylor, S.L., Zonta, M., Vestal, K.D., \& Schuster, M.A. (2007). Availability of high school extracurricular sports programs and high-risk behaviors. Journal of School Health, 77(2), 80-86. doi: 10.1111/j.17461561.2007.00171.x

Desha, L.N., Ziviani, J.M., Nicholson, J.M., Martin, G., \& Darnell, R.E. (2007). Physical activity and depressive symptoms in american adolescents. Journal of Sport \& Exercise Psychology, 29, 534-543. Retrieved from http://eds.a.ebscohost.com.ezproxy.uky.edu/

Doshi, A., Patrick, K., Sallis, J.F., \& Calfas, K. (2003). Evaluation of physical activity web sites for use of behavior change theories. Annals of Behavioral Medicine, 25(2), 105-112. Retrieved from http://eds.a.ebscohost.com.ezproxy.uky.edu/

Downs, A. \& Ashton, J. (2010). Vigorous physical activity, sports participation, and athletic identity: Implications for mental and physical health in college students. Journal of Sport Behavior, 34(3), 228-249. Retrieved from http://eds.a.ebscohost.com.ezproxy.uky.edu/

Dwyer, T., Coonan, W.E., Leitch, D.R., Hetzel, B.S., \& Baghurst, R.A. (1983). An investigation of the effects of daily physical activity on the health of primary school students. International Journal of Epidemiology, 12, 308-313. doi: $10.2337 / \mathrm{dc} 10-2386$

Dyck, D., Cardon, G., Deforche, B., Giles-Cortie, B., Sallis, J., Owen, N., \& Bourdeaudhuij, I. (2011). Environmental and psychosocial correlates of 
accelerometer-assessed and self-reported physical activity in Belgian adults. International Journal of Behavioral Medicine, 18(3), 235-245. doi: $10.1007 / \mathrm{s} 12529-010-9127-4$

Eugeni, M.L., Baxter, M., Mama, S.K., \& Lee R.E. (2011). Disconnections of African American public housing residents: Connections to physical activity, dietary habits, and obesity. American Journal of Community Psychology, 47, 264-276. doi: $10.1007 / \mathrm{s} 10464-010-9402-1$

Fedewa, A.L. \& Ahn, S. (2011). The effects of physical activity and physical fitness on children's achievement and cognitive outcomes: A meta-analysis. Research Quarterly for Exercise and Sport, 82(3), 521-535. Retrieved from http://eds.a.ebscohost.com.ezproxy.uky.edu/

Feldman A.F., \& Matjasko, J.L. (2005). The role of school-based extracurricular activities in adolescent development: A comprehensive review and future directions. Review of Educational Research, 75(2), 159-210. doi: 10.1016/j.dr.2011.10.001

Fishbein, M. (1973). The prediction of behavior from attitudinal variables. In C.D. Mortenson \& K.K. Sereno (Eds.), Advances in communication research (pp. 331). New York: Harper \& Row.

Fishbein, M. \& Ajzen, I. (1975). Belief, attitude, intention and behavior: An introduction to theory and research. Reading, MA: Addison-Wesley.

Fox, C.L., Barr-Anderson, D., Neumark-Sztainer, D., \& Wall, M. (2010). Physical activity and sports team participation: Associations with academic outcomes in 
middle school and high school students. Journal of School Health, 80(1), 31-37. doi: 10.1111/j.1746-1561.2009.00454.x

Gardner, B., de Bruijn, G.J., \& Lally, P. (2011). A systematic review and meta-analysis of applications of the self-report habit index to nutrition and physical activity behaviors. Annual Behavioral Medicine, 42, 174-187. doi: 10.1007/s12160-0119282-0

Goodwin, R.D. (2006). Association between coping with anger and feelings of depression among youths. American Journal of Public Health, 96(4), 664-669. doi: 10.2105/AJPH.

2004.049742

Gordon-Larsen, P., McMurray, R.G., \& Popkin, B.M. (1999). Adolescent physical activity an inactivity vary by ethnicity: The national longitudinal study of adolescent health. Journal of Pediatrics, 135, 301-306. Retrieved from: http://www.cpc.unc.edu/projects/nutrans/publications

Gordon-Larsen, P. McMurray, R.G., \& Popkin, B.M. (2000). Determinants of adolescent physical activity and inactivity patterns. Pediatrics, $105(6), 83$. Retrieved from http:/www.ncbi.nlm.nih.gov/pubmed/10835096

Gordon-Larsen, P. Nelson, J. \& Popkin, B.M. (2004). Longitudinal physical activity and sedentary behavior trends: adolescence to adulthood. American Journal of Preventive Medicine, 27(4), 277-283. doi: 10.1016/j.amepre.2004.07.006

Gorsuch, R. (1983). Factor Analysis. L.Erlbaum Associates: Hillsdale, NJ. ISBN: $089859202 X$ 
Graham, G. (2008). Children's and adults' perceptions of elementary school physical education. The Elementary School Journal, 108(3), 241-249. Retrieved from http://eds.a.ebscohost.com.ezproxy.uky.edu/

Guedes, C. (2007). Physical education and physical activity: A historical perspective. Journal of Physical Education, Recreation, \& Dance, 78(8), 31-48. Retrieved from http://eds.a.ebscohost.com.ezproxy.uky.edu/

Guo, G., North, K.E., Gordon-Larsen, P., Bulik, C.M., \& Choi, S. (2007). Body mass, the $D R D 4$ gene, physical activity, sedentary behavior, and family SES: the national longitudinal study of adolescent health. Obesity, 15(5), 1199-1206. Retrieved from http://www.unc.edu/ gguo/publications.html

Hagger, M.S, Chatzisarantis, N.L.D., \& Biddle, S.J.H. (2002). A meta-analytic review of the theories of resoned action and planned behavior in physical activity: Predictive validity and the contribution of additional variables. Journal of Sport \& Exercise Psychology, 24, 3-32. Retrieved from http://eds.a.ebscohost.com.ezproxy.uky.edu/

Hallal, P.C., Wells, J.C.K., Reichert, F.F., Anselmi, L. \& Victora C.G. (2006). Early determinants of physical activity in adolescence: Prospective birth cohort study. $B M J, 7,1-6$. doi: 10.1136/bmj.38776.434560.7C

Hanson, S.L., \& Kraus, R.S. (1998). Women, sports, and science: Do female athletes have an advantage? Sociology of Education, 71(2), 93-110. Retrieved from http://eds.a.ebscohost.com.ezproxy.uky.edu/ 
Harris, K.M., C.T. Halpern, E. Whitsel, J. Hussey, J. Tabor, P. Entzel, \& J.R. Udry. (2009). The National Longitudinal Study of Adolescent Health: Research Design [WWW document]. URL: http://www.cpc.unc.edu/projects/addhealth/design.

Heck, R.H., Thomas, S.L., \& Tabata, L.N. (2012). Multilevel Modeling of Categorical Outcomes Using IBM SPSS. NY: Routledge.

Hills, A.P., King, N.A., \& Armstrong, T.P. (2007). The contribution of physical activity and sedentary behaviors to the growth and development of children and adolescents. Sports Medicine, 37(6), 533-545. doi: 0112-1642/07/0006-0533

Hobin, E.P., Leatherdale, S.T., Manske, S.R., Burkhalter, R., \& Woodruff, S.J. (2010). A multilevel examination of school and student characteristics associated with physical education class enrollment among high school students. Journal of School Health, 80(9), 445-452. doi: 10.1111/j.1746-1561.2010.00526.x

Hollar, D., Messiah, S.E., Lopez-Mitnik, G., Hollar, L., Almon, M., \& Agatston, A.S. (2010). Effect of a two-year obesity prevention intervention on percentile changes in body mass index and academic performance in low-income elementary school children. American Journal of Public Health, 100(4), 646-653. doi: 10.2105/AJPH.2009.165746

Jarrett, O.S., Maxwell, D.M., Dickerson, C., Hoge, P., Davies, G., \& Yetley, A. (1998). Impact of recess on classroom behavior: Group effects and individual differences. The Journal of Educational Research, 92(2), 121-126. Retrieved from http://eds.a.ebscohost.com.ezproxy.uky.edu/

Johnson, D.R. (2008). Using weights in the analysis of survey data. Population Research Institute: Pennsylvania State University. Accessed March 1, 2014. 
Available at $<$ http://help.pop.psu.edu/help-by-statistical-

method/weighting/Introduction $\% 20$ to $\% 20$

survey\%20weights\%20pri\%20version.ppt>

Kaczynski, A.T. \& Henderson, K.A. (2007). Environmental correlates of physical activity: A review of evidence about parks and recreation. Leisure Sciences, 29, 315-354. doi: $10.1080 / 01490400701394865$

Kjonniksen, L., Fjortoft, I., \& Wold B. (2009). Attitude to physical education and participation in organized youth sports during adolescence related to physical activity in young adulthood: A 10-year longitudinal study. European Physical Education Review, 15(2), 139-154. Retrieved from http://eds.a.ebscohost.com.ezproxy.uky.edu/

Lally, P., Wardle, J., \& Gardner, B. (2011). Experiences of habit formation: A qualitative study. Psychology, Health, \& Medicine, 16(4), 484-489. Retrieved from http://eds.a.ebscohost.com.ezproxy.uky.edu/

Lagerberg, D. (2005). Physical activity and mental health in schoolchildren: A complicated relationship. Acta Paediatrica, 94, 1699-1705. doi: $10.1080 / 08035250500369627$

Maletta, H. (2007). Weighting. Accessed March 1, 2014. Available at $<$ http://www.spsstools.net/Tutorials/WEIGHTING.pdf>

Matton, L.M., Thomis, K., Wijndaele, N., Duvigneaud, G., Beunen, A.L., Claessens, B., Vanreusal, R., Philippaerts, \& Lefevre, J. (2006). Tracking of physical fitness and physical activity from youth to adulthood. Medicine \& Science in Sports \& Exercise, 38(6), 1114-1120. doi: 10.1249/01.mss.0000222840.58767.40 
Miles, L. (2007). Physical activity and health. Nutrition Bulletin, 32, 314-363. doi: $10.1111 / \mathrm{j} .1467-3010.2007 .00668 . x$

Nelson, M.C. \& Gordon-Larsen, P. (2006). Physical activity and sedentary behavior patterns are associated with selected adolescent health risk behaviors. Pediatrics, 117(4), 1281-1290. doi:10.1542/peds.2005-1692

Nguyen-Michel, S.T., Unger, J.B., Hamilton, J., \& Spruijt-Metz, D. (2006). Associations between physical activity and perceived stress/hassles in college students. Stress $\&$ Health: Journal of the International Society for the Investigation of Stress, 22(3), 179-188. doi: 10.1002/smi.1094

Oglivie, D., Bull, F., Powell, J., Cooper, A., Brand, C., Mutrie, N., Preston, J., \& Rutter, H. (2011). An applied ecological framework for evaluating infrastructure to promote walking and cycling: The iConnect study. American Journal of Public Health, 101(3), 473-481. doi: 10.1016/j.psychsport.2010.04.012

Ornelas, I.J., Perreira, K.M., \& Ayala, G.X. (2007). Parental influences on adolescent physical activity: a longitudinal study. International Journal of Behavioral Nutrition \& Physical Activity, 4, 3-10. doi: 10.1186/1479-5868-4-3

Otto, L.B. \& Alwin, D.F. (1977). Athletics, aspirations, and attainments. Sociology of Education, 50(2), 102-113. Retrieved from http://eds.a.ebscohost.com.ezproxy.uky.edu/

Pate, R., Health, G., Dowda, M., \& Trost, S. (1996). Associations between physical activity and other health behaviors in a representative sample of US adolescents. American Journal of Public Health, 86, 1577-1581. Retrieved from http://eds.a.ebscohost.com.ezproxy.uky.edu/ 
Parfitt, G. \& Eston, R.G. (2005). The relationship between children's habitual activity level and psychological well-being. Acta Paediatrica, 94, 1791-1797. doi: $10.1080 / 08035250500268266$

Peltzer, K. (2010). Leisure time physical activity and sedentary behavior and substance use among in-school adolescents in eight African countries. International Journal of Behavioral Medicine, 17, 271-278. doi: 10.1007/s12529-009-9073-1

Peugh, J.L. \& Enders, C.K. (2005). Using the SPSS mixed procedure to fit crosssectional and longitudinal multilevel models. Educational and Psychological Measurement, 65(5), 717-741. doi: 10.1177/0013164405278558

Picou, J.S. (1978). Race, athletic achievement, and educational aspiration. The Sociological Quarterly, 19(3), 429-438. Retrieved from http://eds.a.ebscohost.com.ezproxy.uky.edu/

Raspberry, C.N., Lee, S.M., Robin, L., Laris, B.A., Russell, L.A., Coyle, K.K. \& Nihiser, A.J. (2011). The association between school-based physical activity, including physical education, and academic performance: A systematic review of the literature. Preventive Medicine, 52, S10-S20. doi:10.1016/j.ypmed.2011.01.027

Ratey, J.J. (2008). Spark: The revolutionary new science of exercise and the brain. New York, NY: Little, Brown and Company.

Rhodes, R., de Bruijn, G.J., \& Matheson, D.H. (2010). Habit in the physical activity domain: Integration with intention temporal stability and action control. Journal of Sport \& Exercise Psychology, 32, 84-98. Retrieved from http://eds.a.ebscohost.com.ezproxy.uky.edu/ 
Ridgway, A., Northup, J., Pellegrin, A., LaRue, R., \& Hightshoe, A. (2003). Effects of recess on the classroom behavior of children with and without attention-deficit hyper activity disorder. School Psychology Quarterly, 18(3), 253-268. Retrieved from http://eds.a.ebscohost.com.ezproxy.uky.edu/

Robinson, M., Kendall, G.E., Jacoby, P., Hands, B., Beilin, L.J., Silburn, S.V., Zubrick, S.R., \& Oddy, W.H. (2011). Lifestyle and demographic correlates of poor mental health in early adolescence. Journal of Peaediatrics and Child Health, 47, 54-61. doi: $10.1111 / j .1440-1754.2010 .01891 . x$

Roddy, L.M., Fairclough, S.J., Atkinson, G., \& Stratton, G. (2012). Changes in cardiorespiratory fitness in 9 to 10.9 year old children: Sportslinx 1998-2010. Medicine \& Science in Sports \& Exercise, 44(3), 481-486. doi: 10.1249/MSS.0b013e3182300267

Sagatun, A., Sogaard, A.J., Bjertness, E., Selmer, R., \& Heyerdahl, S. (2007). The association between weekly hours of physical activity and mental health: A three year follow-up study of 15-16-year-old students in the city of Oslo, Norway. BMC Public Health, 7, 155-164. doi: 10.1186/1471-2458-7-155

Samuels, Steven. (2009). Re:st:svy and pweight postestimation tools. Accessed on March 1, 2014. Available at < http://www.stata.com/statalist/archive/200901/msg00842.html>

Shephard, R.J. \& Trudeau, F. (2005). Lessons learned from the Trois-Rivieres physical education study. Pediatric Exercise Science, 6, 75-87. Retrieved from http://eds.a.ebscohost.com.ezproxy.uky.edu/ 
Shephard, R.J. \& Trudeau, F. (2008). Research on the outcomes of elementary school physical education. The Elementary School Journal, 108(3), 251-264. Retrieved from http://eds.a.ebscohost.com.ezproxy.uky.edu/

Sifferlin, A. (2013, November 11). Are you fitter than your fifth grader? Yes, you probably are. Time Magazine. Retrieved from http://www.time.com/time/

Singer, J.D. \& Willett, J.B. (2003). Applied Longitudinal Data Analysis: Modeling Change and Event Occurrence. Oxford University Press: New York.

SPSS Library: Panel Data Analysis using GEE. UCLA: Statistical Consulting Group. Accessed March 1, 2014. Available at <http://www.ats.ucla.edu/stat/ spss/library/gee.htm/>

Stevens, T.A., To, Y., Stevenson, S.J., \& Lochbaum M.R. (2010). The importance of physical activity and physical education in the prediction of academic achievement. Journal of Sport Behavior, 31(4), 368-388. Retrieved from http://eds.a.ebscohost.com.ezproxy.uky.edu/

Story, M., Nanney, M.S., \& Schwartz, M.B. (2009). Schools and obesity prevention: Creating school environments and policies to promote healthy eating and physical activity. The Millbank Quarterly, 87(1), 71-100. doi: 10.1111/j.14680009.2009.00548.x

Taliaferro, L.A., Rienzo, B.A, Miller, M.D. Pigg, R.M., \& Dodd V.J. (2008). High school youth and suicide risk: Exploring protection afforded through physical activity and sport participation. Journal of School Health, 78(10), 545-553. doi: $10.1111 / j .1746-1561.2008 .00342 . x$ 
Taliaferro, L.A., Rienzo, B.A., \& Donovan, K.A. (2010). Relationships between youth sport participation and selected health risk behaviors from 1999 to 2007 . Journal of School Health, 80(8), 399-410. doi: 10.1111/j.1746-1561.2010.00520.x

Tomkinson, G.R., Macfarlane, D., Noi, S., Kim, D.Y., Wang, Z., \& Hong, R. (2012). Temporal changes in long-distance running performance of Asian children between 1964 and 2009. Sports Medicine, 42(4), 267-279. doi:

$10.2165 / 11599160$

Tomporowski, P.D., Davis, C.L., Miller, P.H., \& Naglieri, J.A. (2008). Exercise and children's

intelligence, cognition, and academic achievement. Educational Psychological Review,

20, 111-131. doi: 10.1007/s10648-007-9057-0

Treiman, D.J. (2009). Quantitative Data Analysis: Doing Social Research to Test Ideas. San Francisco: Jossey-Bass.

U.S. Census Bureau. (2000). Chapter 10: Education, Census Atlas. Accessed March 1, 2014. Available at $<$ http://www.census.gov/population/www/cen2000/censusatlas/ pdf/10_Education.pdf $>$

U.S. Department of Education, National Center for Education Statistics. (2012). Chapter 3, Digest of Education Statistics, NCES 2012-001. Accessed March 1, 2014. Available at $<$ http://nces.ed.gov/fastfacts/display.asp?id=98> 
U.S Department of Health and Human Services. (2012). Accessed April 16, 2012. $<$ http://www.healthypeople.gov/2020/topicsobjectives2020/overview.aspx?topici $d=33>$

Valois, R.F., Umstattd, M.R., Zullig, K.J., \& Paxton, R.J. (2008). Physical activity behaviors and emotional self-efficacy: Is there a relationship for adolescents? Journal of School Health, 78(6), 321-327. doi: 10.1111/j.17461561.2008.00309.x

VanDusen, D.P., Kelder, S.H., Kohl, H.W., Ranuit, N. \& Perry, C.L. (2011). Associations of physical fitness academic performance among school children. Journal of School Health, $\quad$ 81(12), 733-740. doi: 10.1111/j.1746-1561.2011.00652.x

Videon, T.M. (2002). Who plays and who benefits: Gender, interscholastic athletics, and academic outcomes. Sociological Perspectives, 45(4), 415-444. Retrieved from http://eds.a.ebscohost.com.ezproxy.uky.edu/

Wankel, L. M., Mummery, W. K., Stephens, T., \& Craig, C. L. (1994). Prediction of physical activity intention from social psychological variables: Results from the Campbell's Survey of Well-Being. Journal of Sport \& Exercise Psychology, 16, 56-69. Retrieved from http://eds.a.ebscohost.com.ezproxy.uky.edu/

Wiles, N.J., Jones, G.T., Haase, A.M., Lawlor, D.A., Macfarlane, G.J., \& Lewis, G. (2008). Physical activity and emotional problems amongst adolescents. Social Psychiatry: Psychiatry Epidemiology, 43, 765-772. doi: 10.1007/s00127-008$0362-9$ 
Yu, C.C.W., Chan, S., Cheng, F., Sung, R.Y.T., \& Hau K.T. (2006). Are physical activity and academic performance compatible? Academic achievement, conduct, physical-activity, and self-esteem of Hong-Kong Chinese primary school children. Educational Studies, 32(4), 331-341. doi: 10.1080/03055690600850016 


\section{Vita}

Frances Jillian Priesmeyer

Birthplace:

Raleigh, NC

August 4, 1984

Education:

Educational Specialist, August 2013

University of Kentucky

Lexington, KY

Master of Science, December 2009

University of Kentucky

Lexington, $\mathrm{KY}$

Bachelor of Arts, May 2006

Transylvania University

Lexington, $\mathrm{KY}$

Professional Positions:

School Psychologist, 2013-Present

Fairfax County Public Schools

Falls Church, VA

School Psychology Intern, 2012-2013

Cypress-Fairbanks ISD

Cypress, TX

Case Manager, 2006-2008

KY SAFE Therapeutic Foster Care

Nicholasville, KY 